\title{
Improving the Efficiency and Capacity of Virtual Genetics Clinics using Human Factors Design Methods
}

\author{
by \\ Maryam Attef
}

A thesis submitted to the Faculty of Graduate and Postdoctoral Affairs in partial fulfillment of the requirements for the degree of

\author{
Master of Design \\ in the \\ School of Industrial Design \\ Carleton University \\ Ottawa, Ontario
}

(C) 2021, Maryam Attef 


\section{Abstract}

The COVID-19 pandemic brought with it significant challenges for healthcare as well as some opportunities. The Prenatal Genetics Clinic at the Children's Hospital of Eastern Ontario (CHEO) in Ottawa moved to virtual care at the outset of the pandemic. Herein, we conducted a quality improvement study focused on developing a better understanding of factors influencing the efficiency of prenatal Genetics Counsellors (GCs) to support virtual care and related patient activities, with the intent of developing strategies to improve workflow. Within the context of the pandemic, we used remote and field methods of quantitative and qualitative inquiry to develop a better understanding of clinical workflows after the implementation of virtual care. This included diary studies to track time on task and naturalistic observation sessions at the Clinic. The Lean Improvement Approach was used to assess barriers to efficient workflows and develop recommendations for improvement. The analysis of GC's virtual and on-site workflows has increased our understanding of the work GCs perform, allowed us to define the challenges with virtual care experienced by GCs, and evaluate the existing processes to help identify systemic design problems and opportunities for improvement. The strategies suggested from this analysis fall within real-world project constraints, which included the inability to increase the number of GCs and inability to renovate the current clinic space. Our results show that GCs spend at least half of their time on patient-related tasks before and/or after the patient's appointment. Therefore, looking at potential inefficiencies or bottlenecks during these phases of work may help improve their overall workflow and flow through of patients. The results and recommendations that emerged were captured in a framework that identifies 3 key areas for strategic improvement measures - digital accommodation, administration support, and clinical assistance. 
Recommendations from the administrative and clinical assistance groups have already been implemented in the form of a new scheduling strategy and a new support staff role for clinical assistance. The remaining recommendations will support the on-going development of a strategic plan for improving work efficiency across the entire patient service unit of the Department of Genetics. 


\section{Acknowledgements}

I would like to express my special thanks and gratitude to my supervisors Prof. Chantal Trudel and Dr. Kym Boycott for their support to shape my thesis, and for giving me the opportunity to perform and complete this project, which was my first step into human factors research and design.

Special thanks to all the staff at the prenatal Genetics Clinic at CHEO for their time, support and continuous feedback during the data collection process. Without their help this study would not have existed.

I dedicate my work to my parents, Dr. Omer Attef and Hana Noman, and my management at Saudi Arabian Cultural Bureau, Dr. Osama Samarkandi and Reem Sleiman for their constant support in all possible ways. 


\section{Table of Contents}

Abstract

Acknowledgments

Table of Contents

List of Tables

List of Figures

List of Appendices

List of Acronyms

List of Definitions

Chapter 1: Introduction

1.1 Research Purpose, Question \& Approach

1.2 Overview of Thesis

Chapter 2: Background

Chapter 3: Literature Review

3.1 About Genetics Clinics

1

3

3.2 Time and Workflow Studies in Genetics Clinics

3.3 Issues with Clinical Workflow, Healthcare Environment \& Wait Times

3.4 Role of EMR \& Virtual Platforms in Care Delivery

3.5 Overview of Common Approach to Improve Clinical Workflow

3.6 Human Factors Design in Healthcare

4.1 The Pre-Research/ Planning

4.2 Study Safety \& Ethics Approval

4.3 Participants

4.4 Methodology

4.5 Use of Lean Improvement Process

Chapter 5: Study Findings \& Results

5.1 Findings from Archival Analysis

5.2 Findings from Stakeholder Mapping

5.3 Findings from Brainstorming Session 35

5.4 Findings from Diary Study 
5.5 Findings from Naturalistic Observation

5.5.1 Time on Task for Site Work

5.5.2 Task Analysis/ Work Process Diagrams

5.6 Results from Lean Improvement Process \& Clinic Feedback

5.7 Summary of Results

Chapter 6: Discussion

6.1 Implementation \& Impact of Virtualizing Genetics Services During COVID-19

6.2 Thoughts on the Lean Improvement Process

6.3 Limitations and Challenges

6.4 Future Work \& Study

Chapter 7: Conclusion

References

Appendices 


\section{List of Tables}

\begin{tabular}{l|l} 
Table 1 Summary of the previous studies on clinical genetics workflow & 10
\end{tabular}

Table 2 Possible strategies to improve capacity and wait-time from the Genetics

Clinic Brainstorming Exercise, in 2019

Table 3 List of patient related activities and non-patient related activities, and the average time on task (in minutes) for 'Own Patient' category

Table 4 Overview of the average time to perform tasks from the Observation Sessions and the Diary Study

Table 5 Time spent by Prenatal GCs on 'Triage'

Table 6 Time spent by Prenatal GCs on 'Case Preparation/Case Review'

'Table 7 Time spent by Prenatal GCs on 'Preparing Requisitions' for One Patient

Table 8 Time spent by Prenatal GCs on 'Results Follow-Up' for One Patient

'Table 9 Time spent by Prenatal GCs on 'Writing Reports' for One Patient

Table 10 Comparison of the results from the Diary Study and Observation Sessions 


\section{List of Figures}

Figure 1 Study overview

Figure 2 Key healthcare workers at the Genetics Clinic at CHEO

Figure 3 Overview of the Lean Improvement process 'DMAIC' methodology

Figure 4 Overview of the methods used in the study

Figure 5 Overview of the Diary Study and the changes made after the pilot study

Figure 6 Interactions among the stakeholders of the Clinic

Figure 7 Results from the Brainstorming Session with clinicians relative to different tasks performed at the Clinic

Figure 8 Total average time per task for work done under 'GC's Own Patient' category

Figure 9 Total average time per task for work done under 'Other Colleagues' category

Figure 10 Map generated from the overall movement of GCs around the Clinic

Figure 11 Overview of the patient related tasks performed at the Clinic

Figure 12 Workflow of 'Triage' at the Clinic

Figure 13 Workflow of 'Case Preparation/ Case Review' at the Clinic

Figure 14 Workflow of 'Ministry Approval Requisitions' at the Clinic

Figure 15 Workflow of 'Lab Orders Requisitions' at the Clinic

Figure 16 Workflow of 'Results Follow-Up' at the Clinic

Figure 17 Workflow of 'Replying to the Referring Doctor's Request' at the Clinic

Figure 18 Workflow of 'Follow-Up Appointment' at the Clinic

Figure 19 Workflow of 'Writing Reports' at the Clinic

Figure 20 Bottlenecks observed with 'Triage' workflow at the Clinic

Figure 21 Suggestions to improve 'Ministry's Approval Requisitions' workflow at the

Clinic

Figure 22 Bottlenecks observed with 'Lab Order Requisitions' workflow at the Clinic

Figure 23 Suggestions to improve 'Lab Order Requisitions' workflow at the Clinic

Figure 25 Bottlenecks observed with 'Results Follow-up' workflow at the Clinic 
Figure 27 Suggested 'Results Follow-up' workflow at the Clinic

Figure 28 Bottlenecks observed with 'Writing Reports' workflow at the Clinic

Figure 29 Suggestions to improve 'Writing Reports' workflow at the Clinic 70

Figure 30 Suggested 'Writing Reports' workflow at the Clinic

Figure 31 Overall average time on task spent by GCs at the Clinic 


\section{List of Appendices}

Appendix A Supportive Documents to Chapter 4: Participants \& Methods 84 \begin{tabular}{l|l} 
Appendix A.1 Ethics Approval & 84
\end{tabular}

\begin{tabular}{l|l} 
Appendix A.1.1 Department of Genetics - CHEO Approval & 85
\end{tabular}

Appendix A.1.2 Carleton’s Research Ethics Board Approval 86

\begin{tabular}{l|l} 
Appendix A.2 Diary Study Method & 87
\end{tabular}

\begin{tabular}{l|l} 
Appendix A.2.1 1st Coloured Diary Study - Pilot Study & 87
\end{tabular}

\begin{tabular}{l|l} 
Appendix A.2.2 1st Grey-Scale Diary Study - Pilot Study & 89
\end{tabular}

\begin{tabular}{l|l} 
Appendix A.2.3 2nd Grey-Scale Diary Study - Pilot Study & 91
\end{tabular}

\begin{tabular}{l|l} 
Appendix A.2.4 Final Grey-Scale Diary Study & 93
\end{tabular}

Appendix B Supportive Documents to Chapter 5: Study Findings \& Results 94

\begin{tabular}{l|l} 
Appendix B.1 Findings from Diary Study & 94
\end{tabular}

\begin{tabular}{l|l} 
Appendix B.1.1 Diary Study completed Excel sheets for each GC & 95
\end{tabular}

\begin{tabular}{l|l} 
Appendix B.1.2 Calculated Frequency and Average time per task per & 99
\end{tabular} category

Appendix B.2 Results from Lean Improvement process 


\section{List of Acronyms}

CHEO Children's Hospital of Eastern Ontario

COVID-19 Corona Virus Disease 2019

DMAIC Define, Measure, Analyze, Improve and Control methodology

EH\&S Environmental Health and Safety

EMR Electronic Medical Record

FTE Full-Time Employment

GC Genetics Counsellor

LSS Lean Six Sigma

MD Medical Doctor

NVA Non-Value-Added

QIT Quality Improvement Team

REB Research Ethics Board

RTLS Real-Time Locating System

TCPS2 Tr-Council Policy Statement 2 


\section{List of Definitions}

Case Preparation / The activity GCs perform before the patient's consultation to review their case, Case Review previous tests performed by the referring doctor, primary care provider's diagnosis, and read the literature on the case.

Case Management The activity GCs perform before and after the patient's appointment.

Bottlenecks Any step within a patient pathway that slows the overall rate of a patient's progress, normally through a reduced capacity of clinic availability.

Direct Care Time The duration of a face-to-face consultation with the patient.

Epic Electronic Medical Record system that is used at CHEO.

Full-Time A full-time workload (1.0 FTE) consists of 37.5 hours per week, anything less than

Employment that is considered part-time, and pro-rated using 7.5 hours per day (e.g., 0.8 FTE is equivalent to 30 hours per week).

GC On-Call Genetic Counsellor who is physically working at the Prenatal Genetics Clinic and performing tasks that the rest of GCs could not perform remotely such as: filling out requisitions, printing out patient's labels and stickers, faxing requisitions, scanning test results, and any other administrative tasks.

Genetics Genetic counselling refers to the activities GCs perform during the patient's Counselling appointment time.

Indirect Care Time The duration of pre-consultation and post-consultation patient activities.

Labels / Stickers The patient's labels/stickers are generated directly from the EMR and contain patient information including their name, date of birth, contact information, address, and health card number. GCs favour printing out patient's labels over filling them out on requisitions to ensure the accuracy of the patient's information when reviewed by other stakeholders and lab technicians.

Lean A design methodology pioneered by Toyota in the 1970s, focused on developing stable, standard processes to provide the best quality and efficiency by eliminating waste/unnecessary steps in workflow.

Lean Improvement The process commonly used to bring about changes in healthcare delivery, by process focusing on eliminating waste and improving patient care flows. Problems are identified by clinical stakeholders as they are the ones doing the work.

My Chart A secure, online personal health record network that is supported by Epic. It contains patient's health information (i.e., history, medications, medical tests)

\begin{tabular}{|c|c|}
\hline $\begin{array}{r}\text { Non-Value-Added } \\
\text { Activities }\end{array}$ & Activities that do not contribute to the patient's care. \\
\hline Patient-Encounter & Patient's appointment/consultation session. \\
\hline $\begin{array}{r}\text { Pre-Consultation } \\
\text { Activities }\end{array}$ & $\begin{array}{l}\text { Activities performed by GCs prior to the patient's consultation, such as chart review, } \\
\text { literature review and consultation with the MD. }\end{array}$ \\
\hline $\begin{array}{r}\text { Post-Consultation } \\
\text { Activities }\end{array}$ & $\begin{array}{l}\text { Activities performed by GCs after the patient's consultation, such as documentation } \\
\text { in the EMR, completing laboratory requisitions and other paperwork, reviewing } \\
\text { results, and writing reports. }\end{array}$ \\
\hline Requisition & $\begin{array}{l}\text { Forms that are used by GCs to communicate precisely with Lab Technicians on the } \\
\text { type of exam required for the medical assessment and to provide important patient } \\
\text { history and relevant information that may impact the performed exam. }\end{array}$ \\
\hline The QIT & $\begin{array}{l}\text { CHEO's Quality Improvement Team consisting of the: } \\
\text { Lead who manages the service delivery model work with the genetics. } \\
\text { Research Coordinator who provides clinical input on workflows and the roles of } \\
\text { GCs and Genetic Assistants. } \\
\text { Chair of the Department of Genetics who is also a physician. } \\
\text { Ergonomics Professional. }\end{array}$ \\
\hline
\end{tabular}




\section{Chapter 1: Introduction}

Patients being served by the Genetics Clinic at the Children's Hospital of Eastern Ontario (CHEO) in Ottawa, Ontario, Canada, are currently experiencing long wait times for non-urgent visits (more than 1 year). Wait times have increased due to emergency closures and delays resulting from the Coronavirus Disease 2019 (COVID-19) pandemic caused by SARSCoV-2. From a patient's perspective, long wait times in a clinic are undesirable and decrease patient satisfaction with the experience (Lin, Gavney, Ishman, \& Cady-Reh, 2013). This highlights the need to optimize healthcare workers' time in outpatient clinical settings.

Key stakeholders on the Genetics Clinic team believe their wait time challenges are related, in part, to workflow inefficiencies. Historically, prenatal patients were seen by genetics counsellors (GCs) and supervised by one medical doctor (MD). As the MD team grew in size, more MDs became involved as part of their on-call duties, but without a formal strategy or plan. Subsequent creation of a prenatal care team (with MD and GC leads) improved patient care immensely with the development of standard-of-care protocols to harmonize clinical practice. However, the prenatal service delivery model has remained largely unchanged despite the many changes in the service context (e.g., reduced resources for care providers, increasing patient volumes and increasingly complex prenatal genetics practice). This is further compounded by a culture of accommodating patient schedules and care provider preferences over efficiency.

The prenatal service delivery model at the time of our study during the pandemic lacked a formal structure to ensure that the necessary providers were available during the virtual prenatal patient consultations and related pre-consultation and post-consultation activities. This led to delays in dealing with urgent patient matters, and inefficient use of time 
for providers. The GCs, for example, found themselves occupied with finding the MD to review cases, to meet the patient, and to ask triage questions. MDs were faced with unpredictable prenatal schedules and demands throughout the week. Providers expressed dissatisfaction with the inefficiency of their current pandemic adaptive model providing virtual care to 22 prenatal patient appointments spread out throughout the week. Patient care was impacted by delays when urgent matters arose, and the MD on-call was rarely available due to competing demands on their time with no notice regarding upcoming appointments.

In 2018, the CHEO Genetics Clinic performed a study to estimate the time spent by GCs on direct and indirect patient care activities. The average time estimated on patient related activities for a routine patient was 120 minutes ( 2 hours), and 300 minutes ( 5 hours) for a complex patient. However, the clinic believes these estimated workload minutes are underestimates of the current reality. The clinic speculates that these estimates do not reflect the additional time required to support virtual workflows which were implemented during the pandemic and before this study was conducted.

On March 16, 2020, virtual care was implemented due to the COVID-19 pandemic. The Genetics Clinic began working remotely through CHEO’s Electronic Medical Record (EMR) system called Epic, and more specifically, through the integrated Zoom (videoconferencing) platform which is part of the EMR software application. The introduction of virtual care brought about additional challenges but also opportunities related to workflow. For example, the clinic discussed the possibility of being able to see more patients because of the flexibility offered by virtual patient care. Stakeholders at the Genetics Clinic also wondered whether some of their prior challenges with the capacity limitations of their physical space could be reduced with a hybrid (in-person and virtual) model of care. They questioned whether leveraging virtual care opportunities could improve patient access to genetics services. Within 
this context, the COVID-19 pandemic rapidly brought the opportunity to study hybrid models of care and identify challenges and develop solutions to ultimately deliver more efficient clinical care.

\subsection{Research Purpose, Question \& Approach}

The goal of this study is to gain a better understanding of factors influencing the prenatal GCs efficiency to see patients virtually to develop strategies to improve their workflow using techniques from human factors and design. To achieve this goal, we studied how prenatal GCs performed virtual care from their homes and the hybrid model of care (virtual and on-site work within the clinic) to assess what tasks they were performing, potential challenges, as well as their time on tasks. We anticipated this would allow us to identify the 'artefacts' (digital technologies, existing space design/layout) being used/not used in work, and related processes and interactions to assess how these elements may be impacting the team's workflow, and by extension, patient wait times. With this understanding, our aim was then to identify challenging areas and develop recommendations to improve workflow so that GCs can increase their capacity to see patients. However, with this, came real world constraints. With any intervention proposed, the number of providers and support staff could not change (e.g., the clinic could not hire more GCs, create a new position or job role), and the space configuration could not change due to lack of infrastructure resources (e.g., there was not a budget for a future renovation).

Although many factors may support or undermine workflow, this study focused specifically on documenting aspects of workflow that could be feasibly documented during the pandemic. This included time on task in both remote and on-site work, as well as on-site work processes and the potential impact of the physical space on workflow. Although this 
study documents the time prenatal GCs spent on tasks working remotely from their homes, their virtual workflow processes could not be directly observed due to physical distancing measures, and to protect the privacy of staff working from their homes. However, our team tracked the types of tasks being performed virtually by GCs, and the amount of time performed on tasks to help us better understand their workflows.

Human factors design methods can help research teams develop a better understanding about people and their behaviours in work settings (National Research Council, 2011). By applying such methods in healthcare, researchers and practitioners aim to support staff deliver safe, high-quality care through the design of clinical environments, equipment, workspace, workflow, safety procedures and training (Chartered Institute of Ergonomics and Human Factors, 2015). Methods can vary from highly controlled experiments to less controlled observational studies in real-world contexts, with this study fitting the latter category of study design. The study also falls under 'research for design', a category of research used by practitioners and researchers within the field of design to support design development and the implementation of successful design outcomes (Frankel \& Racine, 2010).

\subsection{Overview of Thesis}

This thesis begins with a background on the Prenatal Genetics Clinic and service delivery model at the outset of the study (Chapter 2: Background), followed by a literature review which provides: a discussion on efficiency in genetics clinics; potential tools to improve workflow and efficiency in healthcare; and the application of human factors design in the healthcare sector to support this work (Chapter 3: Literature Review). An overview of the human factors/design methods that were selected and applied to work with unit stakeholders, participants and collect and analyze data are discussed in Chapter 4: Participants \& Methods. 
The analysis of the data I collected allowed me to define the challenges GCs are experiencing and evaluate the existing process to help identify systemic design problems and opportunities for improvement (Chapter 5: Study Findings and Results). Although the recommendations that emerged from this analysis were constrained by contextual considerations (e.g., the number of providers and current space configuration could not change), the study provided a glimpse of the rapid uptake of a hybrid care model - a snapshot which could be further leveraged as part of a comprehensive strategy to improve the quality of services in the clinic. In Chapter 6: Study Analysis/Discussion, I discuss the findings and results relative to previous workflow/time efficiency studies in genetics clinics as well as more recent studies that were conducted on virtual genetics workflows during the pandemic. I also reflect on the application of the Lean Improvement process in this study, as well as study limitations and future work. The thesis is then summarized in Chapter 7: Conclusion.

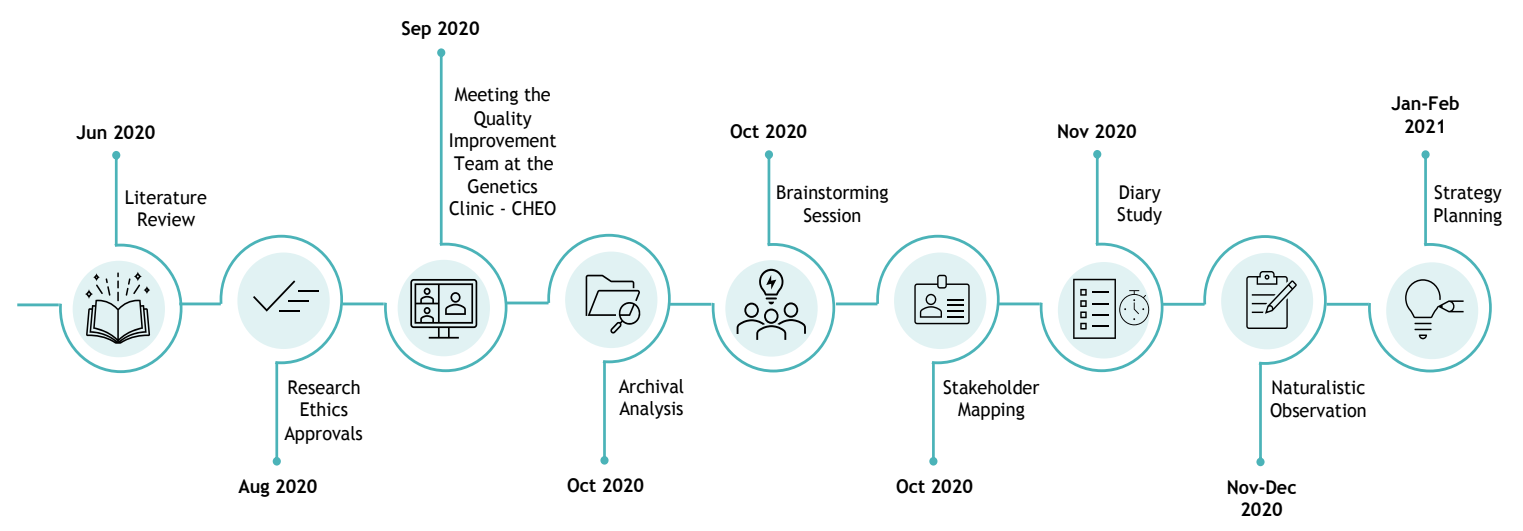

FIGURE 1 STUDY OVERVIEW 


\section{Chapter 2: Background}

The Genetics Clinic team at CHEO consists of medical doctors (geneticists), genetic counsellors (GCs), and support staff. The clinic sees patients who are referred for suspected or diagnosed genetic disorders, a family history of a genetic condition, or other genetic considerations (CHEO, 2020). Geneticists oversee all aspects of clinical care and are ultimately responsible for the patient's medical assessment. Genetic counsellors have advanced training in human genetics and counselling, and work with the geneticists to assess patients (CHEO, 2020). The support staff at the clinic consists of patient service clerks and administrative assistants. The main responsibility of the patient service clerk involves booking new patients and any other activities related to a patient's pre-consultation. The administrative assistant is a new addition to the Genetics Clinic since the summer of 2020, and they are responsible for managing post-consultation activities.

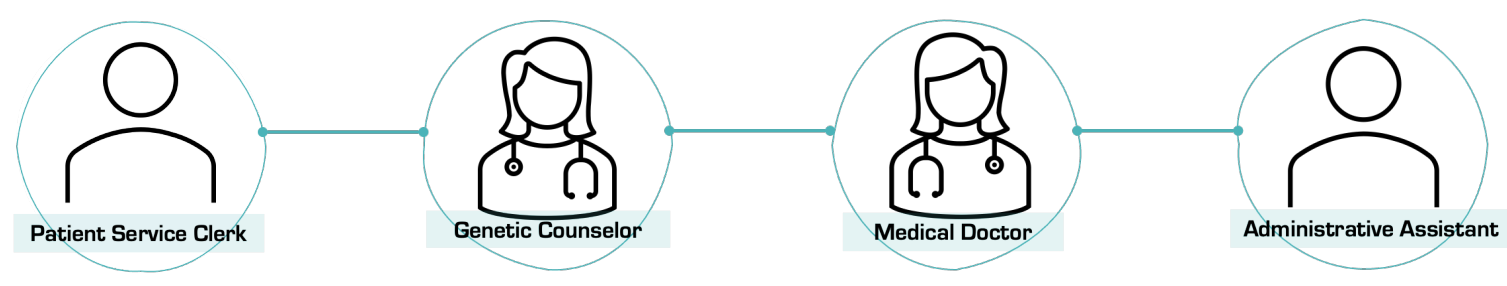

Figure 2 Key healthCare workers at the Genetics Clinic at CHEO

The Prenatal Genetics Clinic at $\mathrm{CHEO}$ serves pregnant individuals from a large catchment area in Eastern Ontario who require a genetics consultation due to an increased genetic risk identified in their pregnancy. Almost all of the referrals seen by this clinic are considered urgent, and most must be seen within 2 weeks of referral. These patients are primarily seen by GCs, with the supervision of the geneticists. Four GCs participate in the Prenatal Genetics Clinic for a full time equivalent (FTE) of 2.3 individuals. One GC is identified as 'on-call' every day and is dedicated to being physically in the clinic for urgent tasks 
such as triaging incoming referrals. Seven geneticists rotate on-call to supervise and cover the prenatal service for pre-clinic, during clinic and post-clinic activities. The Prenatal Genetics Clinic sees an average of 57 new patients per month. At the outset of this study, these patients were seen at appointment times spread out throughout the week, without a holistic view to coordinating the direct and indirect patient care activities, resulting in sometimes chaotic and unpredictable demands on the care providers and support staff involved.

Historically, prenatal patients were seen by GCs and supervised by one MD. Over time, more MDs became involved as part of their on-call duties, but the change occurred without a formal strategy or plan. The creation of a Prenatal Genetics Clinic team (with MD and GC leads) has improved patient care immensely. The leads manage changes in standardof-care protocols, changes to procedures of available testing and other system changes. For example, CHEO adopted the use of Epic, an Electronic Medical Record system, in 2016 which has led to changes in the clinic's workflow. However, the prenatal service delivery model has remained largely unchanged despite the many changes that have occurred within the context of service providers, patient volume, and increasingly complex prenatal genetics practice. In April of 2020, the COVID-19 pandemic dramatically changed the clinic's workflow, and a number of 'temporary solutions' were rapidly developed and deployed to provide virtual care in order to avoid patients having to come to $\mathrm{CHEO}$ for their consultation. This study was conducted to capture the impact of virtual care on GCs tasks (type and time of task) and aspects of their workflow that could be improved to potentially increase efficiency and clinical capacity. 


\section{Chapter 3: Literature Review}

\subsection{About Genetics Clinics}

Genetic service providers focus on the diagnosis and management of hereditary disorders. The profession of genetic counselling began in 1971 (National Society of Genetics Counsellors, 2020) with counsellors working in a variety of practice settings, providing different services. Most GCs in Canada work in a clinic or hospital and are part of a clinical care team with doctors like geneticists, obstetricians, and oncologists (Attard, Carmany, \& Trepanier, 2018). Genetic testing is one of the most complicated aspects of the field as test options are rapidly expanding, which requires professionals to invest time to remain current with emerging practice and testing procedures (Attard, Carmany, \& Trepanier, 2018). As the field of genetics has advanced, it has become evident that there is a need for professionals who understand genetics and can guide and support patients as they make decisions about genetic testing and their healthcare (Attard, Carmany, \& Trepanier, 2018). This has placed pressure on GCs and the service delivery model to increase efficiency so that more patients can be seen. By reducing the time spent on the tasks performed before and after a genetic counselling encounter, GCs can improve access to their services by increasing the number of patients seen per week (Attard, Carmany, \& Trepanier, 2018). While much has been written about informed consent for protocols for predictive genetic testing, and the integration of genetics into the practice of primary care, very little has been published describing the actual practice of medical genetics or the increasing demand for genetic services (Pletcher et al., 2002). 


\subsection{Time and Workflow Studies in Genetics Clinics}

Few studies on workflow in genetics clinics have looked at how GCs spend their service time to identify potential areas to enhance efficiency (Table1). An early study by Bernhardt et al. (1987) set out to review the evolution of the medical genetics specialty and evaluate the time and costs spent on genetic services provided to patients at Johns Hopkins Hospital. The study found that the average time spent by attending geneticists to evaluate, counsel and discuss the diagnosis and treatment plan for newly referred families was 7.1 hours and 4.1 hours for returning families. The study identified the need for more in-depth time assessments of the services provided in genetics clinics (Bernhardt et al., 1987). A follow-up study published by Bernhardt \& Pyeritz (1989) expanded the scope to include diverse clinical genetics services, including a paediatric genetics clinic. The study found that the services provided in the genetics clinics were time consuming, with at least half of the total time dedicated to a patient's care being spent on tasks performed before and after the patient's appointment (Bernhardt \& Pyeritz, 1989). Another time-related study conducted by Pletcher et al. (2002) showed that genetic practice needs more time commitment per patient than any other specialty, with a weekly average of 3.1 hours for new patients and 1.7 hours for followup patients. This time was significantly less than the Bernhardt et al., (1987) study, however this may have been due to changes that occurred over a decade of learning and improvement in clinical practice.

A 2005 study by Cooksey et al. found that the geneticists' work setting can play a major role in the way that individual geneticists spend their professional time (Cooksey et al., 2006). Geneticists in this study reported a small number of follow-up visits because they were able to complete a consultation in one visit. They also reported a limited ability to expand their capacity to take on new patients. This implies that additional geneticists or increasing the 
number of genetic service providers/clinics would be required to meet the substantial growth in the demand for genetic services (Cooksey et al., 2006). Aside from studies focused specifically on time, other studies have examined factors affecting clinical workload in genetics clinics. An early study by Surh, et al. (1995) suggested that clinical workload in these settings may be affected by the size of the patient's family, the health status of the patient, the type of counselling required, access to genetic tests, and the nature of the inherited disease. Identifying factors influencing the time spent before, during and after patient consultations may reveal insights to reduce patient wait times.

\begin{tabular}{|c|c|c|}
\hline TABLE 1 SUMMARY OF THE PREVIOUS STUDIES ON CLINICAL GENETICS WORKFLOW \\
\hline Study & $\begin{array}{c}\text { Time Spent on Newly Referred } \\
\text { Families (in hours/week) }\end{array}$ & $\begin{array}{c}\text { Time Spent on Returning } \\
\text { Families (in hours/week) }\end{array}$ \\
\hline Bernhardt et al. (1987) & 7.1 & 4.1 \\
\hline Bernhardt \& Pyeritz (1989) & 9.1 & 6.1 \\
\hline Pletcher et al. (2002) & 3.1 & 1.4 \\
\hline Cooksey et al. (2006) & 2.5 & 1.5 \\
\hline McPherson et al. (2008) & 7 & 3.5 \\
\hline
\end{tabular}

Workflows in genetics services have been studied by McPherson et al. (2008), where all the genetic staff used electronic tools to record their activities. The study tracked staff workflow in this genetics clinic and included physicians and GCs, but not activities and time spent by secretarial and administrative support staff (McPherson et al., 2008). Their study revealed lower face-to-face time with patients versus more time spent on patient-relatedactivities before and after the visit. The study also showed the total time spent on clinical activity was 7 hours for new patients and 3.5 hours for follow-up patients, again similar to what was found by Bernhardt et al. in 1987. A more recent study by Attard, Carmany and Trepanier (2018) examined the workflow of GCs in multiple clinics and specialties, also using electronic data collection tools. Genetics counsellors in the study reported spending about $20 \%$ of the appointment time on face-to-face interactions with patients, and about $64 \%$ of the 
time on patient-related-activities, where the patient was not involved (Attard, Carmany \& Trepanier, 2018). The clinic saw an average of 9 paediatric patients per week, an average of 56 minutes per session, and an average of 3.5 hours spent on patient-related-activities per patient (Attard, Carmany \& Trepanier, 2018).

Genetic counselling traditionally has been a time-intensive process while the need for genetic counselling services has grown recently (Stoll, Kubendran \& Cohen, 2018). Traditional genetic counselling, which involves an in-person, one-on-one pre- and post-test model of counselling may not be the most efficient method to scale up services to reach a large population (Stoll, Kubendran \& Cohen, 2018). Therefore, new service delivery models to increase efficiency and access to genetic counselling services are being implemented in a growing number of clinics (Stoll, Kubendran \& Cohen, 2018).

These studies reported to date (Table 1) show that genetics service providers spend a significant proportion of their work on tasks before and after the patient's appointment, with a large variation evident across the studies. They highlight the importance of studying nonpatient-facing-related activities as well as the challenges facing genetics service providers to reduce time on patient-related activities before and after patient encounters. This is particularly important considering government policies which prescribe the time that should be spent on patient related activities. As per our discussion with the QIT (Quality Improvement Team) at CHEO, the Ontario Ministry of Health and Long-Term Care prescribes that $70 \%$ of clinical time be spent on patient related activities which includes direct and indirect care. Although the studies in this area of health service delivery are limited, what the existing studies demonstrate is the need to study efficiency in genetics clinics to improve patient access to genetics services. However, to the best of our knowledge, no research has been published to date describing a viable or exemplar service delivery model for genetics clinics. 


\subsection{Issues with Clinical Workflow, Healthcare Environments \& Wait Times}

Bottlenecks in patient care within genetics clinics are a growing concern in healthcare delivery (Lohmann \& Klein, 2014). Bottlenecks are defined as any step within a patient pathway that slows the overall rate of a patient's progress, normally through reduced capacity of availability (Lohmann \& Klein, 2014). Balancing patient quality of care and efficiency is a rising issue in healthcare, where clinic workflow continues to be problematic for a variety of reasons. This may include workflows impacted by poor or inadequate space or layout and excessive workloads resulting from inefficiencies in work processes, all of which impact patient wait times and may lead to burnout (Lohmann \& Klein, 2014).

Wait time is defined as the time it takes one patient from time of referral (start of wait time) to attending their appointment (end of wait time) (Sampalli et al., 2015). Currently, these appointments are scheduled based on prioritization, where faster access is provided for urgent referrals, balanced with allowable wait times for others (McIyntyre \& Chow, 2020). Many of these appointments are for new diagnoses that require careful assessment (Parkash, Eble, \& Dhar, 2018). Longer wait times suggest there is a need to improve the care pathway from primary care providers to genetics clinics. In addition to how wait time is defined above, wait time also includes 'on-site wait time', which is the time a patient spends at the clinic from check-in to the time they exit the clinic. Studies suggest that overcrowding in clinics is related to long wait times and may result from shortages of healthcare providers, and lengthy patient admissions occurring in triage areas (McIyntyre \& Chow, 2020). From the patient's perspective, long wait times in the clinic are undesirable and decrease patient satisfaction with the experience (Lin et al., 2013). The consequences of increased wait times include patient 
dissatisfaction, delayed access to treatments, poorer clinical outcomes, inequality, patient anxiety (McIyntyre \& Chow, 2020) and the risk that patients may experience medical complications due to long wait times (Parkash, Eble, \& Dhar, 2018). These factors point to the need to optimize the efficient use of a clinician's time in the outpatient clinical setting to decrease patient lead times (the total time from arrival to exam start) during a scheduled appointment (Lin et al., 2013).

\subsection{Role of EMR \& Virtual Platforms in Care Delivery}

The introduction and implementation of the Electronic Medical Record (EMR) in healthcare delivery is intended to support Quality Improvement. The digitization of patient records allows medical professionals to promptly access and process patient data, provide automated reminders to avoid medication errors, improve sharing of information across the medical team, and increased transparency by ensuring both complete and legible documentation of the patient's condition (Atasoy, Greenwood \& Mccullough, 2019). The complex environment of hospitals naturally creates the possibility for error or inefficiency. The EMR can support clinical decision-making through a variety of functions including recommendations for tests and screenings, as well as medications and treatments based on the diagnosis. The objective of EMR designs focus on improving the performance of healthcare providers by changing the way patient information is entered and organized to make it easier for other healthcare providers to access this information (Boonstra, Versluis \& Vos, 2014).

The use of health information technologies has been slowly increasing in different Canadian provinces and territories. In 2007, Ontario began its journey to implement a fully integrated EMR system (Riahi et al., 2017). Apart from the introduction of EMRs, virtual care has also been recently introduced in Canada, with accelerated implementation during the 
COVID-19 pandemic. With the unique challenges posed by physical distancing, there has been a rapid change in how medical care is delivered to keep the workforce and patients safe (Pereira \& Chung, 2020). The web-based video conference tool, Zoom, is integrated with EMR systems like Epic to facilitate seamless virtual care sessions.

\subsection{Common Approaches to Improve Clinical Workflow}

Supporting a quality visit in genetics clinics can be challenging, influenced by the clinic's efficiency and throughput. These challenges may be due to different factors such as the variability in the number of patients seen and care provided, the documentation of regulatory and compliance issues, and the computerization of patient care systems and limitations within these systems. Pletcher et al. (2002) identified opportunities and strategies to increase appropriate clinical referrals and patient volume in genetic clinics which include:

- educating healthcare stakeholders about the types of patients and their conditions, and the circumstances that require referrals to genetic services; and

- dividing patient care into shorter sessions where a) a GC meets with the patient to obtain the family and medical history; b) a physician provides medical evaluation; and

c) the GC or physician alone provides diagnostic information and a follow-up plan.

Quality Improvement (QI) work focused on clinical efficiency can takes many forms.

Some QI methods that have been used to increase efficiency and reduce wait times include eliminating automatic rebooking or overbooking, adjusting the ratio of new patient visits to follow-up visits, and increasing the use of physician assistants (Flanary et al., 2020). The concept of Quality Improvement using structured methods began in the manufacturing industry and are now being applied to in healthcare (Lin et al., 2013). Another approach that's been used to improve clinical workflow is called the Lean Improvement process. Lean was 
pioneered by Toyota in the 1970s, where it emphasized the creation of stable, standardized processes to support efficiency and the best quality by eliminating waste/unnecessary steps in production (Flanary et al., 2020; Lin et al., 2013).

Lean Improvement projects use the Define-Measure-Analyze-Improve-Control (DMAIC) methodology (Gijo \& Antony, 2013). The purpose of the 'Define Phase' is to identify the problem by conducting process walks/ workflows. The second step is the 'Measure Phase' which involves the evaluation of the baseline performance of the system that exists prior to any suggested changes. Identifying the root causes that create variation or lags in the system occur during the 'Analyze Phase'. After that, potential solutions can be identified for the root causes during the 'Improve Phase'. Lean methodology is intended to improve processes and performance in the immediate term but is also focused on ensuring sustainability of the results in the long run, which is the last step in the cycle called the 'Control Phase'.

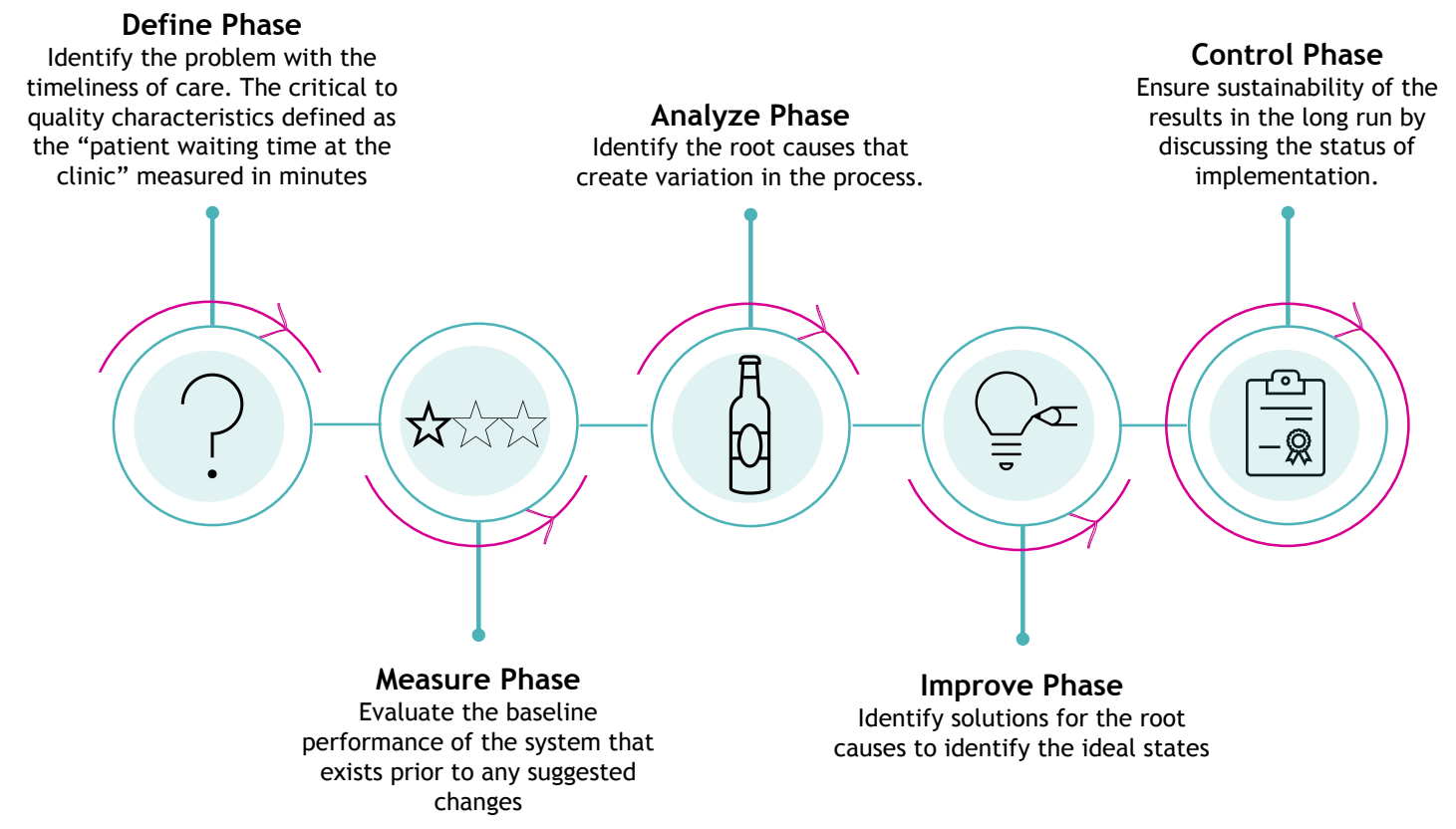

FIGURE 3 OVERVIEW OF THE LEAN IMPROVEMENT PROCESS 'DMAIC’ METHODOLOGY 
As an extension and commercialization of Lean Improvement process, Six Sigma was developed by Motorola in the 1980s, to emphasize improvement by employing statistical rigor to reduce process variability of critical quality characteristics to reduce errors (Lin et al., 2013). According to Gijo \& Antony (2013), Lean Six Sigma (LSS) is the latest generation of improvement approaches that aim to maximize stakeholder value by improving quality, speed, customer satisfaction, and costs. This methodology permits small incremental changes to a process that, over time, can have an enormous effect on an enterprise as a whole and can have an immediate effect on smaller groups within the institution (Waldhausen et al., 2010). One of the basic tenets of this methodology includes 5S (Sort, Stabilize, Shine, Standardize and Sustain). This allows one to clean, organize and standardize a workplace so that the right equipment is where it is needed, whenever it is needed (Waldhausen et al., 2010). This method can decrease the number of times the care provider has to leave the room looking for supplies and thus markedly decrease the distance travelled during one clinic (Waldhausen et al., 2010). Just the decrease in walking alone can decrease the amount of time it takes a clinician to complete a patient visit. Lean Six Sigma uses tracking data and quantitative methods to document progress towards a quality-improvement goal (Lin, Gavney, Ishman, \& Cady-Reh, 2013).

There are studies that reviewed the use of 'Lean' in healthcare, reporting improvements in staff and patient satisfaction, and decreases in errors and mortality rates (Mazzocato et al., 2010). Another study found that although Lean-based redesigns were intended to reduce workload and burnout and increase teamwork, stress and exhaustion among healthcare staff were not alleviated (Hung et al., 2018). The study suggested that the 'redesigns' had not reduced the growing challenges in healthcare that go beyond redesigning workplaces to more systemic concerns such as shortages of clinical and support staff and a 
growing population of patients. There have also been several concerns reported regarding the validity of 'Lean' results. Concerns were related to systematic bias, imprecision and limitations in the methods applied, which made it harder to statistically evaluate and interpret the independent effect of Lean on patient satisfaction and patient safety (Kaltenbrunner et al., 2019). To overcome these limitations, a study found that when staff are involved in the process of decision-making and problem-solving, they can facilitate the adoption and implementation of Lean and enhance positive outcomes (Kaltenbrunne et al., 2019). Having staff as participants of the study can be seen as a strength because they know their circumstances better than anyone. However, their involvement can be seen as a limitation because they may be biased by attitudes toward their workplace.

\subsection{Human Factors Design in Healthcare}

Human factors (or ergonomics) is a scientific discipline that studies the interaction between humans and elements of the system in which they work, with the goal of improving resilience and overall system performance, and minimizing errors (International Ergonomics Association, 2020). The human factors approach has historically been used in complex and high-risk fields such as nuclear power and aviation and has had uptake in healthcare starting in the late 1990s (IOM, 2018).

Health care providers work hard to deliver the best care possible to their patients; however, they can be set up for mistakes by poorly designed medical devices, uncoordinated care processes, and fragmented systems. Usually, these systems are designed in a way that does not account for how people interact with their work environment (Gurses, Ozok \& Pronovost, 2011). People who practice in this area are focused on creating solutions that make it easier for people to do their job right and hard for them to do things wrong. The use of 
human factors design in healthcare is intended to improve human-system interactions (e.g., healthcare worker-technology interaction), but more typically complex multi-stakeholder interactions which include healthcare providers, patients, and their families.

It is common for people who support human factors design to approach their work from a human-centered design approach (ISO, 2010; Maguire, 2013). Human-centered design has been shown to increase the safety of all stakeholders involved in a system, efficiency, stakeholder satisfaction, effectiveness, performance, and cost-effectiveness. In general, human-centered design includes an understanding of the user's needs, tasks, activity flows and environments. The human-centered design approach focuses on the users and other stakeholders in the system, on principles of human behaviour, including usability testing, empirical measurement, and participatory design where users are actively involved (Wickens et al., 2004). A literature review of human factors methods was conducted as part of planning of this study and is discussed relative to the description of the methods in Chapter 4. This quality improvement study focused on developing an understanding of factors influencing the ability of Prenatal GCs to efficiently see patients during the COVID-19 pandemic and strategies to improve their workflow using techniques from human factors and design. Genetics counsellors can improve access to their services by reducing the time spent on the tasks performed before and after a genetic counselling encounter, thereby increasing the number of patients they see. Despite the growth of human factors in healthcare design, and to the best of my knowledge, I believe this may be the first HF/E study focused specifically on the design of genetics services. 


\section{Chapter 4: Participants \& Methods}

\subsection{The Pre-Research/Planning}

The purpose of this study is to evaluate the virtual as well as hybrid (virtual and onsite) workflow at the CHEO Prenatal Genetics Clinic, identify potential bottlenecks which may be impacting the efficiency of GCs, and develop strategies for improvement to support the goal of increasing capacity and reducing patient wait times. The early stages of the study involved a literature review of workflow studies in other genetics clinics. This was followed by a review of the previous studies from the Genetics Clinic which tracked workload minutes prior to the pandemic for routine and complex prenatal patients, the expected number of new patients per full-time GC, and the target number of new patients per fiscal year, among other archival information. Informal discussions and feedback sessions were held with the Quality Improvement Team (QIT) at the Genetics Clinic to gain a preliminary understanding of the current workflow, and the impact of the pandemic. The QIT consists of a Lead who manages the service delivery model work with the prenatal team; a Research Coordinator who provides clinical input on workflows and roles of GCs and clinical assistants; the Chair of the Department of Genetics who is also a physician; and an Ergonomics Professional.

This study used multiple qualitative and quantitative methods to support stages of the Lean Improvement process to: 1) understand the overall context and workflow of the Prenatal Genetics Clinic at CHEO; 2) identify inefficiencies; and, 3) develop strategies to improve the workflow of GCs to increase their capacity to see more patients. First, stakeholder meetings and mapping were used to identify the prenatal genetics team and their roles. A brainstorming session was then held with the prenatal GCs to learn about their thoughts, concerns, and ideas regarding virtual care. At the time, there was little known about the indirect time that GCs 
were spending on virtual care (including pre- and post-consultation activities). Therefore, all prenatal GCs were asked to report time-on-task in a diary study to understand the potential for time-intensive challenges to provide virtual care. This was followed by naturalistic observation sessions which included following a GC on-site at the clinic through a patient care workflow, observing counsellors as they perform tasks, and documenting these steps to identify their activities, general tasks performed in the clinic, as well as paths and spaces used to perform these tasks. A task analysis was developed to map the on-site workflow at the Prenatal Genetics Clinic to identify efficiency issues related to the design of the space, process, and the use of artefacts (paper-based work, equipment, digital platforms, etc.). This information was then analyzed for bottlenecks and potential opportunities to reduce the time it takes to perform a task related to patient flow through.

\subsection{Study Safety and Ethics Approval}

There were no anticipated risks in this study, and no personal health information was collected. The Tri-Council Policy Statement 2 (TCPS2) provides guidance on research ethics in Canada; however, a study on program evaluation and quality improvement (QI), which this study fit, did not fall under the auspices of the TCPS2 or Institutional Research Ethics Boards (REBs). TCPS2, Article 2.5: "Quality assurance and quality improvement studies, program evaluation activities, and performance reviews, or testing within normal educational requirements when used exclusively for assessment, the management or improvement purposes, do not constitute research for the purposes of this Policy, and do not fall within the scope of REB review" (TCPS2, 2018, p. 26).

Although considered a QI study, the proposed work was still reviewed by CHEO's Department of Genetics and Carleton University's Research Ethics Board (see appendices A.1.1 and A.1.2). In line with Carleton's COVID-19 protocols related to research and site 
work, I completed the online training course from Carleton's Environmental Health and Safety $(E H \& S)$ department to provide information regarding the health and safety practices and considerations required for conducting research on-site during the COVID-19 pandemic and complied with CHEO's COVID-19 protocols for field research at the hospital.

\subsection{Participants}

All board-certified Prenatal Genetics Counsellors at CHEO (4 in total) participated in this study. The 4 participants had different workloads: 2 were full-time, 1 worked part-time, and 1 other staff member had an 80\% workload. A full-time workload (1.0 FTE) consists of 37.5 hours per week, and anything less than that is considered part-time and pro-rated using 7.5 hours per day (e.g., 0.8 FTE is equivalent to 30 hours per week). In addition to working with the GCs, I interviewed MDs, service patient clerks and administrative assistants.

\subsection{Methodology}

Within the context of the COVID-19 pandemic, I was limited to certain methods to document the virtual and hybrid (on-site and virtual) workflows.

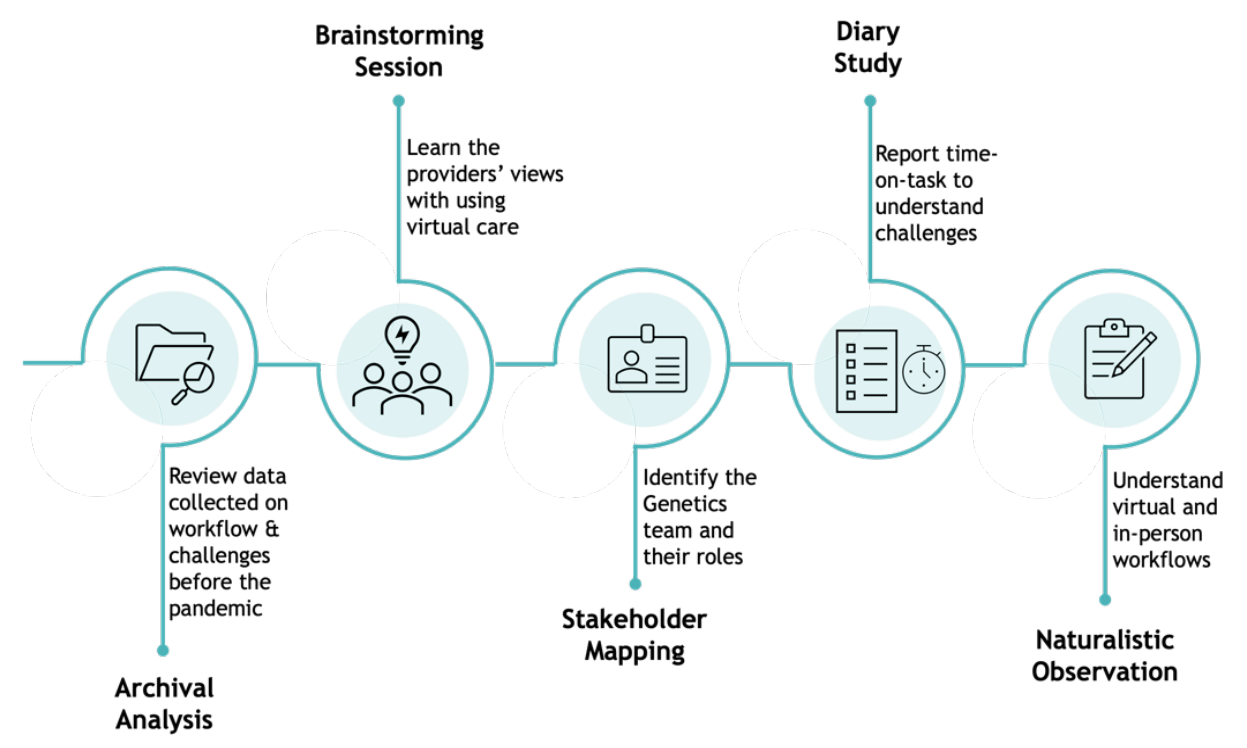

FIGURE 4 OVERVIEW OF THE METHODS USED IN THE STUDY 


\subsubsection{Archival Analysis}

The genetics team conducted two activities prior to the pandemic which I reviewed, analyzed, and used in later stages of our study. The first activity involved a clinic-wide brainstorming exercise that took place in 2018. Participation included all of the staff in the Genetics Clinic (e.g., genetics staff in both the Prenatal and Cancer Genetics Clinics, the genetics lab technologists, support staff, managers). In this session, staff discussed challenges around capacity and wait time and identified possible strategies to address these barriers. The second activity involved examining some of the data that was generated from the clinic's EMR system Epic in 2018, where on-call teams in the Genetics Clinic were asked to enter the estimated time required for direct and indirect patient care. The limitation of this prior work centred on a short time frame for data collection.

The second activity was a workshop that was held in the Genetics Clinic in 2019. GCs tracked their workload (in minutes) for workflows related to routine and complex prenatal patients, and the target number of new patients per fiscal year. In addition to tracking care related to routine and complex patients, the archival analysis provided an understanding of the number of minutes GCs on-call spent on direct patient care (from the start to the end time of the in-person consultation). However, there was still little known about the indirect time that GCs spent on patient care (e.g., preparing for the consultation, sending requisitions, writing reports), specifically with virtual care during the pandemic.

\subsubsection{Stakeholder Mapping}

As I began the study, it was important to identify the key stakeholders invested in the study objectives and proposed outcomes. Stakeholder mapping helped us identify all the clinic team members involved and a high-level overview of their interactions. The challenge with 
stakeholder mapping is that it can be subjective depending on the people involved in developing the map (Kumar, 2013). I therefore started by identifying all the stakeholders involved in the Prenatal Genetics Clinic which included GCs, MDs, administrative assistants, and patient service clerks. Phone call interviews (15 min.) with representatives from the key stakeholder groups were conducted to identify their roles and relationships with other stakeholders. This included discussions with a MD, patient service clerk, and administrative assistant to understand these roles in the Prenatal Genetics Clinic and with patient care.

\subsubsection{Brainstorming Session}

After creating the stakeholder map, a brainstorming session was held with the prenatal team at $\mathrm{CHEO}$ to learn about their views on virtual care, any overall barriers they may be facing in their current workflow, and any delays they had experienced in seeing and processing patients. At this point, the prenatal team had been conducting virtual care since the pandemic had been declared for approximately 6 months, and there was a need to understand the Prenatal Clinic's experience with both virtual and in-person care. The brainstorming session was facilitated virtually through the web-based video conference tool, Zoom. There were 9 participants in this session including 4 GCs, 5 MDs ,1 Administrative Staff Member, 1 Genetics Clinic Director, and 1 QIT member.

One of the QIT sent staff an introductory email with the following questions followed by a virtual 1-hour brainstorming session during the prenatal bi-weekly meetings:

1- What do you think is working well with the virtual care service?

2- What do you think is not working with the virtual care service?

3- What are the opportunities you see for change? 
To help prompt the participants, I asked them to speak about what was working and not working so well in terms of the different categories: triage, booking, pre-consultation activities, actual consultation activities, post-consultation activities, and follow-up consultations. I was introduced to these categories prior to the session by the QIT. The data collection included taking notes of all the points GCs and MDs shared during the session, and I then analyzed these comments to fit the different categories mentioned above. Through this session I was able to determine the potential root causes of problems from their perspective and identified system issues that may be contributing to these problems as well as early opportunities for improvement. The technique helped generate ideas from clinic stakeholders for possible further evaluation in the study.

\subsubsection{Diary Study}

From the archival analysis, I learned that there was no data reported on the real-time GCs spent on tasks and activities. At the time, and due to the novelty of the pandemic situation, there was also little known about the indirect time that GCs were spending on virtual care (e.g., preparing for the consultation, sending requisitions, writing reports, consulting with the patient on-line, etc.). To address this gap in our knowledge, prenatal GCs (4 in total) were asked to report their time-on-task in a diary study to understand the potential for timeintensive challenges in providing virtual care.

Diaries are guiding artifacts that allow people to convey personal details conveniently

and expressively about their daily work. It is a useful tool in exploratory research, preparing the designer for further research by contributing to an understanding of participant user groups. While dairy studies are typically conducted with a relatively small sample, common themes and patterns can emerge (Waddington, 2005). The use of technology in collecting the 
data was limited to encourage genetics counsellors to complete the task in a short time alongside whatever work they were doing. A Microsoft Excel spreadsheet was created for GCs to print and fill out. The GCs were introduced to the diary study at the end of the brainstorming session. The design of the spreadsheet was based on a previous study that was done at the Genetics Clinic looking at the activities done by a GC on-call, but more tasks were added based on the type of work that GCs were doing from home. The form was designed with the help of clinic stakeholders, and I conducted a pilot study to assess the diary's validity and ease of use before carrying on with the actual study.

The initial diary study form consisted of a 2-sided page (one side where GCs could document their own patient activities and the other for work GCs might do for other colleagues) and tested 2 versions (coloured and grey-scale) (see appendices A.3.1 and A.3.2). The forms contained the following information: date of the activity; whether they were working on-call the day of the activity; shift start and end times; 11 task categories (see Figure 5-A); the duration of each sub-task; 5 columns for (duration) for each time a GC performs the task during that one day; and a notes section to add comments on the task.

The pilot period was held over 2 days to test both forms. A detailed email with all the instructions was sent out to all the prenatal GCs through the QIT. The GCs favoured the grey-scale form for ease of printing and had comments on the order and sub-divisions of tasks to match the order of their daily routine. Figure 5-B illustrates the revisions made to the Diary Study. The revised diary study framework was then sent to GCs for any final comments. The GCs preferred the form to be one page to print and fill-out without flipping through the pages while performing tasks. Therefore, I kept the 5 columns of time spent on a task 'for yourself' and replaced the 'Notes' column with 2 columns to document duration on tasks (for colleagues). I instructed the GCs that any notes and other comments could be written in the 
margins or other empty spaces on the page. The final diary study form was sent to the GCs to formally collect the 'task-on-time' data with a goal to collect data for 5 'full-time' days. The 'time on task' reported by GCs in the diary study is the total time it took them to perform the task. For example, GCs reported the time they spent on 'triage' as the total time it took them to work on this general activity, not the time it took them to review 1 chart as part of this activity. For this reason, I documented the actual time it takes to perform the review of 1 chart during the naturalistic observation sessions to provide more granular data about such subtasks.

\section{A - Initial Diary Study Form}

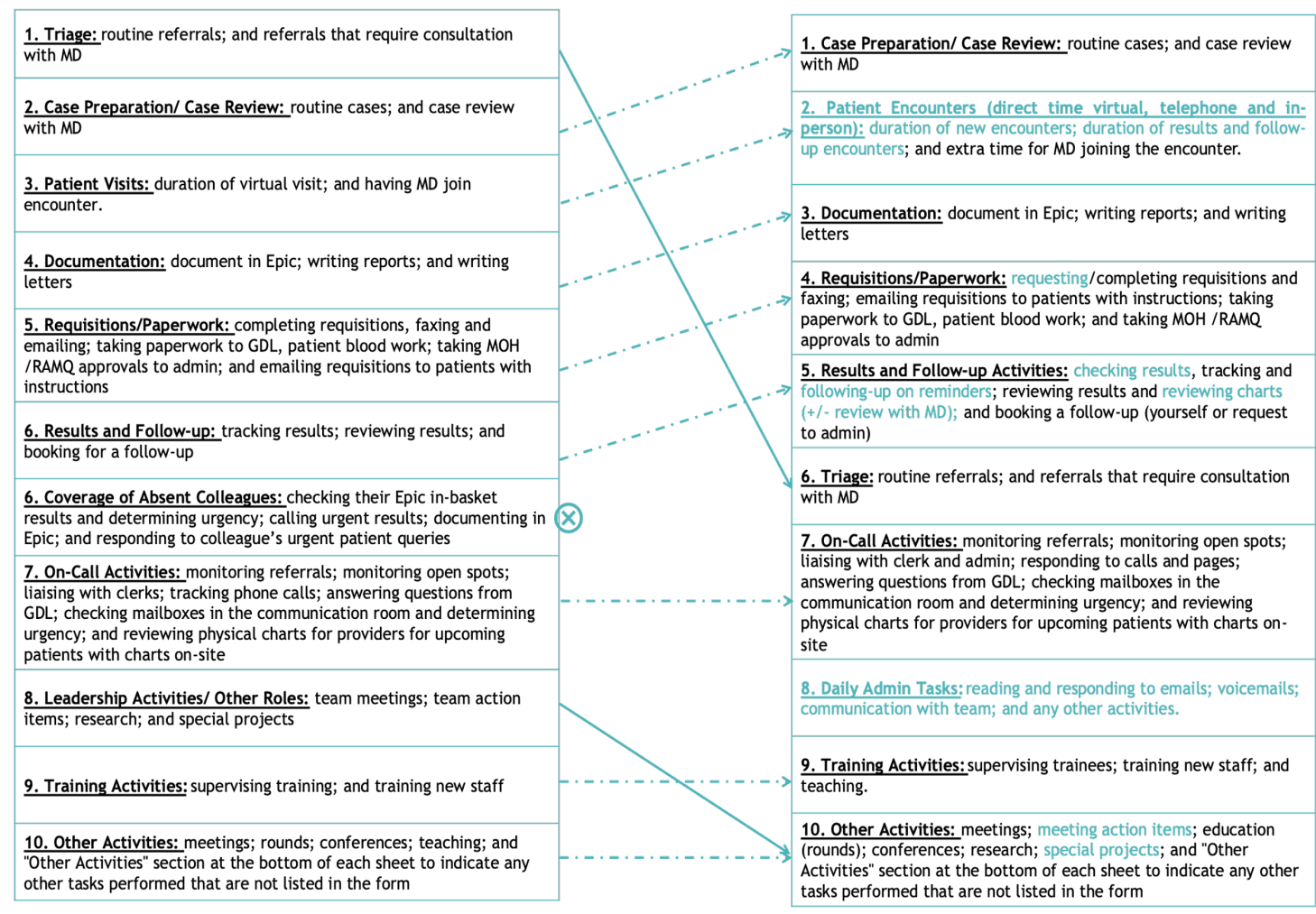

FIGURE 5 OVERVIEW OF THE DIARY STUdY AND THE CHANGES MADE AFTER THE PILOT STUDY

The data provided by GCs in the diary study was divided into 2 categories: 1) data collected reflecting the time on task GCs work to support their own patients; and 2) data collected reflecting the time on task GCs do work to support other colleagues. Genetic Counsellors printed out the form and filled out 1 sheet per day. I received scanned copies of the completed diary study forms, which I then transferred to Excel, with one spreadsheet per 
GC. Since not all GCs have the same workload (two are full time, one works $80 \%$ of a FTE, and one works $50 \%$ of a FTE), and some data collected reflected overtime hours and other data reflected half days, I had to find a way to normalize the data to be able to compare the data gathered from all GCs. First, I combined all the data reflecting the first category, (GC's own patient) time on task for direct and indirect virtual care for all the GCs. Then, I calculated the frequency of each task (how many times that task was done across all GCs) to calculate the average time per task. The same steps were done separately for the category (other colleagues).

\subsubsection{Naturalistic Observations}

A common method used in human factors design consists of recording people's behaviours and utterances during tasks performed under a variety of circumstances. In planning observational studies, the researcher identifies the variables to be observed or measured, the methods to be employed for observing and recording each variable, the conditions under which observation will occur, and the observational timeframe (Reason, 1990). Observations are more valuable than interviews or focus groups because what people say does not always match what they do. Also, people may omit critical details of their work, they may find it difficult to imagine new technologies or new ways of doing things, and they may distort their description to avoid appearing in a negative light. During observations, people's working conditions can be observed directly, and they may be asked to imagine and describe how they would perform a given task or activity within their real-world context (Wicknes et al., 2014). Due to the complexity of healthcare environments, observational studies are useful for gathering data in these contexts. Naturalistic observation is a nonexperimental research method where an individual can analyze a system in its natural 
setting, where data includes detailed information on the user, process, and contextual information (Robson \& McCartan, 2016). However, gathering information through an observation method has associated limitations, since the errors noted may be natural and spontaneous and perhaps not frequent or representative of daily work (Reason, 1990). The potential implications of "observer effect", in which there may be changes in a person's behaviour due to the presence of an observer, is referred to as the Hawthorne effect. Using new technology in time-stamp studies may potentially diminish the Hawthorne effect; for example, the use of wireless tags for location determination in real-time locating systems (RTLS) to track patients and staff removes the presence of a human observer (Lin et al., 2013). For our study, RTLS was not a desirable option because of the expense and potential ethical considerations, and I did not feel this level of automation or granularity was needed since the observations were focused on a small sample of GCs.

During this method, I followed a GC on-call for a day to collect information on their hybrid (on-site and virtual) workflow, to follow a patient care path, observe how they use/move through the system, and identify their activities or general tasks performed in the clinic, while asking questions as needed (Wickens et al., 2014). The QIT put together the schedules for 3-hour blocks of in-person observation and informed 3 out of 4 prenatal GCs of the day and time they would be observed. One of the prenatal GCs was under training during the time of observation; thus, she was not part of this activity. The observations took place over 2 weeks to cover 2 different shifts for a total of 6 sessions or 18 hours in total (Week 1 covered morning shifts from 09:00 am - 12:00 pm and Week 2 covered afternoon shifts from 01:00 pm - 04:00 pm). The collection of qualitative data during the observation sessions was done by taking handwritten notes on the interactions between the stakeholders at the Genetics Clinic, their activities, workflows, the location of the activity, and the duration 
of the task performed. During the observations, I asked questions to clarify and get deeper insight on the GCs activities and workflows. The observation sessions took place in different locations at the Genetics Clinic where GCs travel for different purposes, such as the GC's office, communication room, reception, administrative assistant's office, and Genetics Lab. The notes taken during the observations, were reviewed after each session to add postobservation notes and to edit the notes taken during the sessions. A floor map of the Genetics Clinic was obtained from the QIT to visually track the path and touchpoints of GCs through the clinic while performing their work, document the activities they were performing, and the time it took to perform tasks at specific locations. The post-observation notes included tracing the Genetics Clinic path to create 'spaghetti maps' of the clinic, and the knowledge I developed during the session. In tracking the path and touchpoints GCs experience through the clinic while performing their work, I was able to document the type of activity they were performing, and the time it took to perform the task at specific locations.

The Genetics Clinic hired a clinical assistant in late November 2020, 3 months into this study. The second week of our observation sessions aligned with the second week of the clinical assistant working in the clinic. I observed that the clinical assistant was involved in the post-consultation activities such as helping prenatal GCs working from home to fill out their requisitions and send them by fax or checking prenatal GCs' in-baskets for any results and/or mail. Because of this new addition to the prenatal genetics team, I modified the data collection tools for the observation sessions, so that the clinical assistant could also track her work around the clinic, including the activities performed, location of where the task was performed, and the duration of the tasks. The results of the clinical assistant's activities have been added to the results of the activities for the observations of GCs on-call. 


\subsection{Use of Lean Improvement Process}

This study used the DMAIC methodology of the Lean Improvement Process to identify potential issues, the root causes that may be creating lags or variation in the service delivery model at the Prenatal Genetics Clinic, and identify potential solutions for improvement. The Define Phase started with identifying the problem and the research question of this study (see Chapter 1). In the Measure Phase, I reviewed the literature related to the design of genetics services from other studies to develop a better understanding of the current system in general, reviewed the existing archival data from the CHEO genetics clinic and designed methods to answer the research question (see Chapters $3 \& 4$ ). All the data collected was analyzed in the Analyze Phase to identify potential bottlenecks (see Section 5.5.1), followed by the Improve Phase, where I suggested strategies to improve the Prenatal Genetics Clinic capacity (see Section 5.5.2). Finally, to ensure the sustainability of the results in the long run, I suggested future work and study in the Control Phase (see Section 6.4). 


\section{Chapter 5: $\quad$ Study Findings \& Results of Analysis}

In this chapter, I report the findings of the data collected using the methods described in Chapter 4, and synthesize the data reported in the diary study and the naturalistic observations to identify the bottlenecks and suggest strategies for improvement.

\subsection{Findings from Archival Analysis}

In 2018, all staff (including GCs, MDs, lab technicians, and support staff) in the Genetics Clinic (includes the Prenatal Genetics Clinic and the Cancer Genetics Clinic) were asked to estimate the time spent on direct and indirect patient care activities. Direct time was defined as the duration of a face-to-face encounter with the patient. Indirect time includes preencounter activities (e.g., chart review, literature review, consultation with the medical geneticist) as well as post-encounter activities (e.g., documentation in the EMR, completing laboratory requisitions and other paperwork, reviewing, and calling patients for their results). Stakeholders believed the complexity of Prenatal Genetics Care at CHEO had increased significantly within the past 2 years, in terms of genetic counselling and case management, where genetic counselling refers to the activities GCs perform during the patient's appointment time, and case management refers to the activities GCs perform before and after the patient's appointment. According to the team, the estimated workload minutes were underestimates of the current reality. In addition, the documentation of time spent on direct and indirect care did not reflect the time required to provide virtual care since this study had occurred before the pandemic.

From this prior work, the average time that was estimated for a routine patient was 120 minutes and 300 minutes for a complex patient. But it was unclear to what extent the GCs were appropriately documenting all their direct and indirect workload minutes. According to 
the Ministry of Health, GCs should spend a total of $70 \%$ of their time on patient-related activities, whether it is direct care or indirect care. The 120 minutes and 300 minutes account for time spent on patient-related activities, including direct care (consultations) or indirect care (requisitions, results, and follow-up, writing reports, etc.).

The second activity that was documented in the clinic's archives and analysed as part of this study was a clinic-wide brainstorming exercise that took place in 2019, where all GCs, MDs, and support staff in the Genetics Clinic participated. The workshop examined the challenges with GC's and MD's capacity to see patients and resulting wait times, followed by identifying possible strategies to address these issues. The workshop activity consisted of 3 main questions (below) and the summary of the output activity is shown in Table 2.

1- How can we increase our efficiency so that we can see more patients?

2- How can we see more patients within our clinic given our current space allocation?

3- What mechanisms could the clinical department use to respond to changes in patient volumes in different areas?

Most of the outcomes from this activity were put 'on hold' because of the pandemic, however, the shift in patient care service from being in-person to virtual, forced the rapid implementation and exploration of telemedicine.

The data collected from these activities prior to the pandemic demonstrated the need to change the service delivery model at the Genetics Clinic. What I learned from the archival analysis helped scope our study more tightly to a targeted clinical service (Prenatal Genetics), which could be later applied to improvements for other genetics team workflows. The analysis also highlighted the importance of documenting the types of tasks and times on task more systematically to improve our understanding of time intensive aspects of GC work. 


\begin{tabular}{|c|c|}
\hline \multicolumn{2}{|c|}{$\begin{array}{l}\text { TABLE } 2 \text { POSSIBLE STRATEGIES TO IMPROVE CAPACITY AND WAIT-TIME FROM THE GENETICS CLINIC } \\
\text { BRAINSTORMING EXERCISE, IN } 2019\end{array}$} \\
\hline $\begin{array}{l}\text { Engage Extra Staff } \\
\text { - Clinical Assistants } \\
\text { - GC Assistants } \\
\text { - Co-op Students }\end{array}$ & $\begin{array}{l}\text { Change Appointment Times } \\
\text { - } \quad \text { Create shorter appointment times } \\
\text { - } \quad \text { Extend clinic hours }\end{array}$ \\
\hline $\begin{array}{l}\text { Improve Scheduling/Booking } \\
\text { - Streamline the booking process } \\
\text { - } \quad \text { Automate scheduling } \\
\text { - Implement a telephone reminder } \\
\text { - } \quad \text { system } \\
\text { - Create a self-booking app for } \\
\quad \text { patients }\end{array}$ & $\begin{array}{l}\text { Use Technology to Assist } \\
\text { - } \quad \text { Develop online modules for common } \\
\text { indications of genetic disorders } \\
\text { - } \quad \text { Implement home video follow-up visits and } \\
\text { telemedicine when no exam is required }\end{array}$ \\
\hline $\begin{array}{l}\text { Educate Primary Care Providers } \\
\text { - Educate primary care providers to } \\
\text { order tests in their practice } \\
\text { - Mainstreaming - seeing patients } \\
\text { with positive results }\end{array}$ & $\begin{array}{l}\text { Develop a More Integrated Care Model } \\
\text { - Create a more integrated MD/GC clinic } \\
\text { - Cross train providers } \\
\text { - GC on-call test line - primary care providers } \\
\text { call to see if testing is appropriate }\end{array}$ \\
\hline $\begin{array}{l}\text { Optimize Use of Space } \\
\text { - Use off-site CHEO space for som } \\
\text { - Maximize the use of clinic time/ } \\
\text { - } \quad \text { GCs office-share to free up addi } \\
\text { - } \quad \text { Redesign key areas of current sp }\end{array}$ & $\begin{array}{l}\text { vhen providers cancel/not in the office } \\
\text { linical space/less personal office } \\
\text { eception, communication/file room }\end{array}$ \\
\hline
\end{tabular}

\subsection{Findings from Stakeholder Mapping}

Stakeholders in the Prenatal Genetics Clinic were identified in a stakeholder map to understand their roles in patient care. During brief phone call interviews, stakeholders identified their roles and main tasks at the clinic (general and specific), as well as how they interact with each other. The main stakeholders at the Prenatal Genetics Clinic include prenatal GCs, MDs, patient service clerks, and administrative assistants.

Prenatal GCs see most of the patients and run the prenatal service. They are involved in all the patient consultations, case review, case preparation, documentation, inputting data in patient charts, writing letters to the referring physician about the findings from patient encounters, and submitting billing for consultations. In addition, GCs are involved in case 
management, testing, tracking the test, and tracking the results. Currently, the prenatal team has 4 GCs.

Physicians supervise the prenatal service, medical supervision, signing off on documentation and letters to patients who have been referred. For routine cases, MDs do not review the case with the GCs but normally try to meet the routine patients at the end of the consultation process for billing purposes if available. For complex cases, GCs and MDs work together to review the cases. MDs perform physical exams, and communicate medical diagnoses or management options (e.g., recommendations on medication, surgery). MDs are not dedicated only to the Prenatal Genetics Clinic and mainly see general patients in the Genetics Clinic. Currently, the Genetics Clinic has 8 MDs.

The main responsibility of the patient service clerk involves booking new patients and working on creating a patient's file on the EMR platform which typically consists of documents related to their referral, medical records sent with the referral, consent forms, and any other relevant documentation related to pre-consultation activities. If any additional documentation is needed before seeing a patient, patient service clerks are responsible for sending a fax to the referring doctor's office to get the information. Currently, the Genetics Clinic (Prenatal and Cancer) has 3 patient service clerks.

Administrative assistants are a new addition to the genetics team since the summer of 2020. They are responsible for managing post-consultation activities such as sending letters to the referring doctors, scanning results, requesting approvals for specialized genetic tests from the Ministry of Health and booking follow-up appointments. 


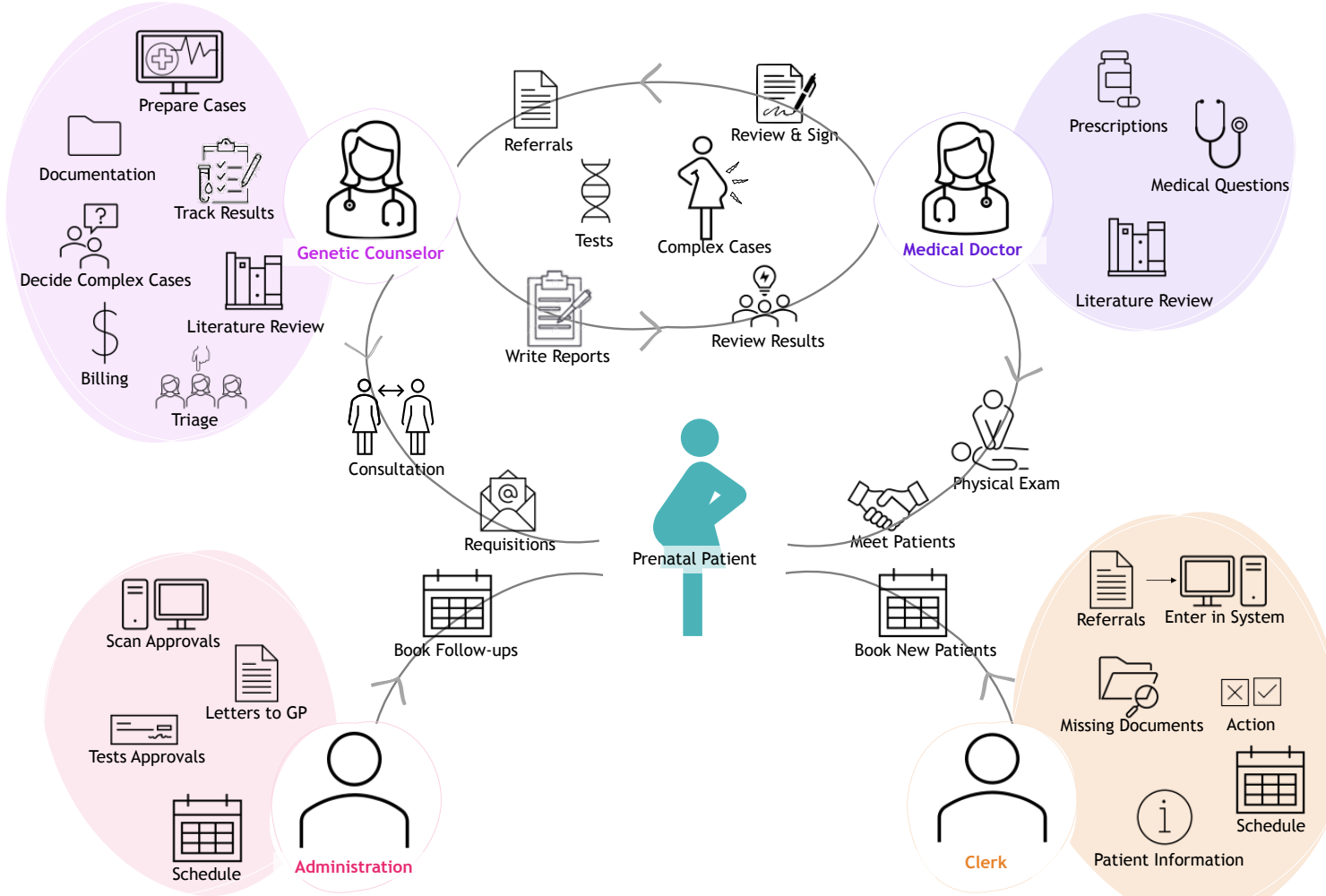

figure 6 Interactions among the stakeholders of the Prenatal Genetics Clinic

\subsection{Findings from Brainstorming Session}

Genetics services have always been delivered in-person, but with the current changes due to the pandemic, genetics services moved to virtual platforms to deliver services. Since the clinic was not prepared for this change, the genetics team faced many challenges to adapt to these circumstances. Through a 1-hour virtual meeting with 9 participants (including 4 GCs, 5 MDs ,1 Administrative staff, 1 Genetics Clinic Director, and 1 QIT member), I developed a basic understanding of the challenges they are facing providing virtual care for a variety of patient care activities. The following questions were asked. 


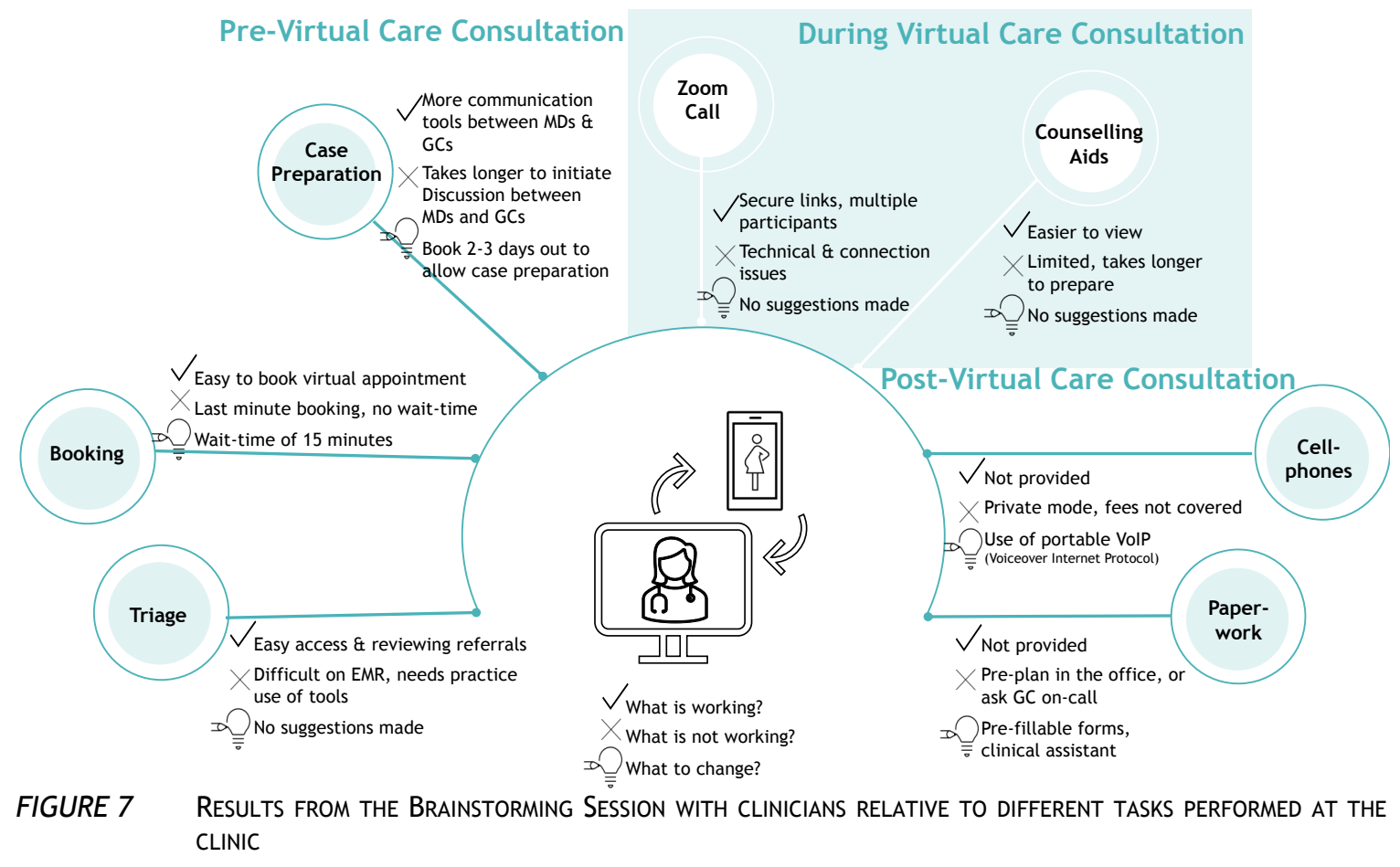

\section{Question 1: What do you think is working well with the virtual care service?}

With the virtual care model, GCs were asked to do triage virtually. Triage is the activity of reviewing referrals from primary healthcare providers to assess if the patient should be seen at the Genetics Clinic and to determine the level of urgency. Participants explained that they could see all the documents needed in triage through Epic, that they could review most patient referrals relatively quickly and that the process was clearer compared to the paper-based method used before the pandemic.

Participants reported that patients expressed their gratitude that their partners could attend the call with them because during the pandemic, partners were not permitted during in-person appointments. Staff also explained that patients appreciated being able to join the Zoom from a preferred location rather than having to be physically in the clinic.

Participants explained that medical students and MDs on-call could easily join a Zoom call because there was no limit to the number of participants on the call. Another benefit that 
was shared in the brainstorming session, was that MDs had time to review the cases before seeing the patients, and that it was easier to move from one patient to another through Zoom. Virtual communication between the MDs and GCs to review cases could also be done in a variety of ways such as sending an in-basket through Epic, phone calls, sending emails, and text messages.

\section{Question 2: What do you think is not working with the virtual care service?}

"All the little things take more time with virtual care" is how one participant described the challenges they face with providing virtual care service. Another noted that "The number of patients might be stable, but the workload increased'. First, GCs who were not used to the different tools in Epic had to rapidly learn how to use it. Clinicians reported that there were occasionally some technical issues with Zoom (e.g., clinicians and patients may not have a reliable internet connection). Staff reported that some appointments were booked at the last minute not giving GCs and MDs enough time to review the case before the appointment. On busy days where appointments were scheduled back-to-back, there was no option to put patients in a 'waiting room' to allow for a 5 min delay between appointments. Additional challenges that were noted by GCs and MDs included the use of their personal devices to provide patient care. For example, they had to use their personal cell phones to communicate with patients and labs in Canada and the United States. Participants also reported difficulties with work-life balance while working from home.

Another challenge the team shared about virtual care was the paperwork required for lab requisitions and/or approvals from the Ministry of Health for tests done outside of the province. The approval process involves confirming that the Ministry of Health will pay for the test before sending the requisition. Otherwise, the Genetics Clinic or the patient will receive a bill for the cost of the test. Some GCs would prepare the documents ahead of the 
appointment (e.g., when reviewing the case) during their on-call duty so that it would be ready to send out after the appointment, and others would ask the GC on-call to fill-out the papers for them.

\section{Question 3: What are the opportunities you see for change?}

Wait time windows and pre-booking appointments were identified as an opportunity for change to support service. MDs stated that their patients were instructed to wait for 15 minutes after their appointment time for the appointment to occur and call an administrative assistant if the MD was more than 15 minutes late. This was implemented to reduce the stress levels of MDs and their patients if the MD was not on time to the appointment, or if a patient happened to be late to the appointment, or if they both faced technical difficulties. Participants noted that the same technique could be applied to GCs and their patients. Booking appointments ahead of time ( 3 days), instead of 1 day, was also seen as a positive change since it allowed GCs to review cases with MDs ahead of the appointment.

Regarding the struggles with completing paperwork in virtual care, the team suggested this could be improved with additional support from a clinical assistant. This assistant could be physically in the office to complete the forms and fax them to the labs. The clinic hired an assistant in November 2020 to support this strategy.

\subsection{Findings from Diary Study}

Based on our archival analysis of the clinic's quality improvement work conducted prior to this study, I suspected that the real time spent on indirect patient care activities was being under-reported because GCs are focused more on delivering patient care than documenting the real time spent performing activities. Further, with the onset of the pandemic, there was an additional need to document direct and indirect care in virtual care. A 
diary study form was created in Excel to study direct and indirect care in virtual workflows and was sent to the prenatal GCs to formally collect this 'time-on-task' data for 5 full-time workdays.

Upon receiving the completed forms from GCs through one of the QIT members, I combined all the data reflecting GC's own patient 'time-on-task' for direct and indirect virtual care for all the GCs in the 2 categories (work done for own patients \& other colleagues). Then, I calculated the frequency and duration of each task (how many times that task was done across all GCs) to calculate the average time per task per category.

As illustrated in Figure 8, the total average per time for the work done for the GC's own patients in descending order are: training activities (181.3 minutes), patient encounters (84.1 minutes), on-call activities (73.6 minutes), documentation (65.6 minutes), requisitions (65.3 minutes), meetings (47.8 minutes), results \& follow-up activities (46.4 minutes), other activities (44.3 minutes), case preparation/review (41.5 minutes), daily administration tasks (41.2 minutes), and triage (21.6 minutes).

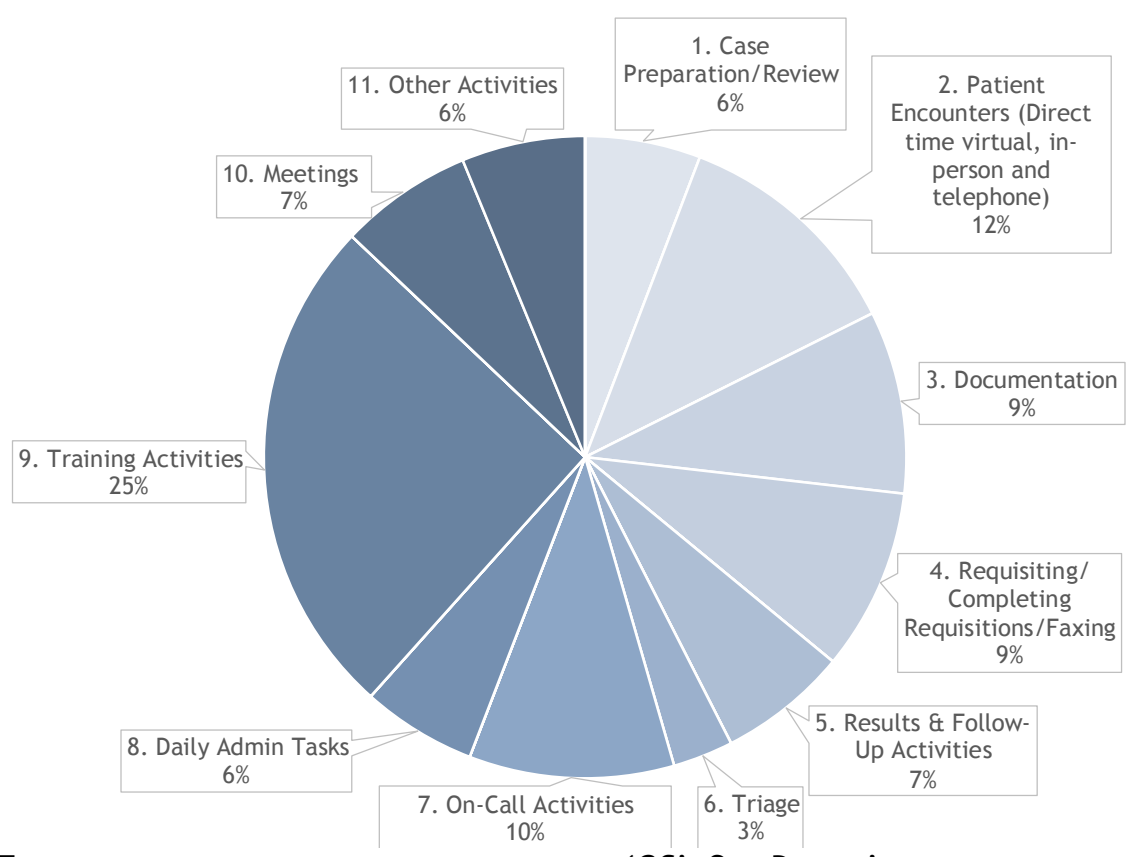

FIGURE 8 TOTAL AVERAge TIME PER TASK FOR WORK DONE UNDER 'GC'S OWN PATIENT' CATEGORY 
The picture looks different for the total average time GCs spend on tasks for other colleagues (Figure 9): triage (40.0 minutes), case preparation/ review (30.0 minutes), requisitions (27.7 minutes), results and follow-up activities (25.0 minutes), documentation (20.0 minutes), daily administration tasks (15.0 minutes), and on-call activities (5 minutes).

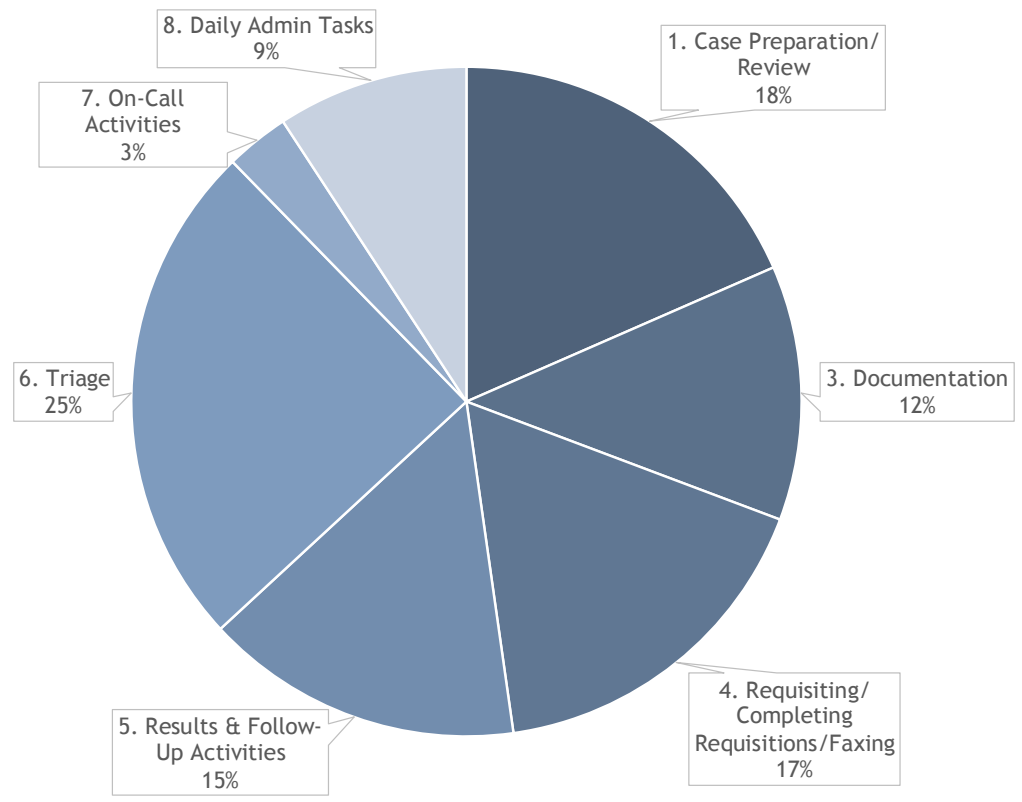

FIGURE 9 TOTAL AVERAGE TIME PER TASK FOR WORK DONE UNDER 'OTHER COlleAgUes' CATEGORY'

I then analyzed the data to determine what was taking most of the GC's time in providing combined patient care (direct and indirect). The diary study revealed that the 2 activities where GCs spent the most total average time working to support the care of their own patients (i.e., the time reported under the 'Own Patient' category), was on training activities (25\%) and patient encounters (12\%). The 2 activities where GCs spent the most total average time per task to support their colleagues (i.e., the time reported under the 'Other Colleagues' category) was on triage (25\%) and case preparation (18\%).

As already mentioned, the Ministry of Health suggests GCs should spend $70 \%$ of their time on patient related activities. These activities include all the activities performed for the patient care, whether it is direct care (consultations) or indirect care (requisitions, results, and 
follow-up, writing reports, etc.). From the data collected from the Genetics Clinic in this study

(Table 3), the prenatal GCs spent around $55.85 \%$ of their time on patient related activities, and $44.15 \%$ on non-patient related activities.

\begin{tabular}{|c|c|}
\hline \multicolumn{2}{|c|}{$\begin{array}{l}\text { LIST OF PATIENT RELATED ACTIVITIES AND NON-PATIENT RELATED ACTIVITIES, AND THE AVERAGE } \\
\text { TIME ON TASK (IN MIN.) FOR 'OWN PATIENT' CATEGORY }\end{array}$} \\
\hline $\begin{array}{l}\text { Patient Related } \\
\text { Activities }\end{array}$ & $\begin{array}{l}\text { Non-Patient Related } \\
\text { Activities }\end{array}$ \\
\hline $\begin{array}{l}\text { Patient Encounters } \\
(84.09)\end{array}$ & $\begin{array}{l}\text { Training Activities } \\
(181.3)\end{array}$ \\
\hline $\begin{array}{l}\text { On-call Activities } \\
(73.58)\end{array}$ & $\begin{array}{l}\text { Meetings } \\
(47.84)\end{array}$ \\
\hline $\begin{array}{l}\text { Documentation } \\
\quad(65.61)\end{array}$ & $\begin{array}{l}\text { Other Activities } \\
(44.33)\end{array}$ \\
\hline $\begin{array}{l}\text { Requisitions } \\
(65.30)\end{array}$ & $\begin{array}{l}\text { Daily Administration Tasks } \\
\qquad(41.19)\end{array}$ \\
\hline $\begin{array}{l}\text { Results and Follow-up } \\
\qquad(46.42)\end{array}$ & \\
\hline $\begin{array}{l}\text { Case Preparation/ Review } \\
\qquad(41.46)\end{array}$ & \\
\hline $\begin{array}{l}\text { Triage } \\
(21.64)\end{array}$ & \\
\hline
\end{tabular}

\subsection{Findings from Naturalistic Observation}

Figure 10 shows the combined movements of all prenatal GCs that participated in this part of the study. These observations show challenges associated with both 'time' and 'bottlenecks' in clinical workflows. What is evident is that the path to travel across the clinic takes time, although this may be healthy depending on the frequency of travel, it was important to understand the time it adds to the Genetics Counsellor's workload. This reveals some potential adjacency issues with touch points in the layout used during workflow to complete tasks. 


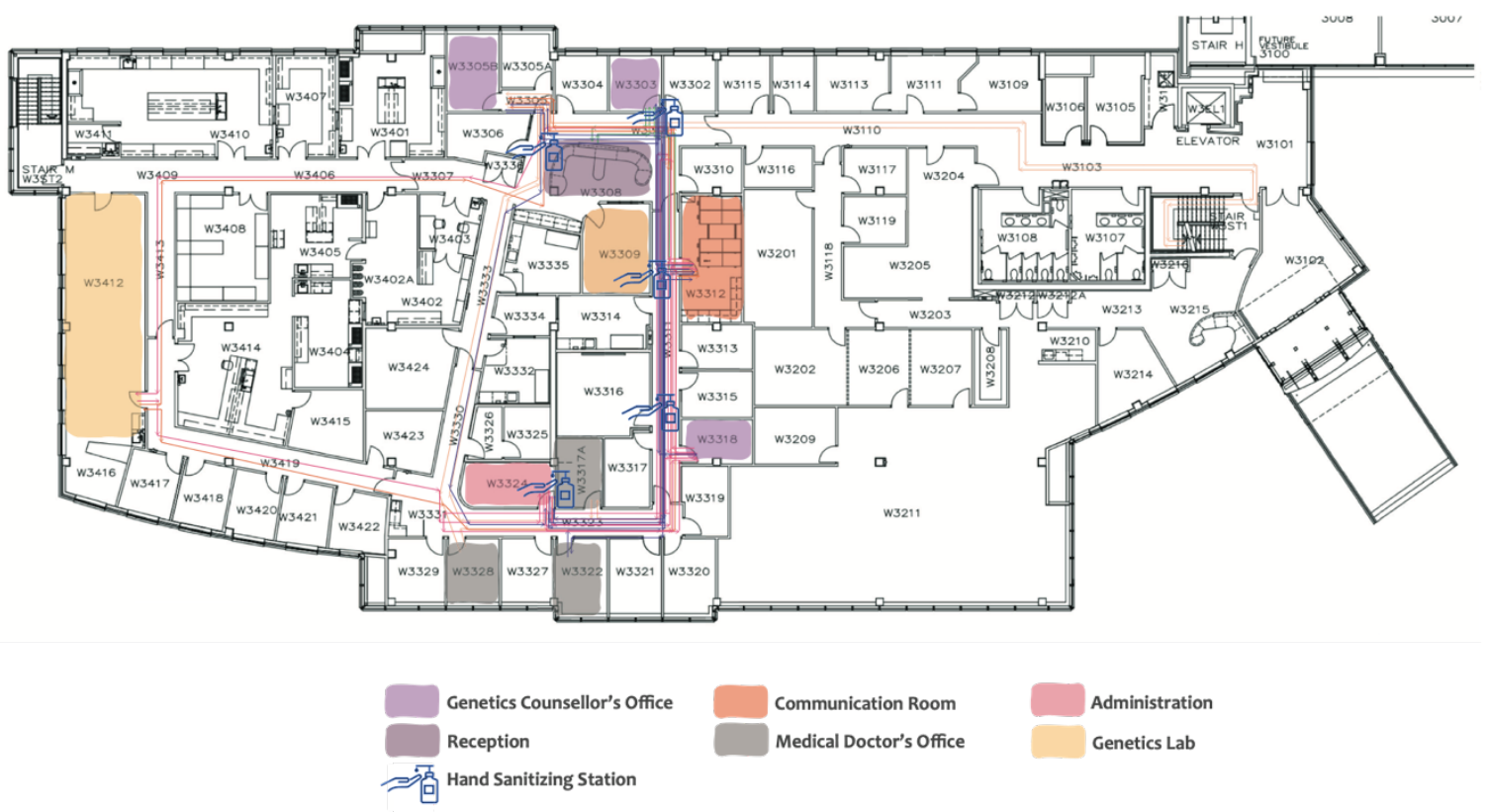

FIGURE 10 MAP GENERATED FROM THE OVERALL MOVEMENT OF GCS AROUND THE CLINIC

The rationale for allocating offices to GCs and MDs and the location of these offices relative to other touchpoints was also explained by our key stakeholder representatives. All the GCs offices are around the core area for providing care since prior to the pandemic they saw their patients in their offices. The MDs offices are located outside of the core clinical area because they see their patients in the exam rooms. All prenatal GCs have their own offices, where they spend most of their 'on-call' time. They use this space to prepare cases, check their emails, hold their virtual appointments, receive calls, and conduct follow-up phone calls with labs, patients, and other healthcare providers. The next space most used by GCs at the Genetics Clinic is the 'Communication Room' or 'Files Room'. All GCs use the 'Communication Room' to get a pager which is connected to a CHEO community number used to reach the GC on-call; print out and obtain forms/requisitions and lab results; check the in-basket for their work that was covered by other colleagues who were on-call; and to get 
labels/stickers of the MD on-call to be included in the requisitions/forms being sent out on that day.

The GCs use the 'Reception' space to write their names on the Genetics Clinic board, which shows the staff who are physically in the clinic; obtain hard copies of the lab order requisitions; and pick up printed patient stickers/labels which contain the patient's information which needs to be added to the requisitions. In addition, GCs travel to the labs (the Genetics Lab and the CHEO Lab) to drop off the requisitions for urgent cases, and to

have discussions with the lab coordinator on certain cases. Sometimes the GCs make trips to the 'Administrative Assistant's Office' to obtain pre-signed forms related to Ministry of Health approvals, and to provide completed forms that are urgent and need to be faxed immediately.

Our findings start by presenting the 'time-on-task' for key on-site activities followed by a task analysis which shows a step-by-step picture of what GCs do on site.

\subsubsection{Time on Task for Site Work}

The data collected during the observation sessions included the time it takes prenatal GCs to perform tasks, and most of these tasks are similar to the list of tasks in the diary study. The main difference is there is additional work that the on-call GC must do to support the GCs working virtually from home, namely with tasks that are difficult to perform from home as they involve physical artefacts, equipment and spaces to perform the work. These 'physical' tasks included: obtaining, filling out and faxing requisitions by hand; obtaining and printing the patient's, GC's, and MD's label information; and receiving results and any requisitions from a referring physician.

The results from the observation sessions were compared to the data reported in the diary study by comparing the time it takes GCs to perform tasks virtually (diary study) and in- 
person (observation session) to help us develop a better understanding of what activities may be occupying a GC's time and strategies to overcome these challenges. The time-on-tasks reported by GCs in the diary study were very similar to the time I observed GCs performing tasks on-site, with the exception of requisitions and follow-up consultations, as shown in Table 4.

\begin{tabular}{|c|c|c|}
\hline TABLE 4 & \multicolumn{2}{|c|}{$\begin{array}{c}\text { OVERVIEW OF THE AVERAGE TIME TO PERFORM TASKS FROM THE DATA COLLETED DURING THE } \\
\text { OBSERVATION SESIONS VERSUS THE TIME REPORTED TO PERFORM TASKS IN THE DIARY STUDY. }\end{array}$} \\
\hline Task & $\begin{array}{c}\text { Observation Sessions } \\
\text { (in min.) }\end{array}$ & $\begin{array}{c}\text { Diary Study } \\
\text { (in min.) }\end{array}$ \\
\hline Triage & 18.5 & 21.6 \\
\hline Case Preparation & 24.2 & 27.8 \\
\hline $\begin{array}{c}\text { Requisitions } \\
\text { (Filling Out forms) }\end{array}$ & 30.8 & 19.25 \\
\hline Results \& Follow-Up & 15.6 & 26.4 \\
\hline Follow-Up Consultations & 53 & 29.9 \\
\hline Writing Reports & 30.5 & $33.4^{*}$ \\
\hline
\end{tabular}

*In the Diary Study, the category 'Documentation' included documenting on Epic and Writing Reports.

Figure 11 illustrates the main tasks prenatal GCs perform that are related to patient care (directly and indirectly). Below we present the time on task documented for each category. These tasks are then described in more detail in the next major section, 5.5.2 Task Analysis/Work Process Diagrams.

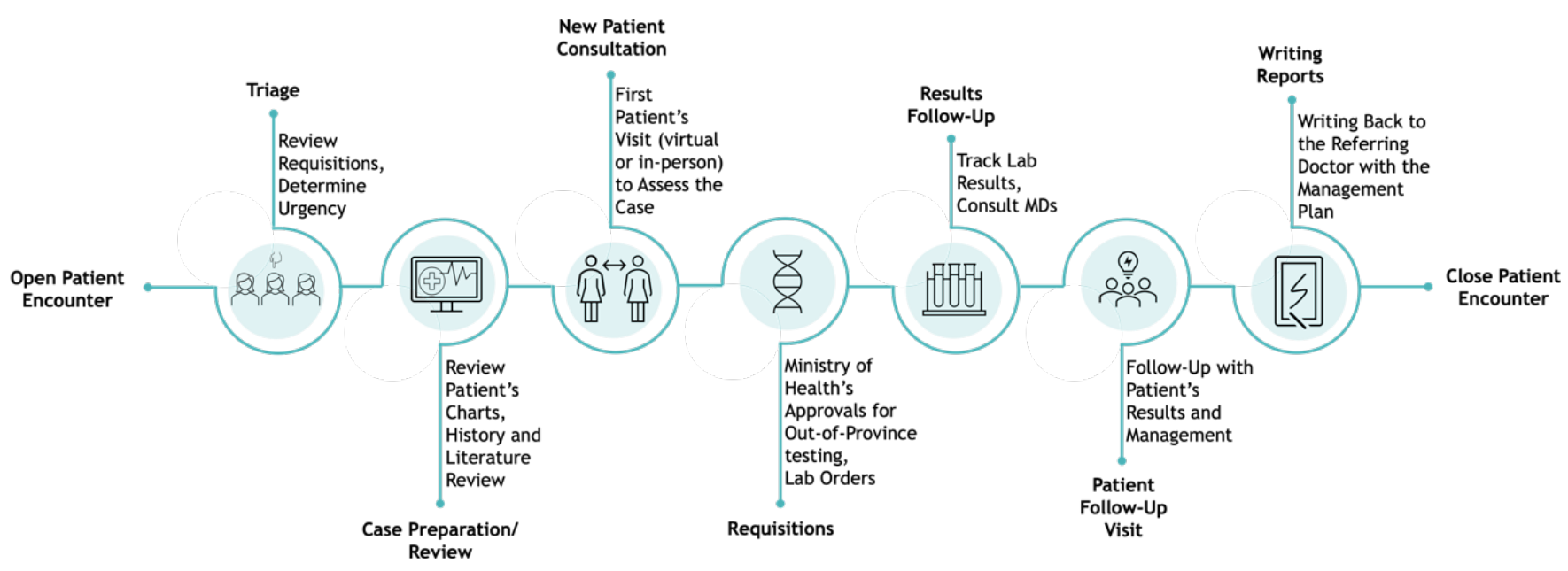

figure 11 OVerview of the patient related tasks performed at the Prenatal Genetics Clinic 


\subsubsection{Triage}

Triage is the activity of reviewing the referrals sent by the primary care providers and determining if the case falls within the specialty of the clinic. Prenatal GCs review cases triaged to both the General Clinic (includes cardiology, neurology, etc.) and the Prenatal Clinic. The reason for this comprehensive review, is that sometimes it not clear if the patient is pregnant or if the referral is for a patient whose partner is pregnant, and therefore a diagnosis that might impact the fetus. Such referrals are re-directed to prenatal triage.

\begin{tabular}{|c|c|c|c|c|}
\hline TABLE 5 & TIME SPENT BY PRENATAL GCS ON 'TRIAGE’ (ON AVERAGE - 2.6 MIN. PER REFERRAL) \\
\hline $\begin{array}{c}\text { Observation } \\
\text { Day }\end{array}$ & $\begin{array}{c}\text { \# Prenatal } \\
\text { Referrals }\end{array}$ & $\begin{array}{c}\text { \# General } \\
\text { Referrals }\end{array}$ & $\begin{array}{c}\text { Total Time Spent } \\
\text { on Triage (in min.) }\end{array}$ & $\begin{array}{c}\text { Average Time Spent } \\
\text { on Triage (in min.) }\end{array}$ \\
\hline Day 1 & 2 & 0 & 4 & 2 \\
\hline Day 2 & 2 & 7 & 32 & 3.5 \\
\hline Day 3 & 5 & 5 & 22 & 2.2 \\
\hline Day 4 & 3 & 6 & 30 & 3.3 \\
\hline Day 5 & 0 & 3 & 6 & 2 \\
\hline Day 6 & 0 & 6 & 17 & 2.8 \\
\hline
\end{tabular}

Triage includes reviewing all the lab results and tests that have been completed to-date, approving or declining the case, and determining the urgency to see the patient. During our observations, prenatal GCs spent time reviewing hand-written referrals to understand the diagnosis by the primary care provider and reviewing if all the required documents were included with the referral. When documents were missing, GCs asked the patient service clerk to request them from the patient and/or referring doctor.

\subsubsection{Case Preparation/ Case Review}

After accepting a referral and prior to the patient's consultation, prenatal GCs review the medical and family history information provided. Case preparation involved: reviewing the referral letter; reviewing ultrasound results and other previous tests; checking the patient's consent forms to allow virtual care; and reading the literature on the case. I unfortunately was not able to collect detailed data on case preparation due to the limited amount of this specific 
work currently taking place at the clinic during the pandemic. Table 6 presents the results I do have on this activity.

\begin{tabular}{|c|c|c|c|}
\hline $\begin{array}{l}\text { TIME S } \\
\text { PER CA }\end{array}$ & \multicolumn{3}{|c|}{$\begin{array}{l}\text { TIME SPENT BY PRENATAL GCS ON 'CASE PREPARATION/CASE REVIEW’ (ON AVERAGE - } 19.2 \text { MIN } \\
\text { PER CASE) }\end{array}$} \\
\hline Observation Day & \# Cases Reviewed & $\begin{array}{c}\text { Total Time Spent } \\
\text { on Case } \\
\text { Preparation/ } \\
\text { Review (in min.) }\end{array}$ & $\begin{array}{l}\text { Average Time Spent Per } \\
\text { Case Preparation/ Case } \\
\text { Review (in min.) }\end{array}$ \\
\hline Day 1 & 3 & $95(58+22+15)$ & 31.7 \\
\hline Day 2 & 1 & 15 & 15 \\
\hline Day 3 & 0 & 0 & 0 \\
\hline Day 4 & 0 & 0 & 0 \\
\hline Day 5 & 0 & 0 & 0 \\
\hline Day 6 & 1 & 11 & 11 \\
\hline
\end{tabular}

\subsubsection{Requisitions}

Prenatal GCs fill out requisitions by hand, and they feel it is easier to do it this way due to the need to apply labels/stickers with patient information to each requisition. Patient's labels/stickers are generated directly from Epic, and it contains the patient's name, date of birth, contact information, address, and health card number. Using labels ensures the patient's information is accurate when reviewed by other stakeholders and laboratory personnel. During pandemic working conditions, prenatal GCs working from home (not on-call) are struggling to prepare the requisition forms since they are not on-site to physically fill them out and adhere the patient labels to these forms.

The workflow of requisition changed during our two-week observation sessions. In the first week, some prenatal GCs spent time during their on-call shifts to prepare the necessary requisitions for their future consultations when they were reviewing the patient's case. They would then leave the completed forms in their in-basket in the 'Communication Room' until their patient consultation day. Filling out the requisition included determining the date the test should be conducted depending on the gestational age of the pregnancy. After the patient's consultation, and if the patient wished to proceed with the tests, they would then 
ask the GC on-call to put the patient's labels on the prepared requisitions and send them to the required labs. The observations took place over 2 weeks, where during the second week a clinical assistant was hired and was given the task of completing the requisitions on-site. Table 7 shows the results of the time spent by GCs on-call preparing requisitions.

\begin{tabular}{|c|c|c|c|}
\hline $\begin{array}{l}\text { TIME SF } \\
15.6 \mathrm{M}\end{array}$ & $\begin{array}{l}\text { T BY PRENATAL GCS } \\
\text { PER PATIENT) }\end{array}$ & 'PREPARING REQUISITI & FOR ONE PATIENT (ON AVERAGE \\
\hline Observation Day & $\begin{array}{l}\text { \# of Requisition } \\
\text { Forms for } 1 \\
\text { Patient }\end{array}$ & $\begin{array}{c}\text { Total Time Spent } \\
\text { on Preparing } \\
\text { Requisitions } \\
\text { (in min.) }\end{array}$ & $\begin{array}{l}\text { Average Time Spent Per } \\
\text { Patient* (in min.) }^{*}\end{array}$ \\
\hline Day 1 & 1 & 15 & 15 \\
\hline Day 2 & 1 & 16 & 16 \\
\hline Day 3 & 5 & $\begin{array}{c}79 \\
(50+12+3+7+18)\end{array}$ & 15.8 \\
\hline Day 4 & 1 & 18 & 18 \\
\hline Day 5 & 1 & 16 & 16 \\
\hline Day 6 & 2 & $26(10+16)$ & 13 \\
\hline
\end{tabular}

\subsubsection{Results and Follow-up}

The Genetics Clinic receives results from labs outside CHEO by fax, and the ones ordered within $\mathrm{CHEO}$ are uploaded directly into Epic. Prenatal GCs then review the results and consult the MDs to discuss the patient's plan of care. Prenatal GCs determine if the patient needs a follow-up appointment or a phone call to inform the patient of the results. Table 8 shows the time spent on results and follow-up activities.

\begin{tabular}{|c|c|c|c|}
\hline TABLE 8 & \multicolumn{4}{c|}{$\begin{array}{c}\text { TIME SPENT BY PRENATAL GCS ON ‘RESULTS FOLLOW-UP’ FOR ONE PATIENT (ON AVERAGE - 6.4 } \\
\text { MIN. PER RESULT) }\end{array}$} \\
\hline Observation Day & \# Results & $\begin{array}{c}\text { Total Time } \\
\text { (in min.) }\end{array}$ & $\begin{array}{c}\text { Average Time Spent Per } \\
\text { Result (in min.) }\end{array}$ \\
\hline Day 1 & 2 & $13(4+9)$ & 6.5 \\
\hline Day 2 & 5 & $42(9+4+7+14+8)$ & 8.4 \\
\hline Day 3 & 3 & $9(3+3+3)$ & 3 \\
\hline Day 4 & 1 & 10 & 10 \\
\hline Day 5 & 0 & 0 & 0 \\
\hline Day 6 & 1 & 4 & 4 \\
\hline
\end{tabular}




\subsubsection{Writing Reports}

The final step in providing service in the Genetics Clinic involves writing back to the referring doctor with all the lab results, a conclusion and future care plan. The prenatal GCs write reports on Epic, which has a tool to write a report. However, this tool does not allow the GCs to attach a lab result. To overcome this obstacle, prenatal GCs take a screen shot of the results and paste it at the end of the report as a picture. The MD then reviews the report and signs off and the report is then sent by fax to the referring doctor. I did not observe an adequate number of 'writing reports' activities because the GCs on-call try to dedicate their time at the office on activities that are difficult to perform virtually (e.g., administrative tasks, requisitions, and results and follow-up). Table 9 outlines the limited results from this observation.

\begin{tabular}{|c|c|c|c|}
\hline TABLE 9 & \multicolumn{3}{c|}{$\begin{array}{c}\text { TIME SPENT BY PRENATAL GCS ON 'WRITING REPORTS’ FOR ONE PATIENT (ON AVERAGE - 19.9 } \\
\text { MIN. PER REPORT) }\end{array}$} \\
\hline Observation Day & \# Reports & $\begin{array}{c}\text { Total Time } \\
\text { (in min.) }\end{array}$ & $\begin{array}{c}\text { Average Time Per Results } \\
\text { (in min.) }\end{array}$ \\
\hline Day 1 & 0 & 0 & 0 \\
\hline Day 2 & 1 & 29 & 29 \\
\hline Day 3 & 0 & 0 & 0 \\
\hline Day 4 & 0 & 0 & 0 \\
\hline Day 5 & 3 & $32(12+10+10)$ & 10.7 \\
\hline Day 6 & 0 & 0 & 0 \\
\hline
\end{tabular}

\subsubsection{Summary of Time on Task}

Our results of virtual and on-site workflows, summarized in Table 10, show that GCs spend at least half of their time on tasks before and/or after the patient's consultation. The results highlight the potential challenges prenatal GCs face to reduce patient wait times considering 'work as done in reality' versus 'work as imagined'. Therefore, looking at potential inefficiencies or bottlenecks in workflows before and after a patient's consultation may help improve patient access to genetics services. The collection and analysis of these results combined with a basic Lean analysis of bottlenecks and opportunities for improvement, and 
clinic feedback on these findings is informing the on-going development of a strategic plan for improving the work efficiency at the Prenatal Genetics Clinic.

\begin{tabular}{|c|c|c|c|c|}
\hline TABLE 10 & \multicolumn{4}{|c|}{$\begin{array}{c}\text { COMPARISON OF THE RESULTS FROM THE DIARY STUDY AND OBSERVATION SESSIONS ON THE TIME } \\
\text { GCS SPEND ON ACTIVITIES PERFORMED BEFORE PATIENT'S CONSULTATION, AND AFTER PATIENT'S } \\
\text { CONSULTATION }\end{array}$} \\
\hline Time of Task & Task & $\begin{array}{c}\text { Data from } \\
\text { Diary Study } \\
\text { (in min.) }\end{array}$ & $\begin{array}{c}\text { Data from } \\
\text { Observation } \\
\text { (in min.) }\end{array}$ & $\begin{array}{c}\text { Average Time } \\
\text { (in min.) }\end{array}$ \\
\hline $\begin{array}{c}\text { Before } \\
\text { Patient's } \\
\text { Consultation }\end{array}$ & $\begin{array}{c}\text { Case Preparation/ } \\
\text { Review }\end{array}$ & 21.6 & 18.5 & 20.05 \\
\hline $\begin{array}{c}\text { After } \\
\text { Patient's }\end{array}$ & $\begin{array}{c}\text { Requisitions } \\
\text { (filling out forms) }\end{array}$ & 19.8 & 24.2 & 26 \\
\cline { 2 - 5 } Consultation & Results Follow-Up & 26.4 & 30.8 & 25.03 \\
\cline { 2 - 5 } & Writing Reports & 33.4 & 15.6 & 21 \\
\hline
\end{tabular}

\subsubsection{Task Analysis/Work Process Diagrams}

A visual task analysis was developed to map the key steps in on-site workflows at the Prenatal Genetics Clinic to identify efficiency issues related to the design of the space, process, and the use of artefacts (e.g., paper-based work, equipment, digital platforms) - issues that may be influencing serving patients in a timely manner. Task analysis is a fundamental method in human factors design to make existing systems explicit and help identify design problems (The Human Factors, 2011). The basic elements of task analysis include defining the task or activities performed, dividing these activities into subtasks/steps, and specifying the tools/technology involved in the performance of these activities (The Human Factors, 2011).

\subsubsection{Triage Workflow}

The triage workflow includes 2 stakeholders: patient service clerks and GCs. Patient service clerks receive the referral by fax, open a patient encounter, and decide the specialty of the referral (e.g., prenatal, general). Then, GCs review the referral assigned to them and decide 
whether to accept or reject the referral, and the urgency of the case. When accepting the referral, GCs note any missing documents to be requested by patient service clerks when contacting the patient to book their first appointment. Figure 12 illustrates the triage workflow during the time of observations.

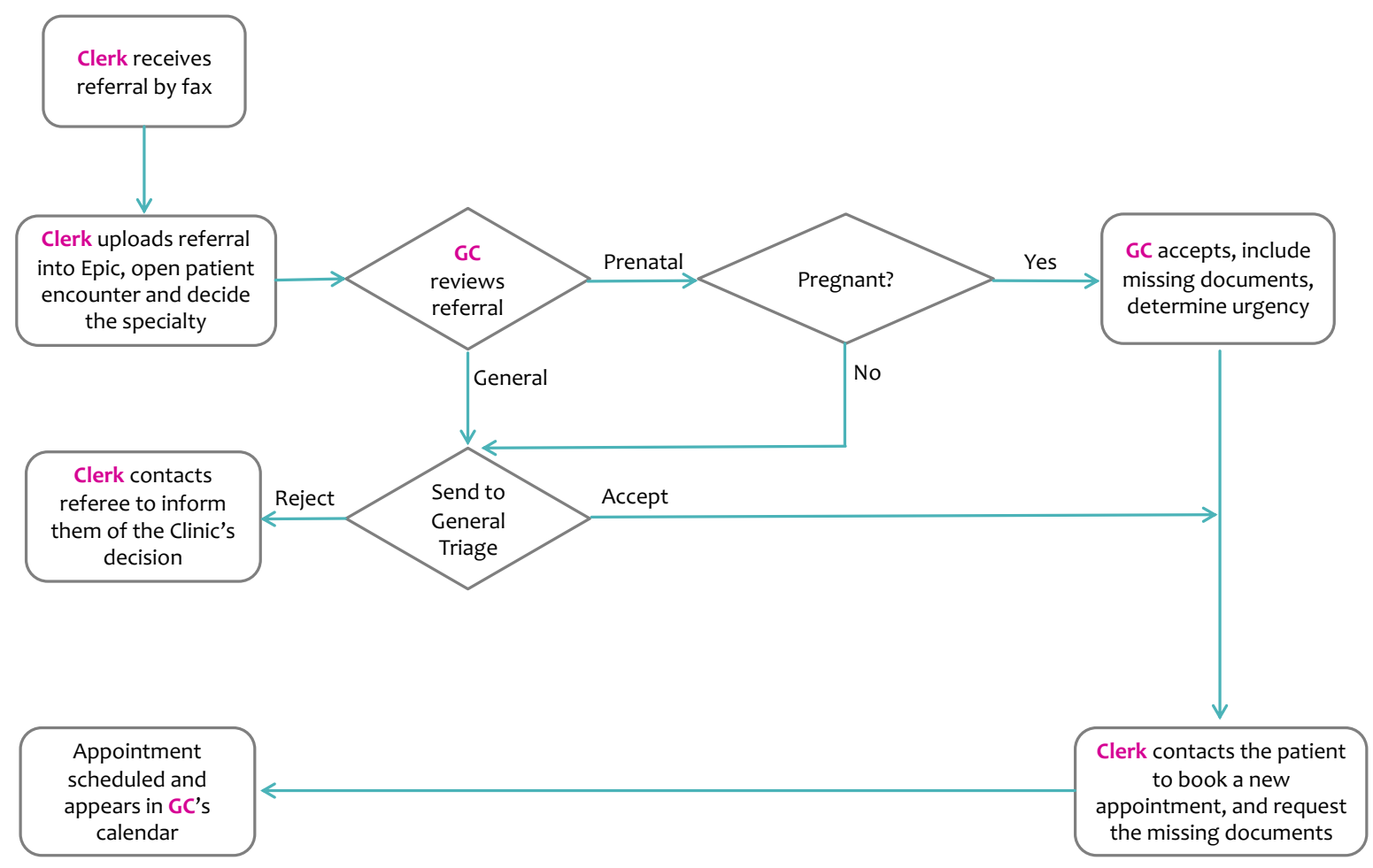

FIGURE 12 WORKFLOW OF 'TRIAGE' AT THE CLINIC

\subsubsection{Case Preparation / Case Review Workflow}

The second step in prenatal patient care is case preparation/case review, which takes place 2-3 days prior to the appointment. The workflow includes 3 stakeholders: patient service clerks, GCs, and MDs. Patient service clerks book the appointment and request any missing documents requested during triage. Next, the GC reviews the patient's referrals, previous tests, consent forms, and the literature on the diagnosis. During the observations, I noticed the patient's file was missing the consent form from the patient, so the GC had to email the patient 
service clerk to request these documents and that they be received before the appointment. After that, GCs consulted with the MDs on the complex cases. Also, GCs booked the MD on-call on the day of the appointment to attend the session where possible. Finally, the last step of the case preparation task involved GCs documenting in Epic what had been done for the patient and adding notes to be reviewed at the time of the appointment. Figure 13 illustrates the case preparation/case review workflow during the time of observations.

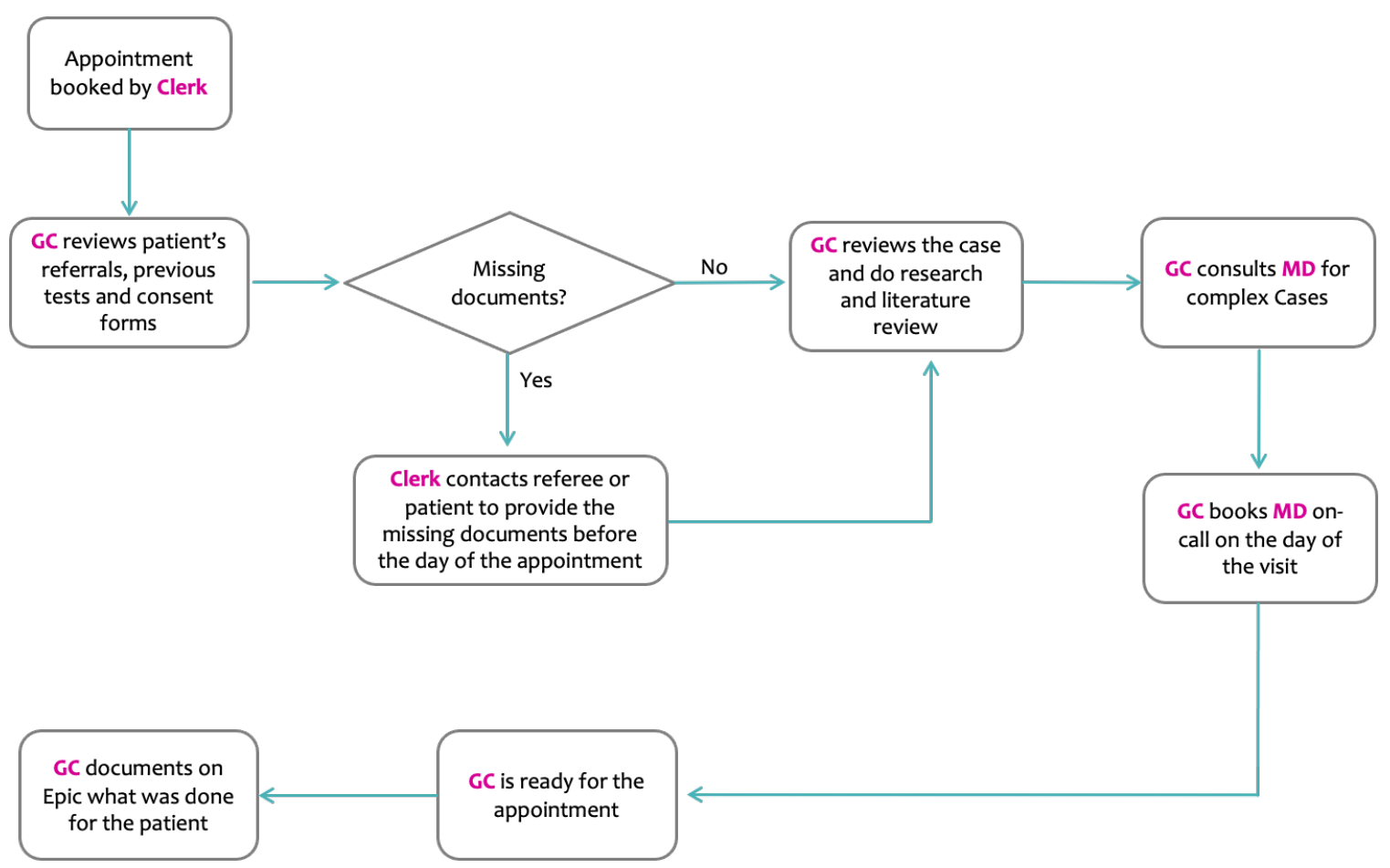

figure 13 Workflow of 'Case Preparation/Case Review’ at Clinic

\subsubsection{New Patient Consultation Workflow}

Due to the pandemic and the limited work permitted at the Genetics Clinic during the time of the observations, I did not observe any new patient consultations (either virtually or in-person) during the on-call days. Therefore, I have no results to report on this activity. 


\subsubsection{Requisitions Workflow}

The Prenatal Genetics Clinic sees patients from the provinces of Ontario and Quebec. After the patient's appointment and diagnosis, GCs request genetic testing to further investigate the diagnosis. GCs fill out 2 types of requisitions: Ministry of Health's approvals to run tests outside the provinces of Ontario or Quebec, and lab orders within CHEO and/or outside CHEO but within the province. During the first week of observations, the GC on-call prepared the forms for their own patients and for the other GCs working from home. However, this was changed with the introduction of the clinical assistant who became responsible for this task. This did not change the outcomes of the study as it was used to determine how the help of a clinical assistant at that time improved the workflow for GCs.

For the first type of requisitions (Ministry of Health's approvals), the Prenatal Genetics Clinic has pre-signed forms that are stored in the 'Administrative Assistant's Office'. If there are not any pre-signed copies, GCs ask the MD on-call to sign an empty form, make copies and leave these forms at the administrative assistant's desk. Next, GCs fill out the form (by hand) and print out the patient's sticker/label with the patient's information. Along with the patient's label, GCs add their own label and the on-call MD's label. After that, GCs make a copy of the forms, scan a copy to their emails or to their colleagues' email, and ask an administrative assistant to fax the forms to the Ministry of Health either in Ontario or Quebec depending on the residential address of the patient. Finally, GCs set reminders in Epic to follow-up on the approval, which is within 2 weeks from sending the forms. After they obtain the approval, they fill out the second type of requisition - lab orders. Figure 15 illustrates the Ministry of Health's approvals requisitions workflow. 


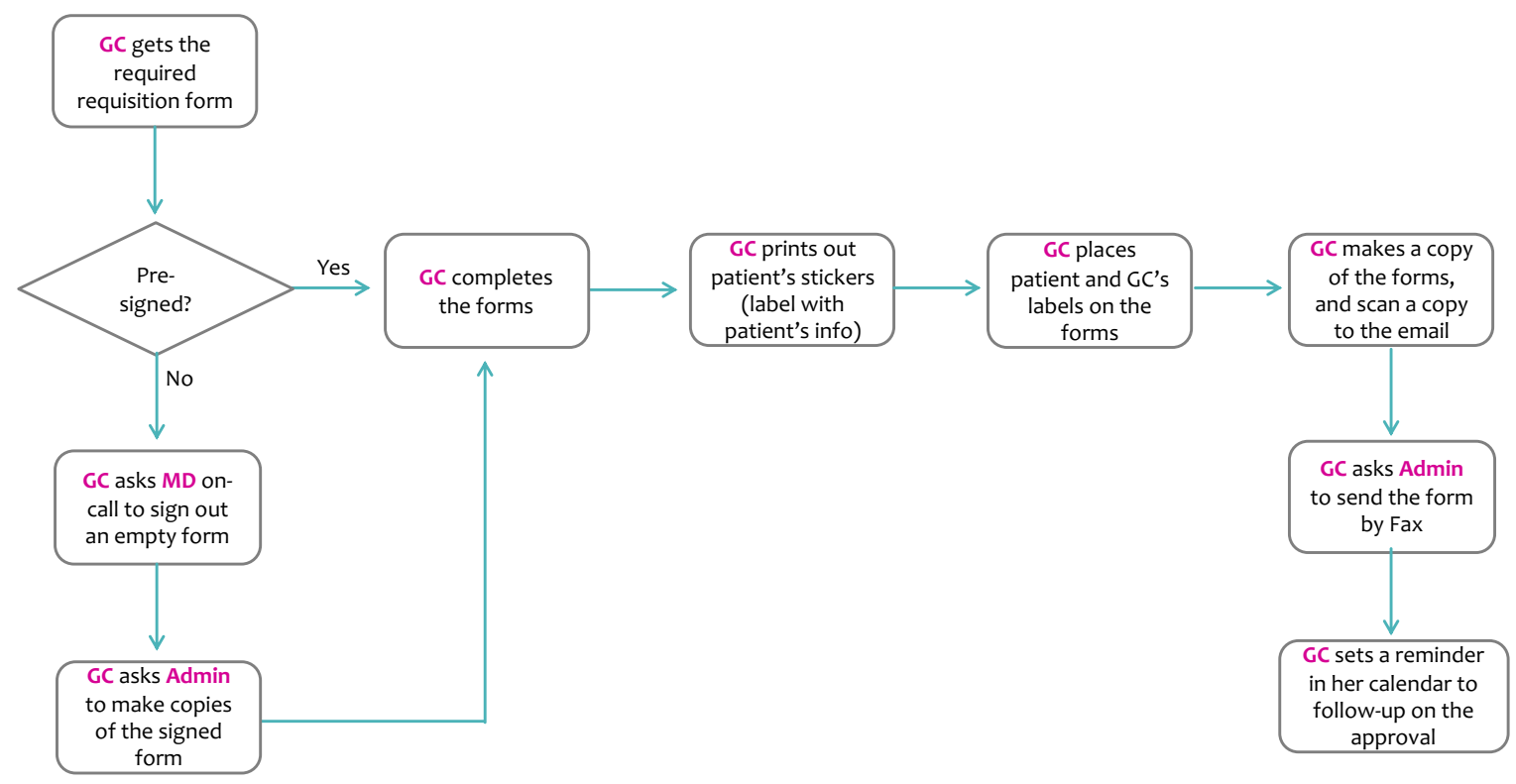

FIGURE 14 Workflow of 'Ministry Approval Requisitions’ at the Clinic

For the second type of requisitions (lab orders), GCs obtain the requisition form from either the 'Reception Desk', 'Communication Room', or they print it out from the lab offering the testing. Second, GCs fill out the form (by hand) and determine the day of the tests depending on the gestational age. Next, GCs print out the patient's sticker/label which contains the patient's information. Along with the patient's label, GCs add their own label and the on-call MD's label. After that, GCs make copies of the forms at the 'Communication Room', scan a copy to their email address or to their colleagues' email address, and send the completed forms to the lab and the patient. If the test is done outside CHEO, GCs ask an administrative assistant to send it to the requested lab by fax. If the test is done at the Genetics Department Lab, GCs take the forms in-person to the lab and send an email to the lab to confirm receipt of the forms and provide any necessary instructions. If the test is done at the CHEO Blood Lab, GCs ask an administrative assistant to send the forms to the lab, or they take the forms in-person for urgent cases. In addition, GCs send the forms to the patient with 
instructions on where and when to do the test in a detailed email. Finally, GCs set reminders in Epic to follow-up on the results, which is usually within 2 weeks from the test day.

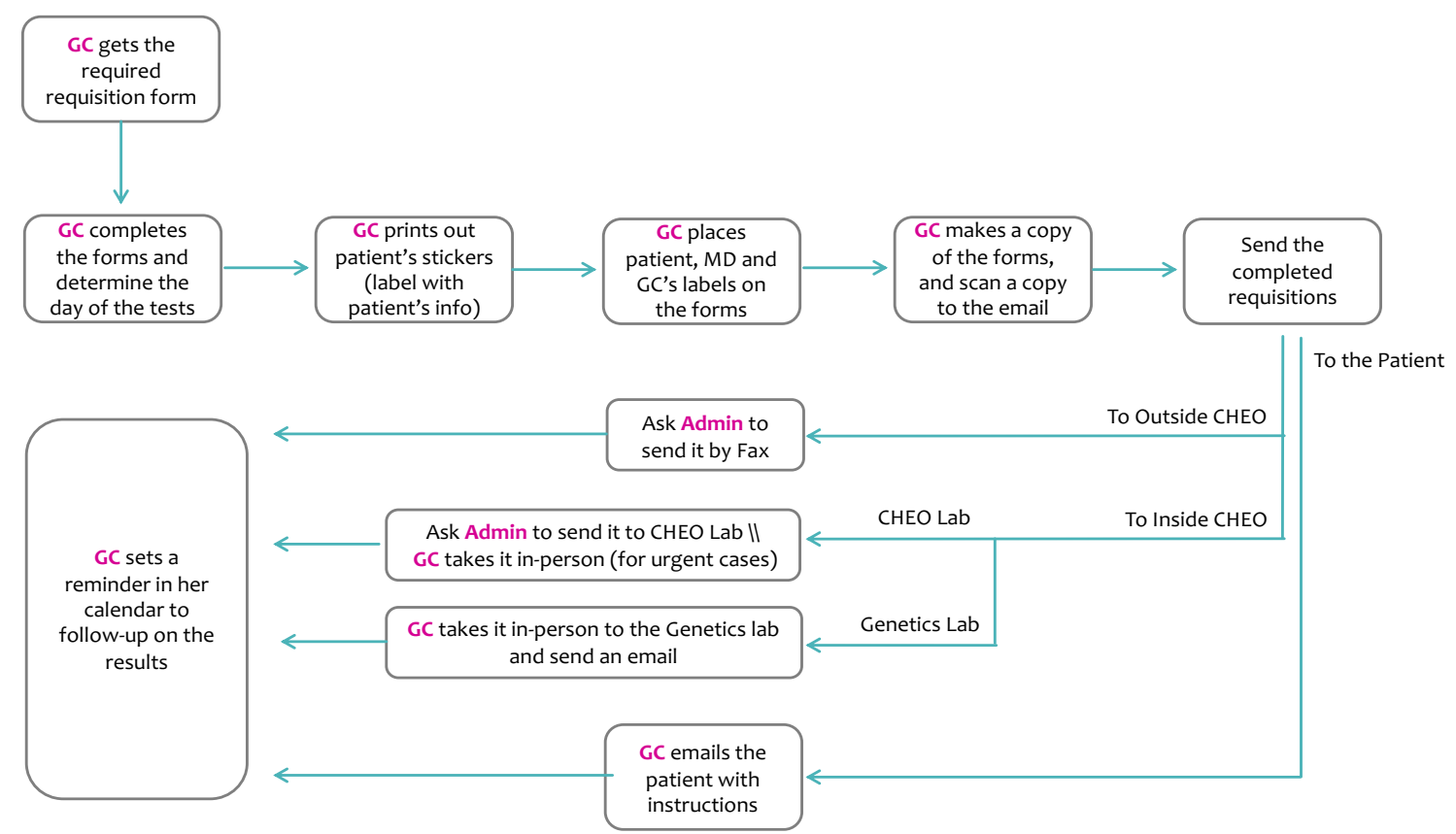

figure 15 Workflow of 'Lab Orders Requisitions’ at the Prenatal Genetics Clinic at the time of Observations

\subsubsection{Results Follow-Up Workflow}

After the patient has had the testing initiated, the results are received within 2 weeks. For the tests requested from labs inside $\mathrm{CHEO}$, the results are uploaded on Epic by the lab staff and Epic notifies the GCs of the new uploaded results, which can be accessed by the GC working from home. For the tests requested from labs outside CHEO, the Prenatal Genetics Clinic requests that results are sent by fax to the clinic. Administrative assistants print a copy of the results, find the patient's information, and assigned GC on Epic, place the patient's label on the results, and then place the results in the GC's basket in the 'Communication Room'. The GC on-call then scans the results to their email address (if the patient is their own) or to their colleague's email address (if the patient is assigned to another GC). After that, GCs consult with the MD to discuss the next steps in the treatment plan, which includes booking 
for a follow-up appointment and/or requesting more tests. If a follow-up appointment is needed, the GC asks an administrative assistant to contact the patient and book their appointment. Then, the GC adds the appointment time to the Microsoft Outlook Calendar of the MD on-call so they are aware of the appointment and can join. Figure 16 illustrates the results follow-up workflow. However, this workflow changed after the clinical assistant was introduced as she managed scanning and emailing the results to the GCs working from home.

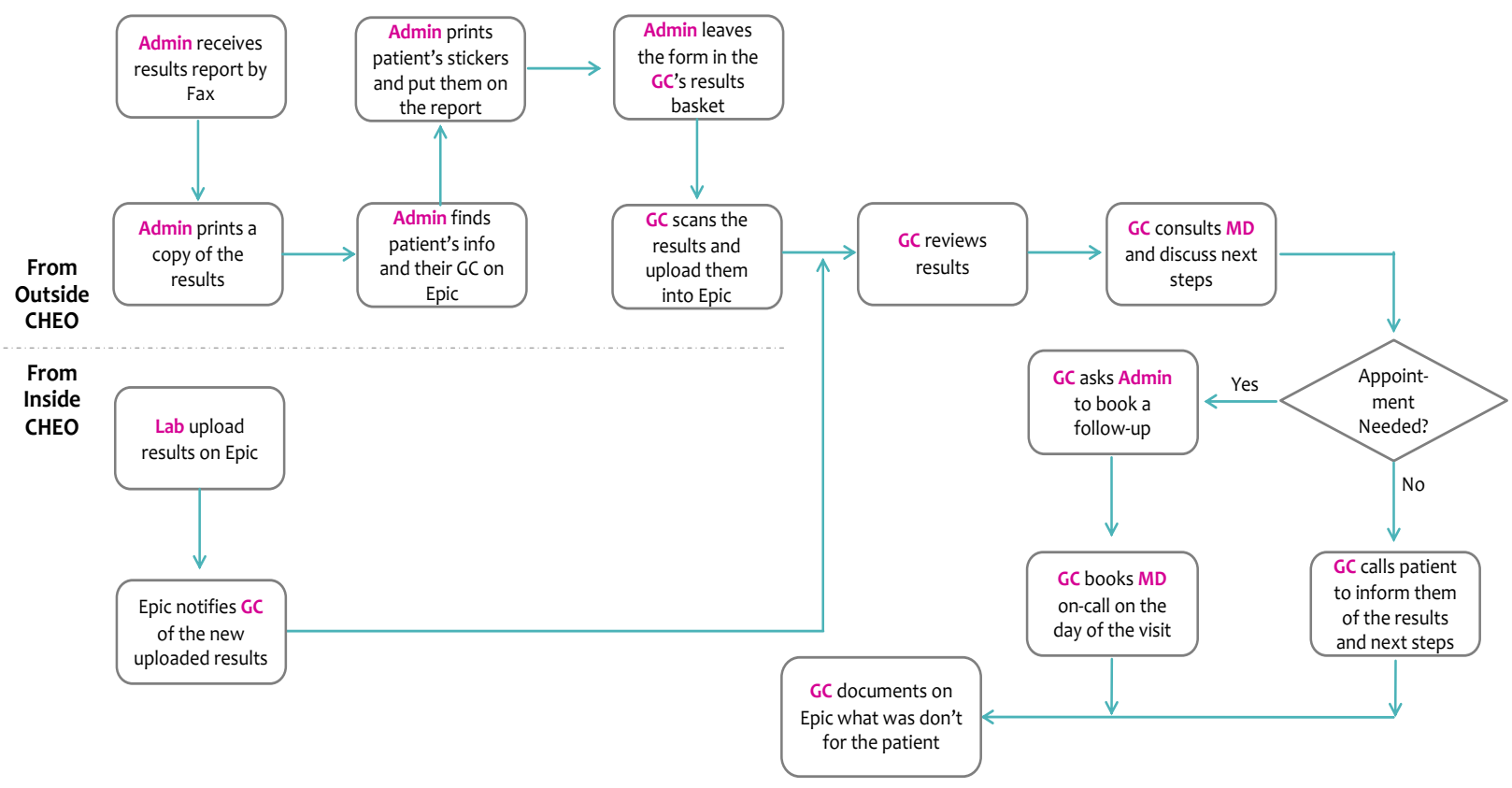

Figure 16 Workflow of ‘Results Follow-Up’ at the Prenatal Genetics Clinic at the time of Observations

During the time of observations, the Prenatal Genetics Clinic received requests from the referring doctor requesting a copy of the results for their patient, if they did not receive it from the lab. The requests are received by fax, an administrative assistant prints it out, puts the patient's label on the request and then places the request in the GC's basket in the 'Communication Room'. As mentioned in the previous workflow, the GC on-call reviews these letters and faxes the doctor's office the results. Figure 17 illustrates the workflow for responding to referring physician requests for lab results. 


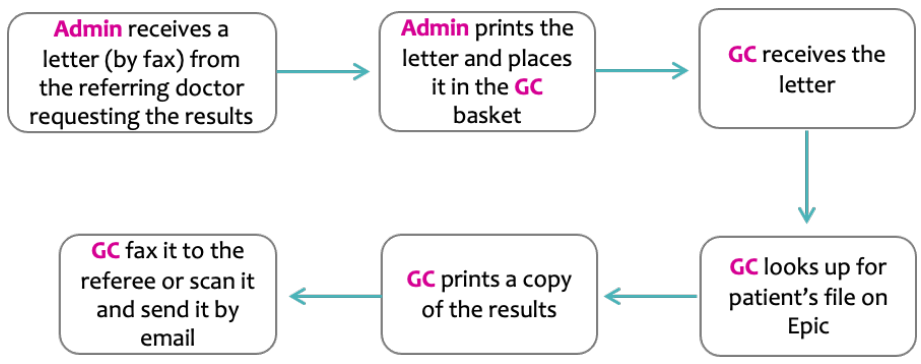

FIGURE 17 WoRkFLOW OF 'REPLYING tO THE REFERRING DoctoR's REQUEST' AT THE CLINIC

\subsubsection{Patient's Follow-Up Consultation Workflow}

Due to the pandemic and the limited work permitted at the Genetics Clinic during the time of the observations, I observed one virtual follow-up consultation with a patient. At the time of the appointment, the GC opened the patient's file on Epic, started the Zoom call and welcomed the patient and their partner. The GC discussed the results and the next steps. Near the end of the appointment, the GC sent a text message to the MD on-call to join the appointment. Both, MD, and GC answered the patient's questions and ended the Zoom call. After that, the GC documented on Epic what was done for the patient. Figure 18 illustrates the follow-up consultation workflow I observed.

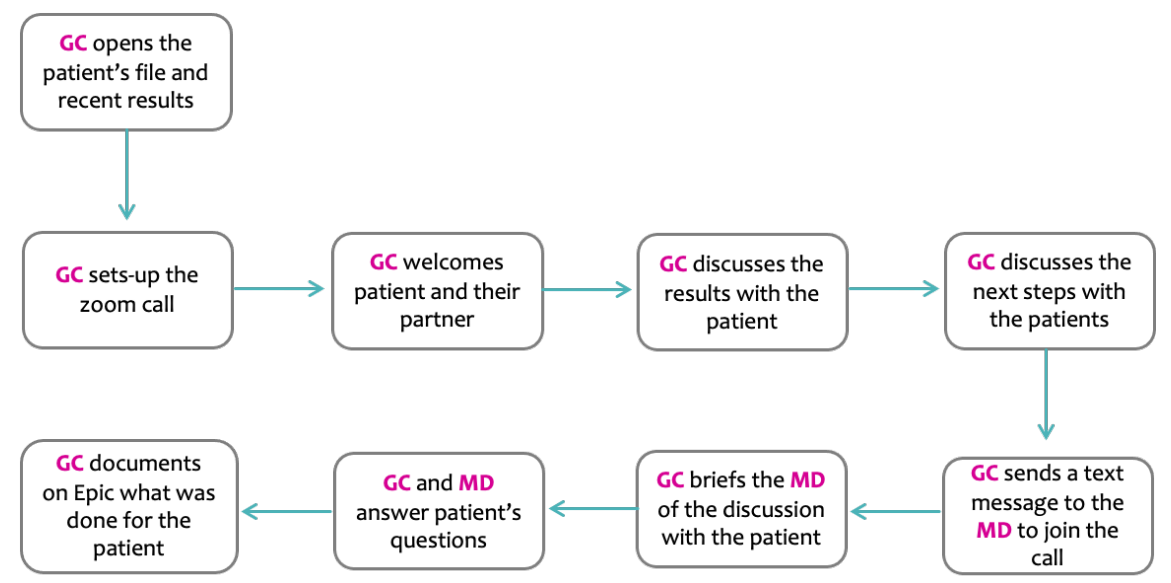

figure 18 Workflow of 'Follow-Up Appointment’ at the Prenatal Genetics Clinic at the time of Observations 


\subsubsection{Writing Reports Workflow}

The last step in patient care before closing the patient encounter is to write a report to the referring doctor with the final outcome of the genetics assessment. Genetic Counsellors use Epic tools to generate the report, where they can fill in pre-defined sections. Genetic Counsellors mentioned that Epic does not support attaching files to the report, so they must take a screenshot of the results which they then paste as a picture at the end of the generated report. After this is complete, the GC determines which MD should co-sign the report. Finally, the GC sends the report to the referring doctor by email through Epic or by fax, updates the patient's file on Epic and closes the patient encounter. Figure 19 illustrates the workflow for writing reports.

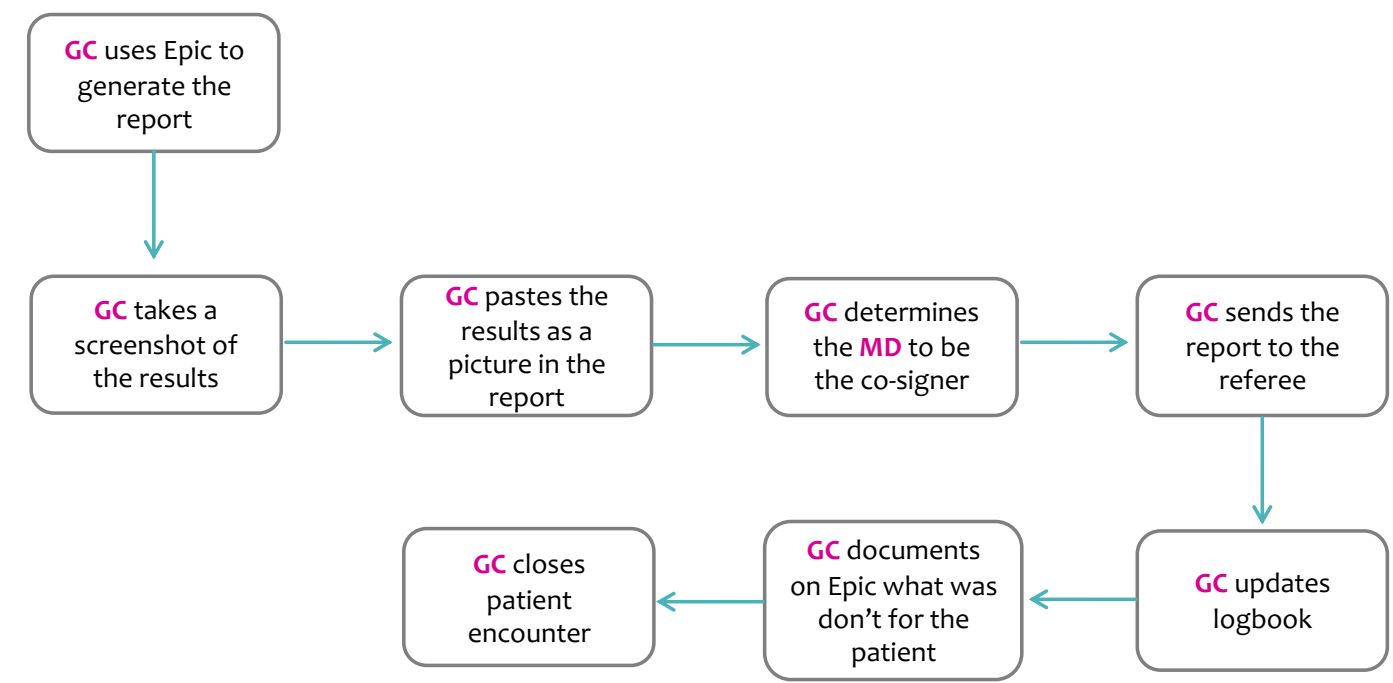

FIGURE 19 WORKFLOW OF 'WRITING REPORTS' AT THE CLINIC

\subsection{Results from Lean Improvement Process \& Clinic Feedback}

All the workflows generated in the task analysis were reviewed to determine the bottlenecks in the system and the root causes of these bottlenecks using the Lean Improvement process. Clinical flow is the process by which a patient moves through his/her visit and recently there has been an uptake of the Lean Improvement process to improve 
clinical flow. The Lean Define-Measure-Analyze-Improve-Control (DMAIC) approach (Figure 3) aims to eliminate waste (time, energy, or resources), and improve clinical flow to maximize patient satisfaction. The process involves identifying the steps, processes, and services that are of value to support patient care paths. This principle can increase efficiency and may help reduce wait times at the clinic and increase time for patient care.

Using the DMAIC approach, I first identified potential issues through the 'Define' phase, by conducting process walks/ workflows. Then, I evaluated the baseline performance of the system that existed prior to any suggested changes through the 'Measure' phase. The objective of the 'Analyze' phase is to identify the root causes that may be creating lags or variation in the service delivery model at the Prenatal Genetics Clinic. Since the aim of this study is to identify ways to increase capacity and decrease patient wait times, I analyzed the processes documented during our observations to identify any non-value added (NVA) steps, bottlenecks, and inefficiencies. During the 'Improve' phase, I identified potential solutions to address these root causes. I categorized these proposals to improve workflows into three groups: digital accommodation, administration support, and clinical assistance. The Lean Improvement methodology is also focused on ensuring the sustainability of the results in the long run. To support this 'Control' phase I suggested the prenatal team engage in a monthly review to discuss the status of implementing and evaluating these proposals and potential impact within the Prenatal Genetics Clinic. The next sections show in detail the results of the 'Analyze' and 'Improve' phases through an analysis of workflow/process diagrams that were generated from the task analysis.

The Lean workflow analysis was developed for all the workflows and then shared with the QIT team to refine the documentation of the workflows (i.e., were there any errors in our understanding of workflows?) and to assess whether and how the proposed solutions 
resonated with the clinic in terms of feasibility or the desire to make the changes. Some of the workflow charts are presented in the next section, and please refer to Appendix B.2 for the complete package of Lean workflow diagrams.

\subsubsection{Triage Workflow}

Analyze Phase: GCs spend time on reviewing handwritten referrals from the primary care provider/referring doctor which may be difficult to read. The other bottleneck in triage occurs when a referral is received that is not for a pregnant individual but for their spouse which takes time to carefully sort out. In this case, the partner must be referred, not the prenatal patient (see Appendix B.2 for workflow diagram).

Improve Phase: To improve the process of complete referrals, I discussed the use of fillable PDF forms which the Prenatal Genetics Clinic could ask all referring doctors to complete. Also, I suggested that the patient service clerk reviews the referrals to ensure they are not handwritten. This would result in clear referral forms and reduce the amount of time GCs spend time on second guessing the content of the letter. To overcome the second challenge, I suggested the help of a clinical assistant to review referrals during triage instead of GCs (see Appendix B.2 for workflow diagram).

QIT Feedback: The Genetics Clinic submitted a request to Epic technicians to activate the forms on Epic, a process that takes time to implement. As for our suggestion that a clinical assistant reviews the referrals during triage, the QIT mentioned that triage is a medical task and requires a medical health provider to perform the task (see Appendix B.2 for workflow diagram). 


\subsubsection{Case Preparation/ Review Workflow}

Analyze Phase: I observed only a few case preparations, which take place 1-2 days before the appointment day, and documented the steps where GCs spend most of their time when reviewing cases. First, GCs spend time on reviewing the consent form and other necessary information in the patient's chart followed by asking the patient service clerk to obtain any missing documents. The other bottleneck with case preparation is where GC's spend time coordinating and adding appointments to the MD on-call's calendar on Outlook, summarizing the case and including the Zoom link (see Appendix B.2 for workflow diagram).

Improve Phase: To overcome the first challenge, I suggested the clinical assistant follow up with the patient service clerk to request and receive the missing documents before the appointment. To address the second challenge, I suggested that the Prenatal Clinic be run at specific times when the MD on-call is committed to being available every week. The review of cases can happen before the clinic starts and the MD's appointments can be set up such that they overlap with the GC provider. The MD can then move from call to call to meet the routine patients and counsel the complex patients with the GC (see Appendix B.2 for workflow diagram).

QIT Feedback: The QIT showed their interest in including the clinical assistant in activities before the patient's visit, as the clinical assistant is only assigned tasks related to postconsultations. As for booking MDs, the Genetics Clinic changed their service care model to include specific dates and times dedicated for patient consultations. These times are now clear in the GCs and MDs calendars and patient service clerks and administrative assistants can easily view these calendars to book consultations accordingly (see Appendix B.2 for workflow diagram). 


\subsubsection{Requisitions Workflow}

\subsubsection{Ministry’s Approval Requisitions}

Analyze Phase: GCs expressed concerns about completing requisitions during the pandemic where the service care model is mostly virtual. GCs on call spend time finding pre-signed forms, filling out the forms by hand, and printing-out the patients' stickers. Some of this work was accelerated with the addition of the clinical assistant.

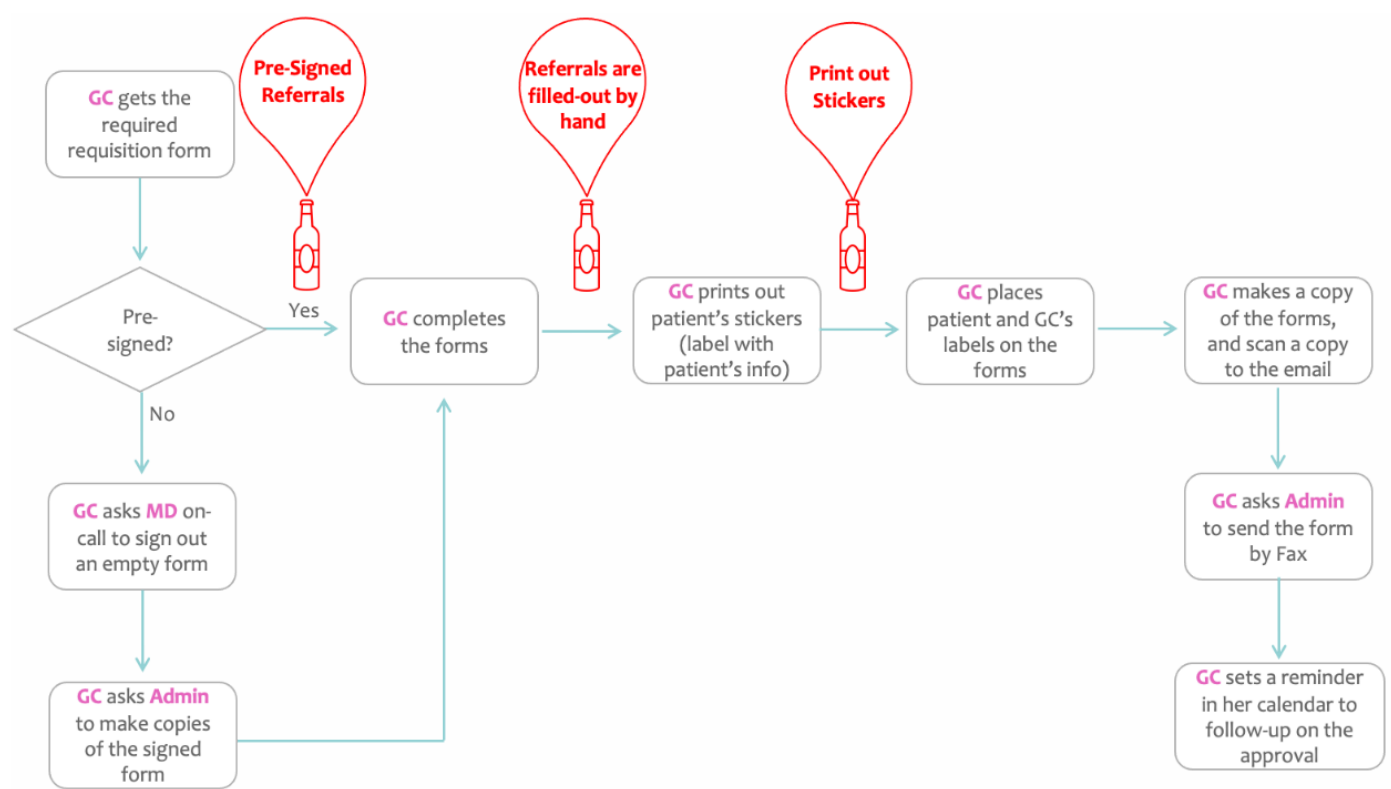

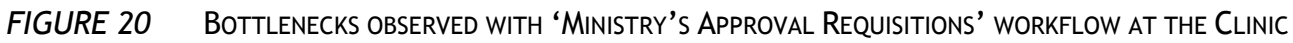

Improve Phase: The solutions suggested to overcome the challenges listed above involved further investigating the use of Epic to move the requisition process to an electronic format to create fillable digital forms, where signatures and labels could be added to digital forms. The availability of tools in Epic was beyond the scope of this project, but nevertheless was recommended for further investigation to assist requisition workflows. Since this time, the Ministry of Health has moved to an on-line digital platform for submission of forms and 
faxing is no longer an option; this modernization of the process will improve the management of this workflow for the clinical assistants working with the GCs.
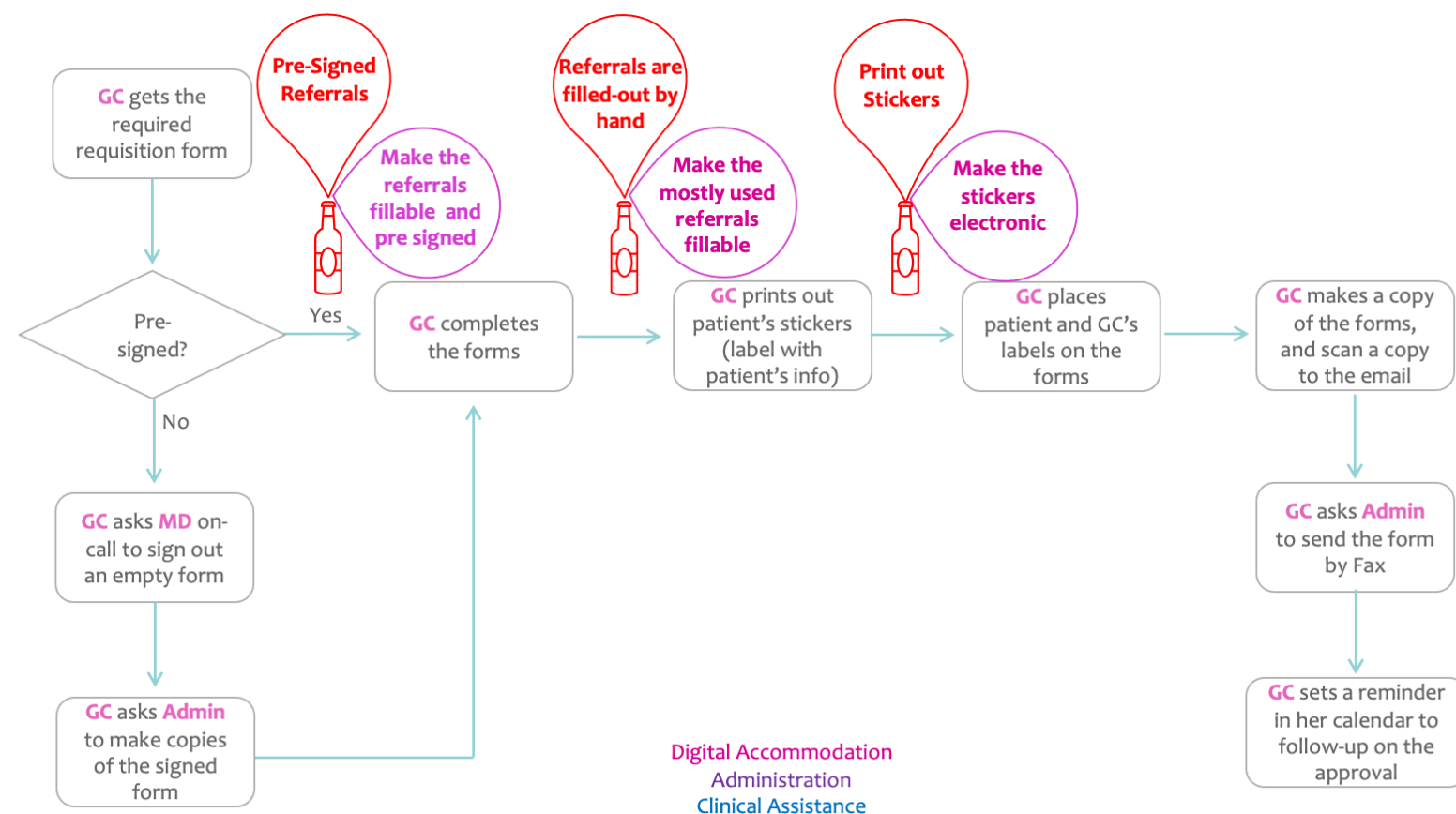

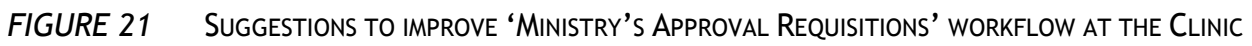

\subsubsection{Lab Orders Requisitions}

Analyze Phase: Similarly, GCs faced challenges/bottlenecks with completing lab order requisitions. First, GCs spend time to obtain/print out a hard copy of the requisition form. Then, they spend time on filling out the forms by hand and printing out the patient's labels. Upon completion, they make copies of the completed forms for their record. Also, GCs spend time on writing emails with instructions to their patients and to provide them with a copy of the requisition forms. From our observations, GCs used the 'Smart Phrases' tool in Epic to save any repeated phrases and instructions they use frequently to save them time from retyping the same information. However, for some GCs it took them time to recall the title of the saved phrases. Epic's 'Smart Phrases' tool is a feature of the interface designed to help users recall previously used phrases where they begin by typing a few characters to initiate the 
expansion of the larger, previously used phrase (Nitkin, 2019). However, recalling key characters/words to even recall the saved phrases seems to be a challenge and requires further investigation on possible usability issues with this specific feature in Epic. As a redundancy, the Prenatal Genetics Clinic also has a centralized file on a shared drive listing all the collective smart phrases, and the GCs also have their own phrases they use in drafting emails.

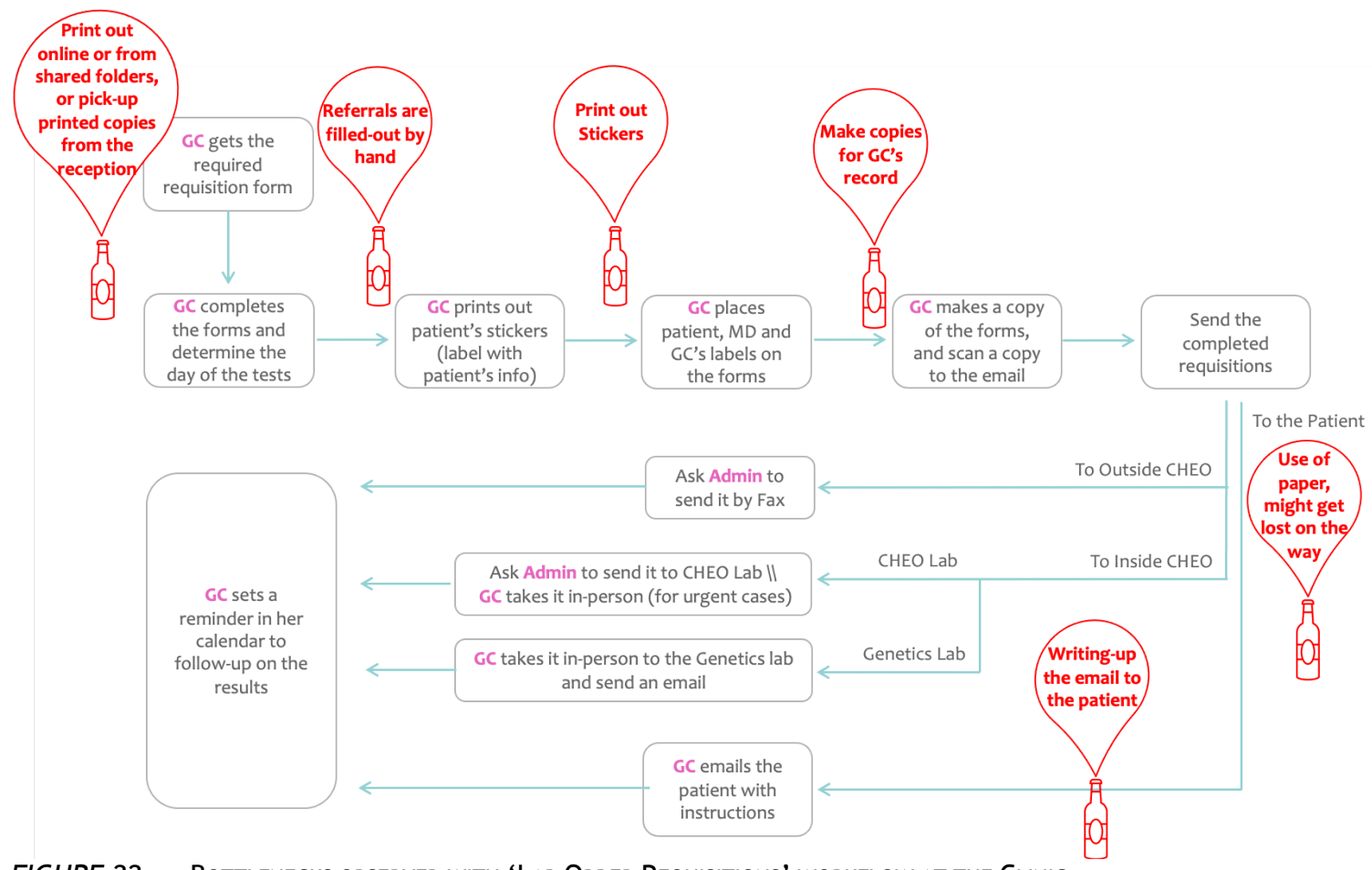

FIGURE 22 BotTleneCKS OBSERVED WITH 'LAB ORDER ReQUISITIONS’ WORKFLOW AT THE CLINIC

Improve Phase: There could be advantages in further investigating Epic tools for erequisitions to create fillable forms and adding electronic signatures. In addition, Epic tools may allow GCs to save copies of the generated requisitions to the patient file and send these requisitions to the labs whether inside or outside CHEO through Epic. However, requesting changes related to Epic software takes time to be studied and implemented. Therefore, I suggested an alternative, interim solution, namely, to make the frequently used forms PDF fillable, where GCs could fill them out electronically, and add e-signatures as well as e-labels. To overcome the last challenge with sending instruction emails to patients, I suggested that 
clinical assistants reduce GC's workload by preparing these emails and sending them to patients, where they can save typical or standardized instructions in Outlook (e.g., instructions could be saved as part of a unique Outlook signature).

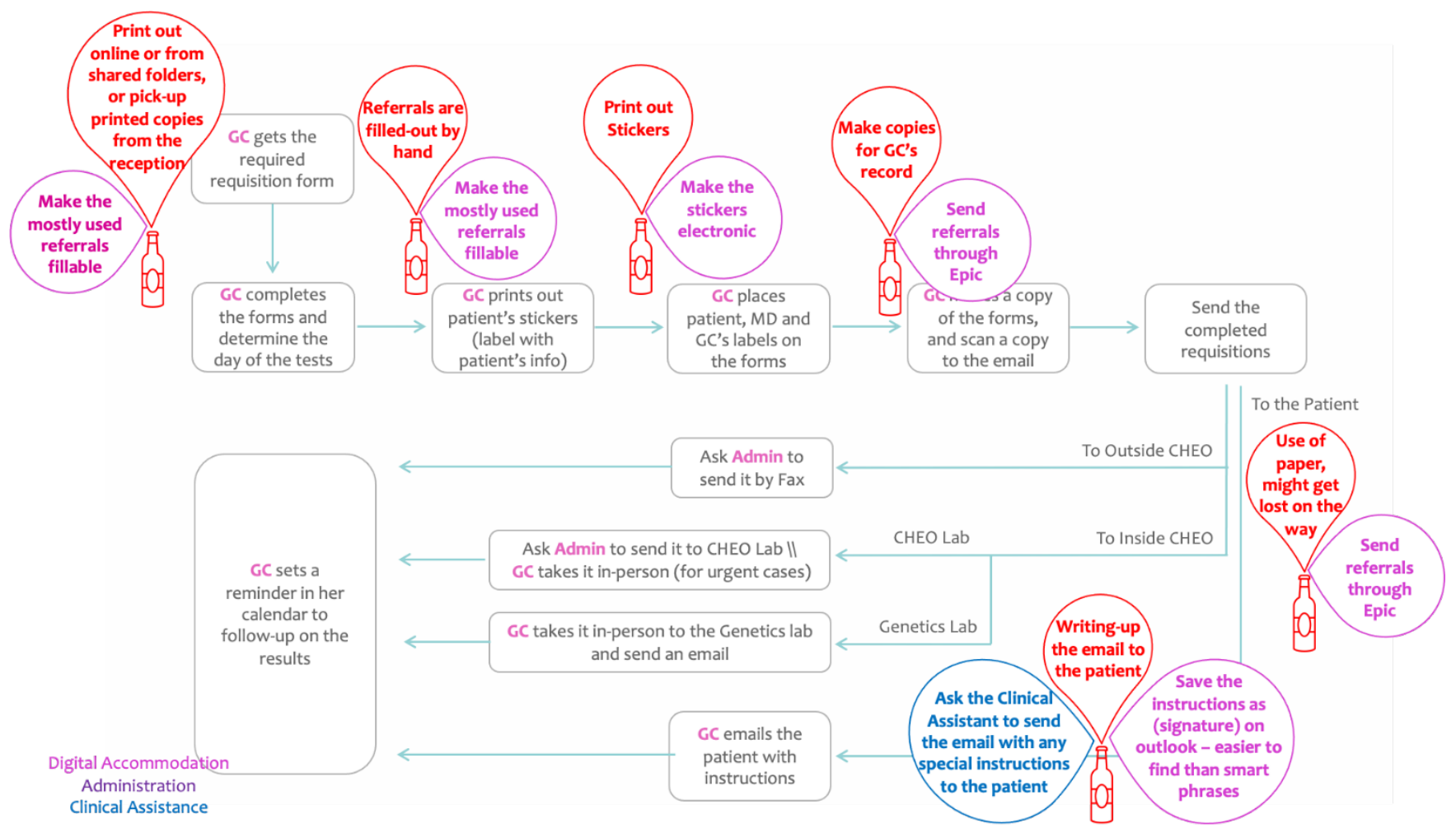

FIGURE 23 SUgGestions tO IMPROVE ‘LAB ORder ReQUISITIONS’ WORKFLOW AT THE CLINIC

QIT Feedback on Both Requisition Processes: Our discussions with the QIT on the suggested

solutions to improve requisitions workflow focused on the content design of the requisition forms, which differ from each other depending on the medical assessment required and the lab performing the testing. Also, they identified a need to centralize the hard copy of requisitions to be in a workstation made specifically for the Prenatal Genetics Clinic instead of being in different locations (currently they are in both the 'Reception' and 'Communication Room'). This suggests the need to look at the design of the 'Communication Room' (current workstation for all the Genetics Clinic GCs and MDs) and plan it to meet the GCs needs. The other strategy discussed, which has now occurred, was to convert an office into the prenatal 
on-call office and co-localize all necessary requisitions there. In addition, the Genetics Clinic has requested Epic technicians to activate e-requisitions, where GCs can fill out and submit requisitions directly through Epic. This way, GCs do not need to print out the patient's label, as Epic would include the information on the form. As for our suggestion of assigning the sending of requisitions and instruction emails to patients, the clinical assistant is now preparing these emails and sending them to patients with the new changes in the clinics' service model.

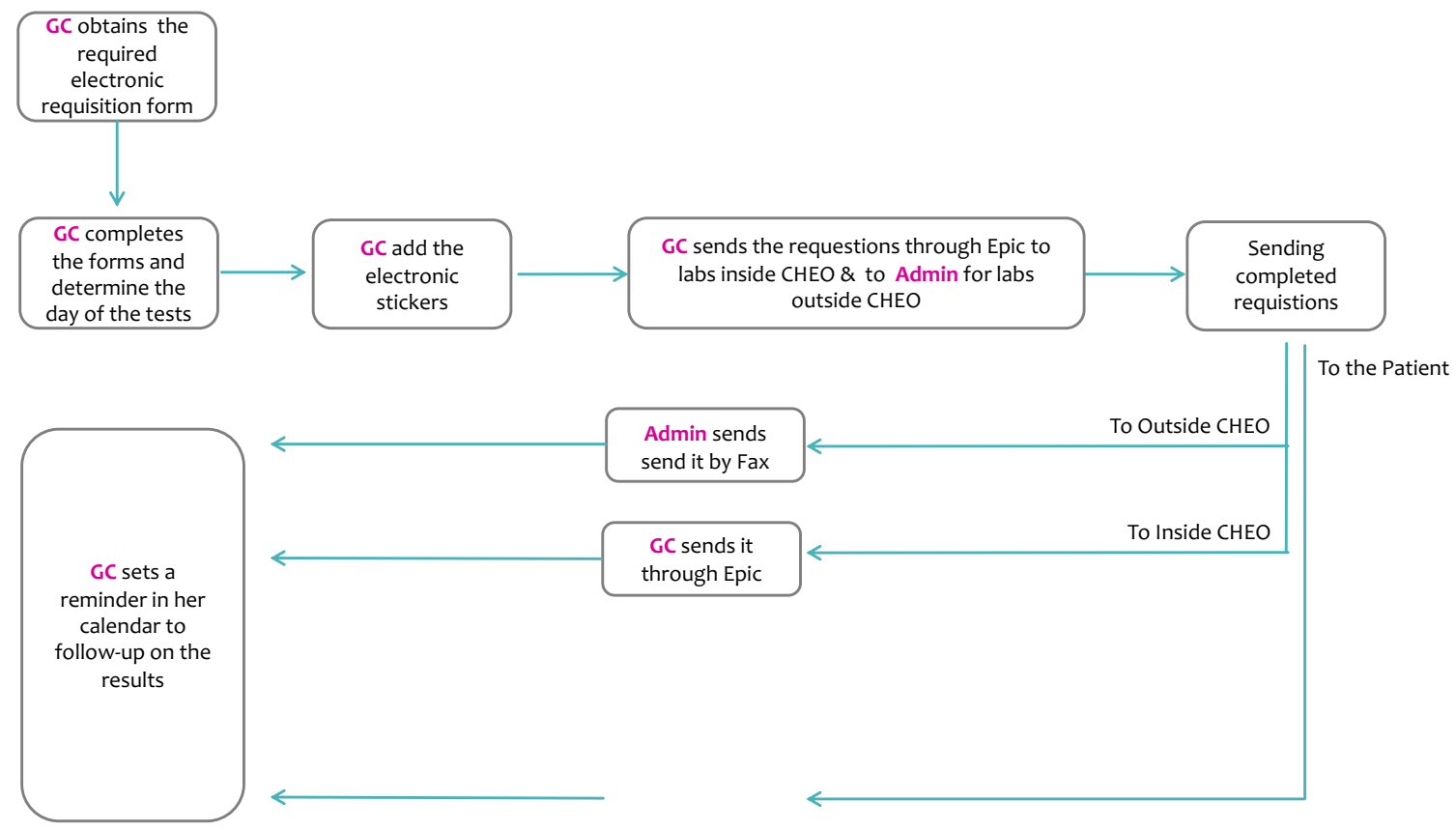

FIGURE 24 Suggested ‘Test Approvals/ Lab Orders’ workflow at the Clinic

The discussion with the QIT revealed other underlying issues GCs face when completing requisitions. A significant problem they are facing involves the fetal record and mother's record. On the system, the fetus has a different chart than the mother; however, the lab refers to the sample as a fetal sample instead of adding the sample to the mother's file. Unfortunately, the QIT stated that the Genetics Lab does not want to change the process. 


\subsubsection{Results Follow-Up Workflow}

\subsubsection{GCs Following Up on Results}

Analyze Phase: When GCs receive results from labs outside CHEO they transfer the faxed results into Epic. This process takes a long time and degrades the resolution of the results. Also, GCs spend time adding the follow-up appointment time and Zoom link to the MD oncall's calendar on Outlook and summarizing the case in the calendar invite.

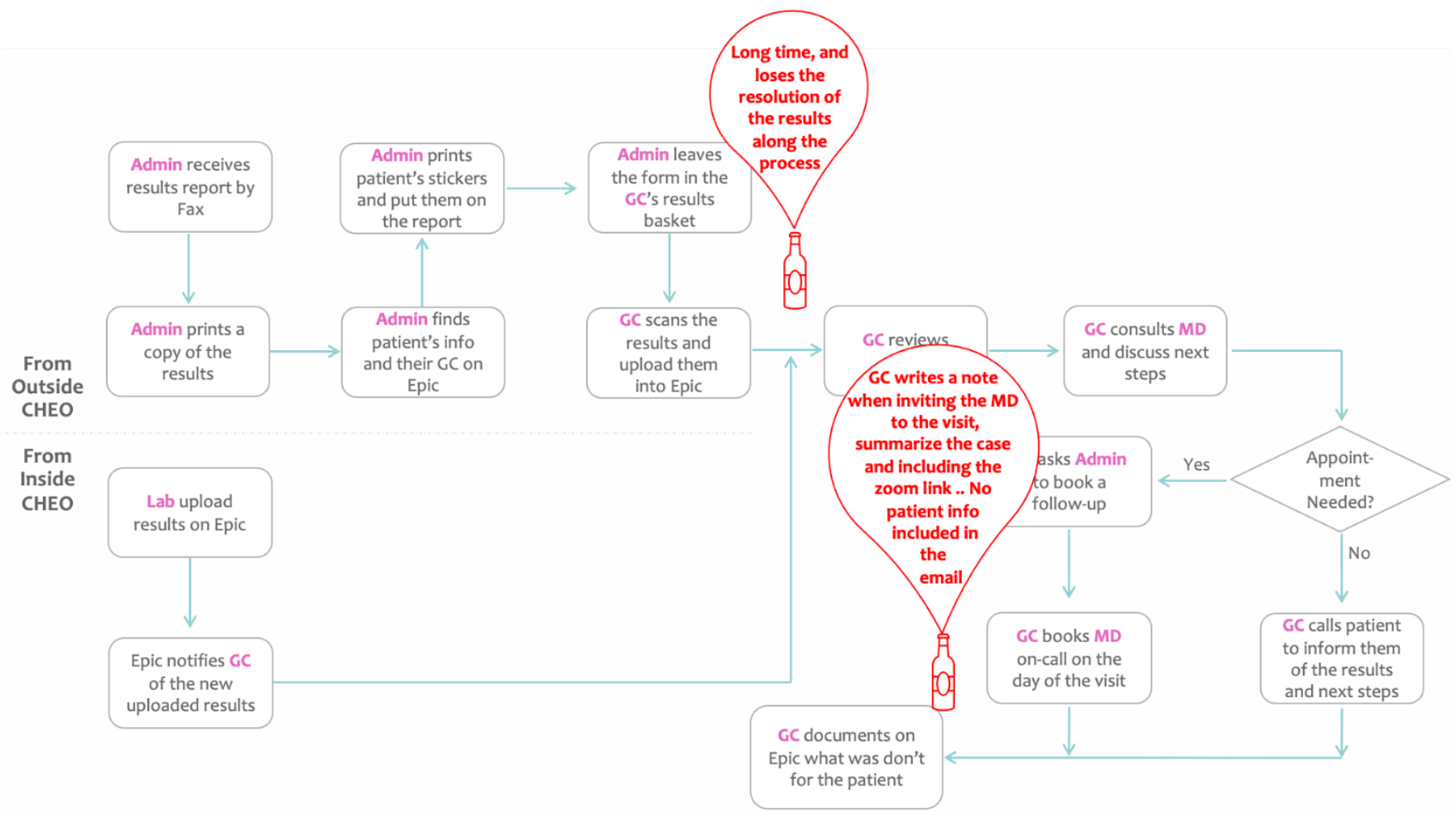

FIGURE 25 BOtTLENECKS OBSERVEd WITH ‘Results Follow-UP’ WORKFLOW AT THE CLINIC

Improve Phase: As discussed in the requisitions workflow, Epic tools may offer opportunities to reduce the steps and lags in these processes while improving the quality of information transfer. If CHEO staff are able to send requisitions to labs outside the hospital, then it may be able to receive results through the system. However, requesting changes to Epic software takes time to be implemented as already noted. Therefore, I suggested an alternative solution 
- to ask administrative assistants to upload a high-resolution file of the results into the patient's

file on Epic, which can be accessed by the GC who is working remotely.

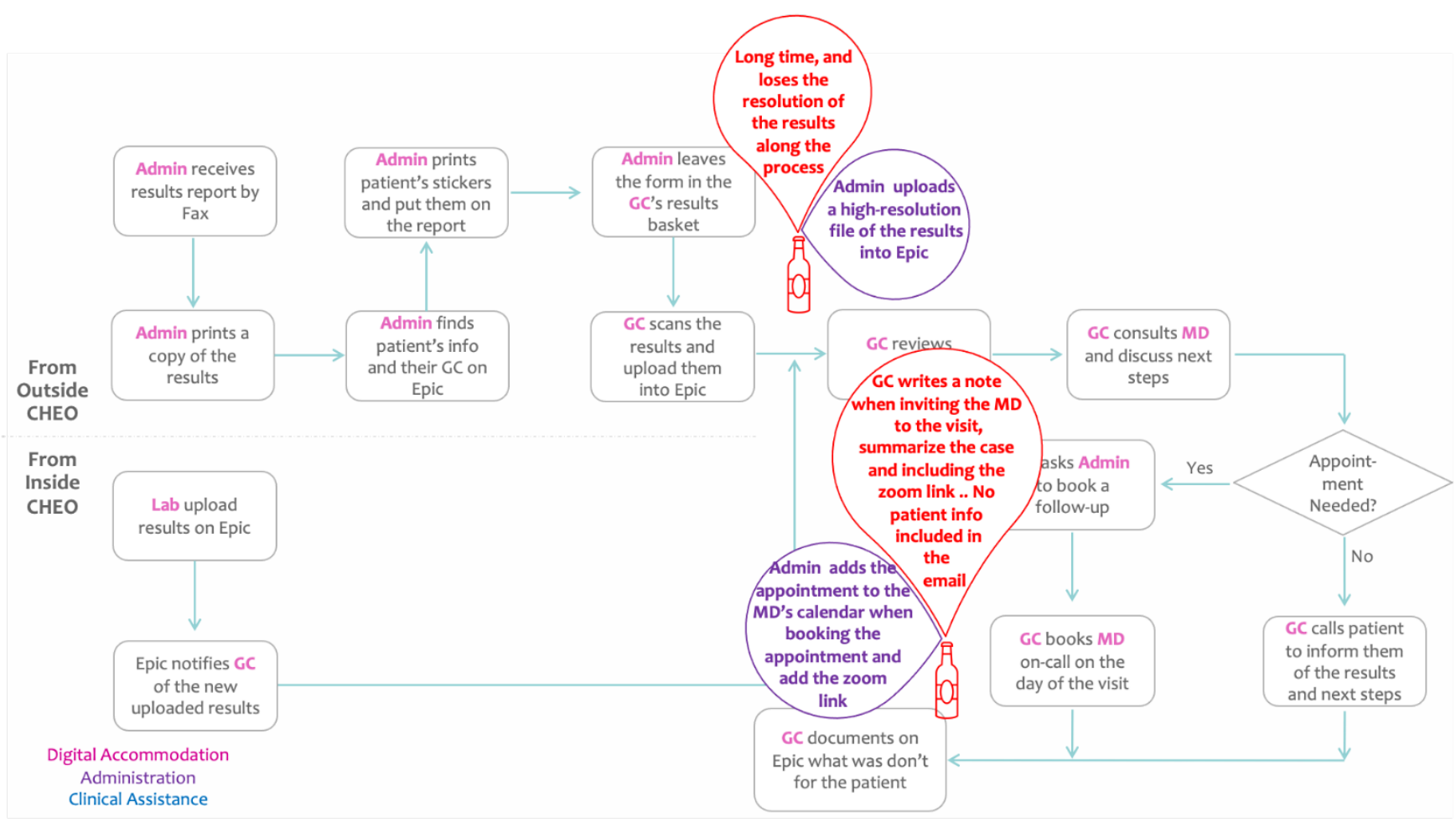

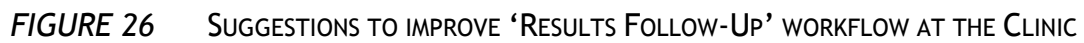

QIT Feedback: Historically, the prenatal results were considered urgent, and there were delays in scanning them into Epic, which explains the reason the clinic requested labs outside CHEO to fax the results directly to the Prenatal Genetics Clinic. Now all results are uploaded directly into Epic, which validates our suggestions to utilize the Epic 'Results' tool. With the new service model implemented in early 2021, the Genetics Lab has modified the process of external lab results to reduce duplication and confusion caused by the number of copies of results being received, to ensure that the lab can meet its accreditation requirements by matching a result to every order, and to minimize the number of documents they receive by fax. The new process includes GCs placing the lab order, the result being faxed to the 'Administrative Assistant's Office' and entered from this office into Epic. 


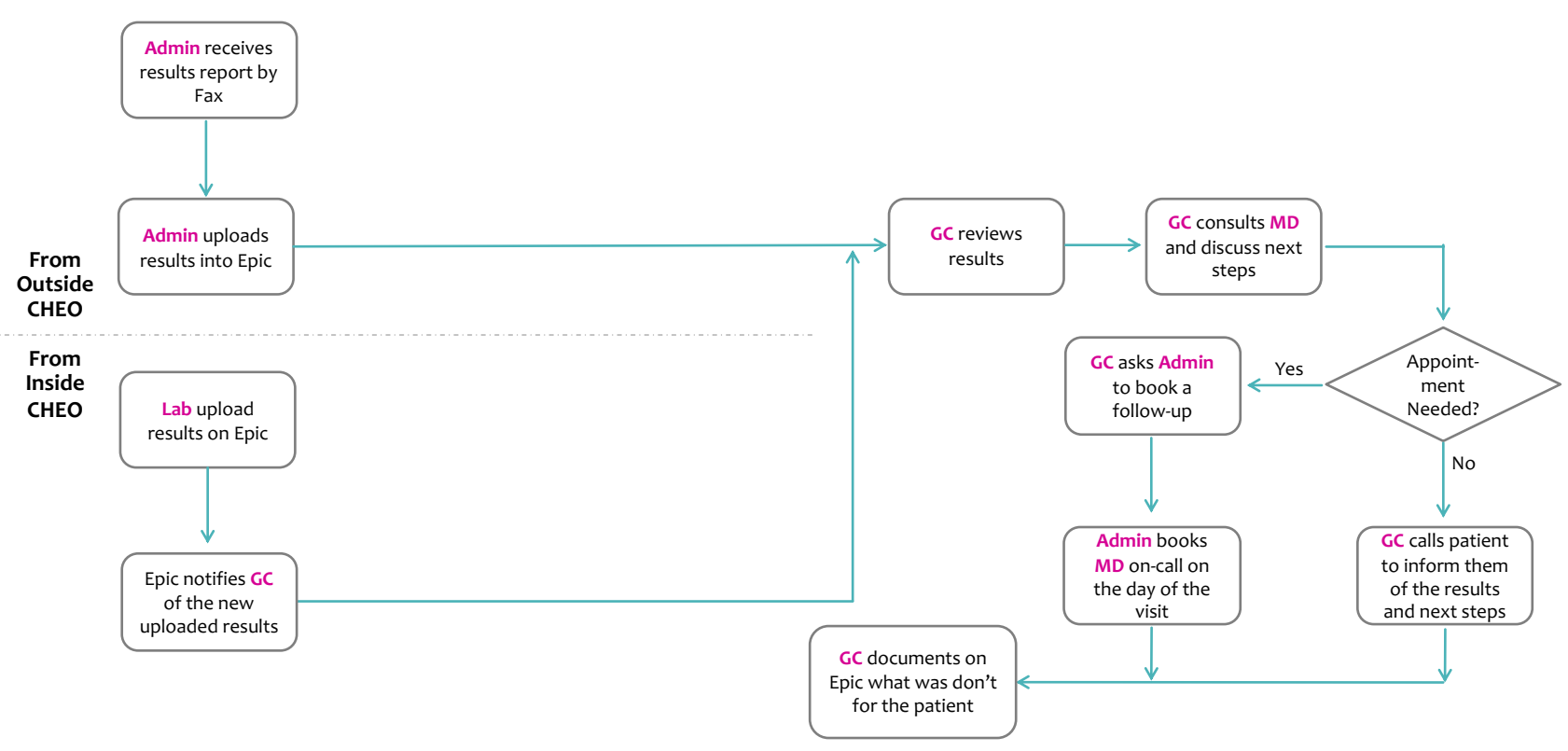

FIGURE 27 SUgGeSTED ‘Results Follow-Up’ WORKFLOW AT THE CLINIC

\subsubsection{Referring Doctor Following-Up on Results}

Analyze Phase: When an administrative assistant receives a request from the referring doctor requesting a copy of the results for their patient, they send the request to the GCs to complete the task. GCs print out the requested documents and then fax them to the doctor, where the resolution of the document is degraded in the process (see Appendix B.2 for workflow diagram).

Improve Phase: During the first week of observations, the GC on-call was responsible for completing this task. However, the clinical assistant took over this task in the second week of observations. To overcome these challenges, I suggested that the administrative assistant take over the task, since they have access to the patient's file and can reply back to the referring doctor, when the doctor's request is solely about missing results (see Appendix B.2 for workflow diagram).

QIT Feedback: The QIT clarified that the task of providing results to referring physicians requires a medical staff member to look into the requests and make a clinical decision on what 
to send to the doctor. Therefore, an administrative assistant could not support this task. In addition, the view of Epic to the stakeholders at the clinic is different, depending on the permission and functionalities given to them, so certain medical staff may not be authorized to do this task. Going forward, the clinical assistant will work with the GC to send the GCapproved documents to the requesting physician (see Appendix B.2 for workflow diagram).

\subsubsection{Patient Follow-Up Visit Workflow}

Analyze Phase: I only observed one follow-up session during the observation sessions. The challenge I observed is that the MD took a long time to join the Zoom call, since they had booked patient consultations close to one another, rather than allowing time between consultations (see Appendix B.2 for workflow diagram).

Improve Phase: To overcome the challenge noted above, I suggested that the design of the Prenatal Clinic schedule ensure that MDs have enough time between the patients to transition to the consult. (see Appendix B.2 for workflow diagram).

QIT Feedback: The MD on the QIT confirmed the struggle I observed with MDs attending patient consultations as their calendars are closely booked with other obligations. The suggestion to dedicate the on-call MD time to the Prenatal Clinic was implemented and has largely alleviated this issue (see Appendix B.2 for workflow diagram).

\subsubsection{Writing Reports Workflow}

Analyze Phase: The challenge with writing reports on Epic is that the GCs can't upload a file to the report, and their way to resolve this issue is to take a screenshot of the results, a process which may degrade the resolution of the results. 


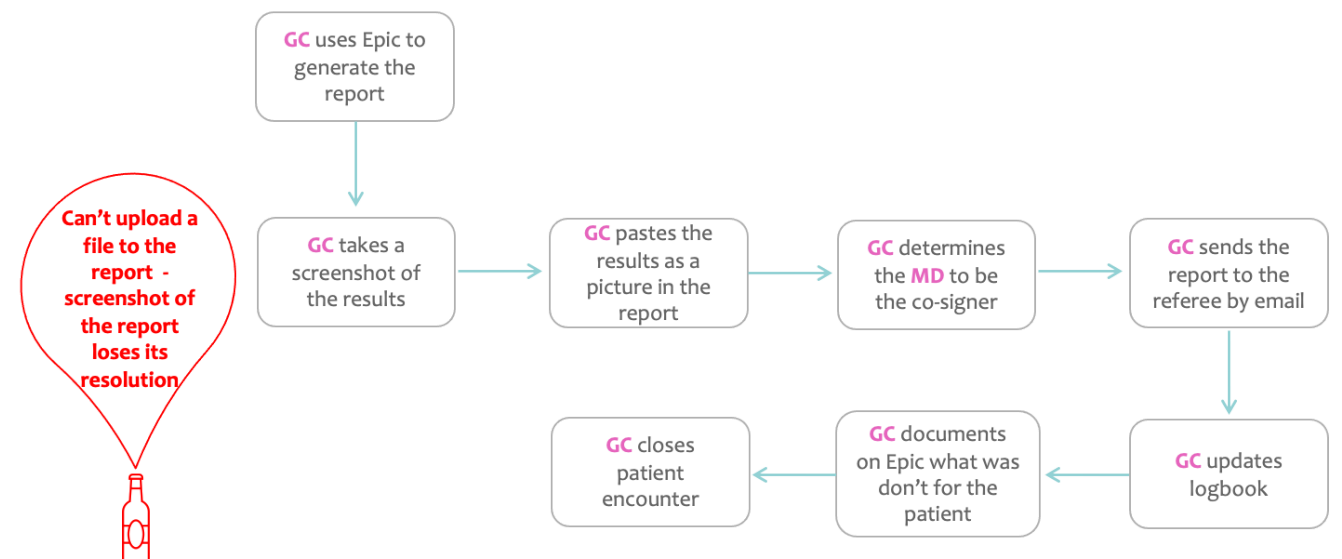

FIGURE 28 BOtTLENECKS OBSERVED WITH 'WRITING REPORTS’ WORKFLOW AT THE CLINIC

Improve Phase: As discussed in previous sections, there is a need to further investigate the capabilities of Epic tools to upload/attach documents to the final report.

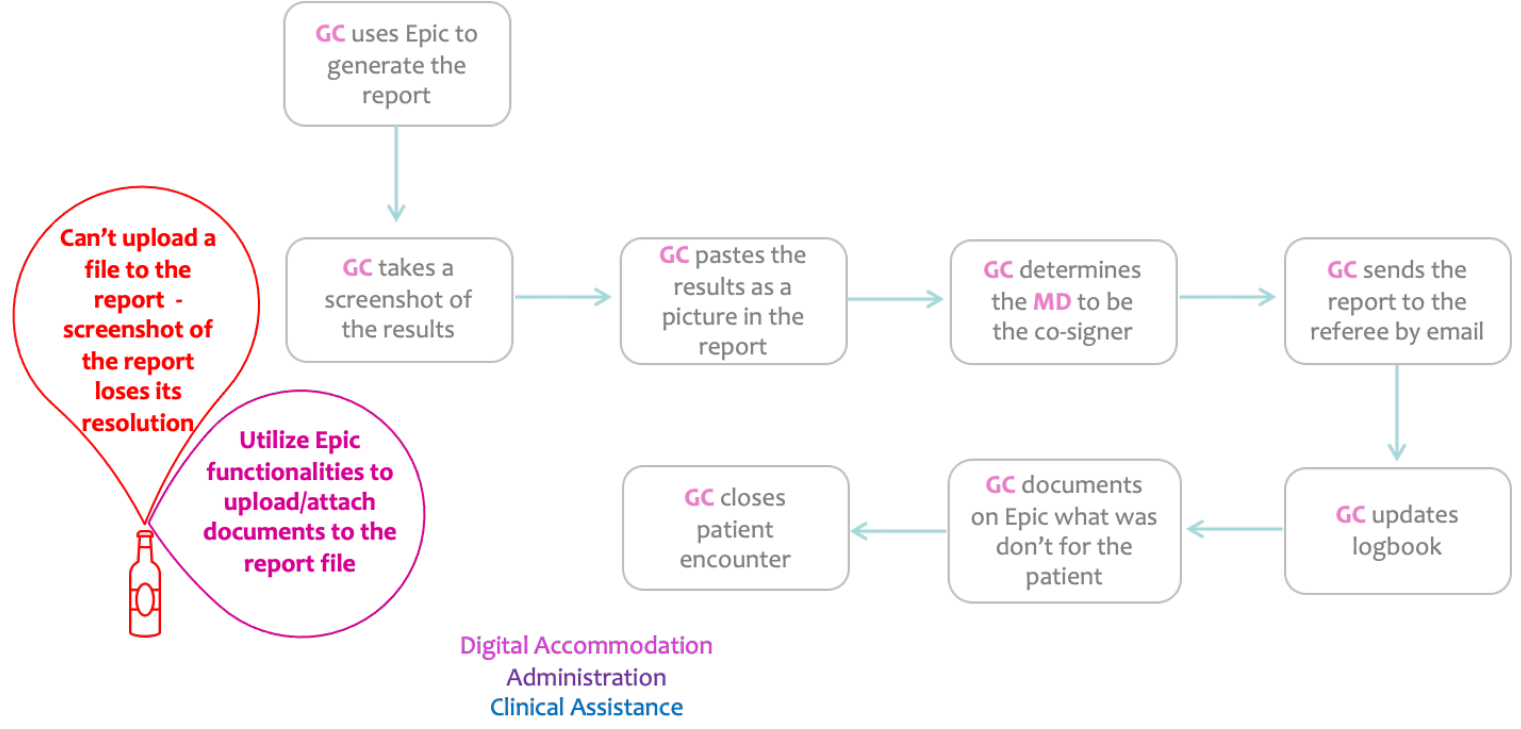

FigURE 29 SUggestions to improve 'Writing Reports' workflow at the Clinic

QIT Feedback: The QIT corrected the workflow generated from our results. After GCs complete the form and determine the co-signing $\mathrm{MD}$, the system routes the report to the MD to sign the report. The report gets faxed to the referring doctor through Epic 'Auto-Fax', and the patient can view it instantly through their personal health record on 'MyChart'. 
The QIT indicated that Epic does not allow users to download a document from the patient's chart and attach it to the report feature. The copy-and-paste option that GCs are currently using is a workaround to overcome this challenge and complete the report task. They identified a risk associated with this work-around, namely a lapse in copying the required results to the final report. Also, they noted that long reports may crash the system. Further work with Epic tools may improve this workflow.

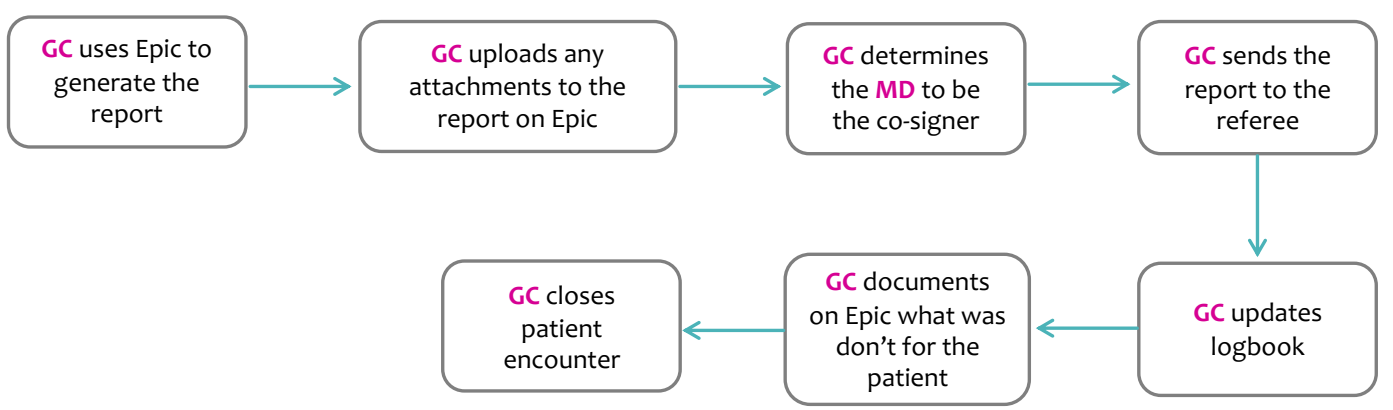

FIGURE 30 SUgGeSTed ‘WRIting RePorts’ WORKFLOW AT THE CLINIC

\subsection{Summary of Results}

The archival analysis of previous studies from the clinic estimated time required for direct and indirect patient care prior to virtual care. However, there was a need for more robust data on the time spent on different tasks, particularly in the context of virtual care. Prenatal GCs shared their thoughts, concerns, and ideas regarding virtual care during a brainstorming session. They felt that time spent on tasks of the virtual care model was not reflective of the hours that had been previously documented. There was little known about the indirect time that GCs were spending on virtual care, such as preparing for the visit, sending requisitions, and writing reports. The results of the diary study revealed that prenatal GCs spend $55.85 \%$ of their clinic time on patient care, and $44.15 \%$ of their time on non-patient care, mainly on training activities. The main bottleneck identified for GCs working remotely was completing 
paper-based tasks such as requisitions for procedures and tests performed at external sites, so these could proceed without delay (as they are of prime importance in the prenatal setting). The results and recommendations for improvements were categorized into a framework of three groups: digital accommodation, administration support, and clinical assistance. In the first group digital accommodations, I suggested exploring and utilizing the tools provided by Epic to complete pre- and post-consultation activities. For example, there may be potential offered by e-referrals, e-requisitions, and receiving results through the system. I observed interface design issues that caused the prenatal GCs to have difficulties using the system, and I suggest engaging with the CHEO Epic team to address some of these challenges. The second set of recommendations revolve around potential design opportunities in administrative support and clinical assistance, where re-defining the roles of patient service clerks and administrative assistants, and bringing in a new role, namely that of the clinical assistant (pre- and postconsultation non-medical activities), in the patient delivery model could reduce the workload of GCs. This includes activities such as scheduling Prenatal Genetics Clinics with the MD oncall to ensure availability for review of cases and for new and follow-up patient consultations. Recommendations from the administrative and clinical assistance groups have already been implemented in the form of a new scheduling strategy and a new support staff role focused on clinical assistance. The remaining recommendations will support the on-going development of a strategic plan for improving work efficiency across the patient service unit of the Department of Genetics. 


\section{Chapter 6: Discussion}

The demand for Prenatal Genetics clinical care is rising which has increased pressure for GCs to become more efficient (Attard, Carmany, \& Trepanier, 2019). Genetic Counsellors can improve access to their services by reducing the time spent on the tasks performed before and after a genetic counselling encounter, thereby increasing the number of patients they see (Attard, Carmany, \& Trepanier, 2019). Genetic counselling traditionally has been a timeintensive process while the need for genetic counselling services has grown recently (Stoll, Kubendran \& Cohen, 2018). Traditional genetic counselling, which involves an in-person, one-on-one pre- and post-test model of counselling may not be the most efficient method to scale up services to reach an expanding patient population (Stoll, Kubendran \& Cohen, 2018). Therefore, new service delivery models to increase efficiency and access to genetic counselling services are being implemented in a growing number of clinics (Stoll, Kubendran \& Cohen, 2018).

Bottlenecks in patient care within genetics clinics are a growing concern in the healthcare field. Bottlenecks are defined as any step within a patient pathway that slows the overall rate of a patient's progress, normally through a reduced capacity of availability (Lohmann \& Klein, 2014). Balancing patient quality of care and efficiency is a rising issue in healthcare, where clinic workflow continues to be problematic for a variety of reasons, including factors such as limited or inefficient space design or unsustainable workload conditions - factors that may negatively impact patient wait times and lead to healthcare worker burnout (Flanary et al., 2020).

The service delivery model of the Prenatal Genetics Clinic at the time of our study lacked a formal structure to ensure that the necessary providers were available during prenatal patient consultations and related pre- and post-consultation activities. This led to delays in 
dealing with urgent patient matters or inefficiencies in providing care. Examples of time that could potentially be recouped to support the clinic include GCs spending time to find MDs to review cases, meet the patient, or ask triage questions; and MDs being pulled in unmanageable directions due to unpredictable schedule demands throughout the week.

To support the on-going restructuring efforts of the clinic, our analysis included defining the activities performed at the Prenatal Genetics Clinic through archival analysis and stakeholder mapping, timing virtual care activities performed from home by GCs and observing on-site activities performed by the GC on call. I divided on-site tasks into subtasks to identify the artefacts, tools, techniques, and spaces involved in performing these activities. Using the Lean Improvement process has increased our understanding of the subtasks and bottlenecks in GC's workflow to better inform strategies for improving workflows. In addition, I was able to identify tasks that non-medical staff of the Prenatal Genetics Clinic can perhaps perform to support GCs.

Studies reviewed of genetics services show that providers spend a significant proportion of their work on tasks before and after the patient's appointment, with a large variation evident across the studies - see Table 1 on page 10 (Bernhard et al., 1987; Bernhardt \& Pyerit, 1989; Pletcher et al., 2002; Cooksey et al., 2006; \& McPherson et al., 2008). The results of this study cannot be compared to the results in Table 1 because I observed fragments of the work done for different patients whether routine or complex, not a complete set of activities done for one patient. The studies reviewed highlight the importance of studying nonpatient-facing-related activities as well as the challenges facing genetics service providers to reduce time on patient-related activities before and after patient encounters. Although the studies in this area of health service delivery are limited, there are no published research describing a viable exemplar service delivery model for genetics clinics. The results of the diary 
study and observation sessions provided us with a baseline to better understand the work being performed during pandemic conditions and through first ventures into virtual care. This study helped us highlight the potential challenges prenatal GCs face to reduce patient wait times in light of 'work as done in reality' under these conditions versus 'work as imagined'.

As per our discussion with the QIT, the Ontario Ministry of Health and Long-Term Care prescribes that $70 \%$ of clinical time be spent on patient related activities which includes direct and indirect care, and our study revealed that GCs spend $55.85 \%$ of their time (6 hours and 38.1 minutes average time per task), less than this recommendation. On the other hand, the data showed that prenatal GCs spent $44.15 \%$ of their time (5 hours and 14.66 minutes) on non-patient related activities, mainly on training activities, which accounted for $57.61 \%$ of non-patient related activity time, and $25 \%$ of the total activity time at the clinic.

This approach should be applied within the context of other prenatal genetics clinics in Ontario to understand whether the $70 \%$ patient-care time is indeed attainable within the context of a tertiary care centre, where professional development is critical for sustaining knowledge and best practice in a rapidly changing field. Couple this with the high demand for genetics services, and it is reasonable to anticipate the need to train staff to manage their service to patients well and responsibly. In addition to learning new hospital-wide technologies and EMR systems, genetic staff must also learn the new tools and testing approaches developed in the genomics field. The diary study showed that Prenatal GCs spend around 181.3 minutes on training activities that includes supervising trainees and training new staff. Our data raises the question of how the need for training in tertiary care centres is reflected in the policies from the Ministry on Health, training which ultimately supports patient care. This study also points to the need to study non-patient care activities in more detail to understand how and why they are time intensive to support improvement. 


\subsection{Implementation and Impact of Virtualizing Genetics Service During COVID-19}

Before the COVID-19 pandemic, all staff at the Prenatal Genetics Clinic at CHEO worked on-site full-time providing an in-person service delivery model. The pandemic led to the rapid adoption of virtual care in healthcare delivery to maintain physical distancing measures and keep healthcare providers and patients safe. Recent studies have also examined the impact of virtualizing the service model of genetics services during pandemic conditions. A study from Columbia University Irving Medical Center (CUIMC) examined the impact of virtual care on staff and patient satisfaction. Like CHEO, the CUIMC conducted all outpatient appointments via video visits through their electronic health record (EHR) using Zoom since it allows for team-based care and multiple video conferencing participants, such as GCs, MDs, and other healthcare providers (Pereira \& Chung, 2020). The results of the study showed the advantage of using video consultation in paediatric genetics care to observe patients in naturalistic settings, and that patients were able to invite extended family members to the consultation to translate, and provide accurate family history (Pereira \& Chung, 2020). However, the study did not provide information on the pre- and post-clinical encounter workflows and how these were impacted by the pandemic.

Another study from the Familial Cancer Clinic at the University Health Network in Toronto examined the impact of virtualising genetics services. The study showed that the rapid virtualisation of genetic services allowed the cancer genetics clinic to navigate the COVID-19 pandemic without compromising clinical volumes or access to genetic testing (Norman et al., 2020). However, the results of the study revealed a decrease in referral volumes and an uptake of genetic testing, which may be attributable to pandemic-related clinical restrictions and 
decreased demand for tertiary care services (Norman et al., 2020). The study suggests that there were longer wait time for results as there was significant longer time for patients to have their blood drawn for testing (Norman et al., 2020). This was not observed at the Prenatal Genetics Clinic at CHEO and was not a concern that was discussed by the QIT. This may be because the Prenatal Genetics Clinic provides blood lab services at $\mathrm{CHEO}$, not requiring prenatal patients to conduct their tests at external laboratories, or the urgency of the clinical situation in the prenatal setting.

\subsection{Thoughts on the Lean Improvement Process}

In the literature I reviewed on the implementation of Lean, one of the main barriers that was discussed was stakeholders' resistance to change (Kaltenbrunne et al., 2019). I did not experience this issue with the QIT nor frontline stakeholders, possibly because: I did not rely solely on applying Lean methods, but rather, created a tailored strategy with stakeholders to suit the nature of pandemic conditions drawing on fundamental and appropriate research methods from human factors design with an emphasis on participatory research practice; I involved the Genetics Clinic leaders (the QIT) and front-line stakeholders in dialogue and in the process of decision-making/planning/designing the study and changes or refinements to the suggested tools (e.g., the diary) and solutions (e.g., the work diagram proposals). At front of mind throughout the study was that the QIT and front-line stakeholders know best their culture, conditions, and the goals they are trying to achieve to support continuous improvement at the Genetics Clinic. The role of the QIT in this study helped in encouraging the different stakeholders at the Genetics Clinic to take part in the study. However, the solutions suggested in the study through Lean are specific to segments of the workflow at the Prenatal Genetics Clinic and associations with space design. This may be a limitation of Lean 
as it does not propose to study larger systems and their potential external impact, but rather, work arrangements or parts of the system. I saw, for example, the need to study Epic in more depth to support a more comprehensive understanding of the potential influence of the larger system and opportunity for more systemic improvements.

\subsection{Limitations and Challenges}

The study took place at a single clinic; therefore, the results may not be generalized to other genetics clinics. With the current pandemic, I faced a challenge observing typical clinical flows due to physical distancing restrictions and the limited amount of work that is currently taking place at the clinic. In addition, improvements suggested through this analysis were constrained to not increase the number of providers and support staff and avoid reconfiguration of the space. However, the study conditions offered an unprecedented opportunity given the rapid uptake of virtual care to study virtual care in its infancy. This study provided the systematic collection of detailed information on how a team adapted to novel, and presumably stressful sociotechnical conditions to inform future improvement projects. Many of the challenges facing the Prenatal Genetics Clinic are technical issues and related to utilizing the resources available in Epic. This study lacks the knowledge of Epic's role and the tools and services that may be available to support a more comprehensive strategic plan for improvement.

\subsection{Future Work \& Study}

It is necessary to keep evaluating the lasting effect of the pandemic on the models of genetics services at the Prenatal Genetics Clinic at $\mathrm{CHEO}$ and monitoring the modified process to study the changes that have been implemented for improving patient wait times. 
This includes training all staff on the new processes to ensure no staff revert back to the previous methods. As I have already noted, I also suggest the need to further explore Epic and the tools provided to improve efficiency in referrals, requisitions and writing reports.

Our results suggest the need to further explore the non-patient related activities, in general, that are performed at the Prenatal Genetics Clinic which takes up to $44.15 \%$ of GCs' time, especially training activities which take 181.3 minutes (or $57.61 \%$ ) as an average time per task performed by GCs. Similar studies should also be conducted at other genetics clinics in Ontario and at the policy level to understand whether the provincial recommendations for time spent on patient care align with how these clinics work in reality. 


\section{Chapter 7: Conclusion}

This study examined the efficiency of virtual care in the Prenatal Genetics Clinic 6 months post implementation and to develop recommendations to improve clinical workflows for Genetic Counsellors (GCs) using human factors design methods. Our findings over 2 weeks of observations show that prenatal GCs spend around $55.85 \%$ of their time on direct and indirect patient care, which is less than the guidelines provided by the Ontario Ministry of Health and Long-Term Care which prescribes that $70 \%$ of time be spent on patient related activities. With respect to the time GCs spend on patient related activities, GCs spend an average of $21.12 \%$ of this time on direct patient related activities (i.e., patient clinical encounter), an average of $15.85 \%$ of this time on indirect patient-related activities before patient consultation (i.e., case preparation and review, and triage), and 63.03\% of this time on indirect patient-related activities after a patient consultation (i.e., on-call activities, documentation on Epic, requisitions, and results \& follow-up).

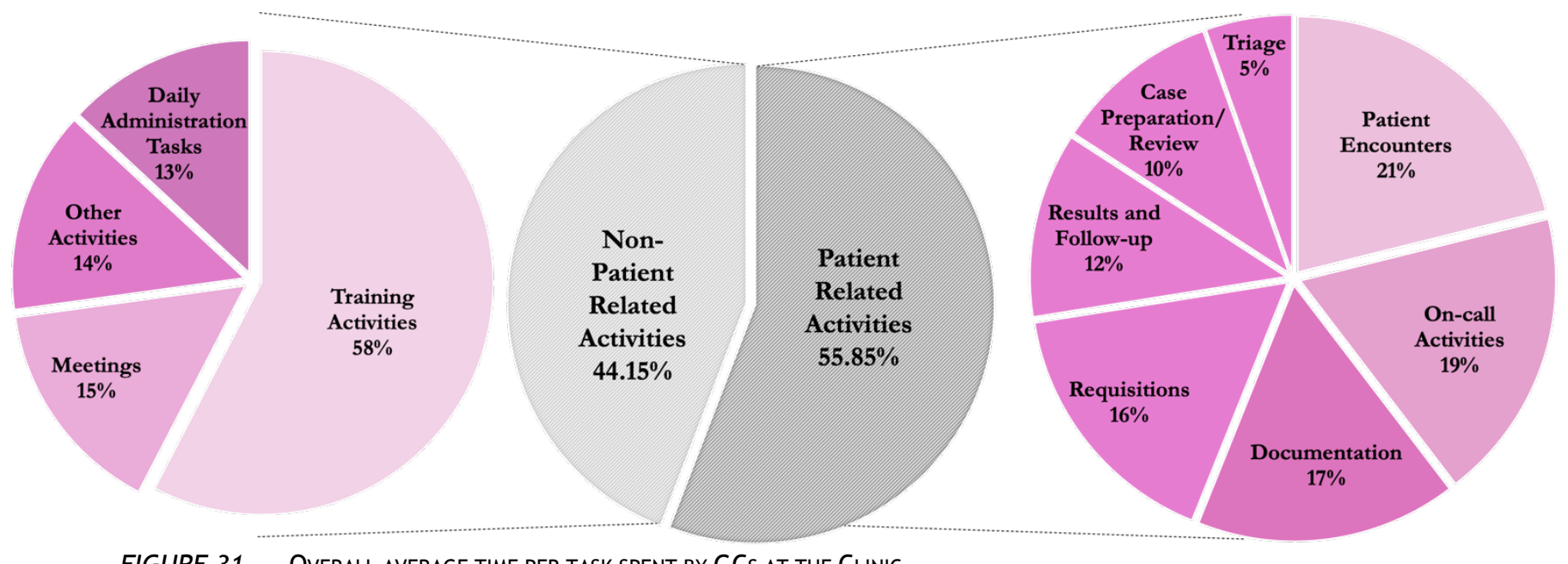

FIGURE 31 Overall aVerage tIME PeR tASK SPENT by GCS AT the CLINIC

Improving the availability and scheduling of Medical Doctors (MDs) and supporting patient-related activities with the addition of a GC clinical assistant are both strategies the Quality Improvement Team (QIT) have implemented and are currently being assessed. On 
the other hand, the data reported showed that prenatal GCs spent $44.15 \%$ of their time over the course of 5 working days ( 1 work week) on non-patient related activities, mainly on training activities $(57.61 \%)$ (i.e., supervising trainees, training new staff, teaching, and education rounds).

Future studies focused on the non-patient related activities performed by prenatal GCs will be necessary to strategically facilitate a viable redistribution of their time to support patient flow through and wait times. This project provides a Lean Improvement toolkit to be used by any other division within the Genetics Clinic at CHEO. Some of these strategies were currently implemented at the Prenatal Genetics Clinic.

Despite the growth of human factors in healthcare design and to the best of my knowledge, I believe this may be the first human factor/ ergonomics study focused specifically on the design of genetics services. This study provides a documentation of the time on tasks at the Prenatal Genetics Clinic, which the Clinic can compare with the Ministry's recommendations. In addition, this study provides rigorous documentation of the small steps/ subtasks to process patients, which are visualized through 22 workflows along with recommendations for improvements. Some of these strategies are currently being implemented at the Prenatal Genetics Clinic. Finally, this project provides a Lean Improvement toolkit to be used by any other division within the Genetics Clinic at CHEO to assist the clinic improve the design of their services. 


\section{References}

Atasoy, H., Greenwood, B.N., \& Mccullough, J.S. (2019). The Digitization of Patient Care: A Review of the Effects of Electronic Health Records on Health Care Quality and Utilization. Annual Review of Public Health, 40(1), 487-500. doi:10.1146/annurev-publhealth-040218-044206

Attard, C.A., Carmany, E.P., \& Trepanier, A.M. (2018). Genetic counselor workflow study: The times are they a-changin'? Journal of Genetic Counseling, 28(1), 130-140. doi:10.1002/jgc4.1041

Bernhardt, B. A., Weiner, J., Foster, E. C., Tumpson, J. E., \& Pyeritz, R. E. (1987). The Economics of Clinical Genetics Services. II. A Time Analysis of a Medicial Gentics. American Journal of Human Genetics, 41(4), 559-565.

Bernhardt, B., \& Pyeritz, R. (1989). The economics of clinical genetics services. III: Cognitive genetics services are not self-supporting. American Journal of Human Genetics, 44(2), 288-293.

Boonstra, A., Versluis, A., \& Vos, J.F. (2014). Implementing electronic health records in hospitals: a systematic literature review. BMC Health Services Research, 14(1), 370-370. doi:10.1186/1472-696314-370

Chartered Institute of Ergonomics and Human Factors. (2015). Retrieved in February 2020 from https://www.ergonomics.org.uk/Public/Resources/Sectors/Healthcare.aspx

Cooksey, J.A., Forte, G., Flanagan, P.A., Benkendorf, J., \& Blitzer, M.G. (2006). The medical genetics workforce: an analysis of clinical geneticist subgroups. Genetics in Medicine, 8(10), 603-614. doi:10.1097/01.gim.0000242307.83900.77

Flanary, J.T., Rocco, N.R., Dougherty, T., \& Christman, M.S. (2020). Use of Lean Six Sigma to Improve Access to Care in a Surgical Subspecialty Clinic. Military Medicine, 185(5-6), e887-e893. doi:10.1093/milmed/usz426

Gijo, E.V, \& Antony, J. (2013). Reducing Patient Waiting Time in Outpatient Department Using Lean Six Sigma Methodology. Quality and Reliability Engineering International, 30(8), 1481-1491. doi:10.1002/qre.1552

Hung, D.Y., Harrison, M.I., Truong, Q., \& Du, X. (2018). Experiences of primary care physicians and staff following lean workflow redesign. BMC Health Services Research, 18(1), 274-274. doi:10.1186/s12913-018-3062-5

International Ergonomics Association. The Discipline of Ergonomics. Retrieved in February 2020 from http://www.iea.cc/

Institute of Medicine Report (IOM) (2018). The future of nursing: leading change, advancing health. Retrieved from: https://www.policymed.com/2011/02/institute-of-medicine-report-the-futureof-nursing-leading-change-advancing-health.html

ISO 9241-210: Ergonomics of human-system interaction - Part 210: Human-centred design for interactive systems. Geneva. Retrieved in April 2021 from https://www.iso.org/obp/ui/\#iso:std:iso:9241:-210:ed-1:v1:en

Kaltenbrunner, M., Bengtsson, L., Mathiassen, S.E., Högberg, H., \& Engström, M. (2019). Staff perception of Lean, care-giving, thriving and exhaustion: a longitudinal study in primary care. $B M C$ Health Services Research, 19(1), 652-652. doi:10.1186/s12913-019-4502-6

Kumar, V. (2013). 101 design methods: a structured approach for driving innovation in your organization. Hoboken, NJ: John Wiley \& Sons.

Laux, C., Antony, J., Mosher, G.A., Aduraibi, M., Nour, R., \& Salentijn, W. (2021). Utilising Lean Six Sigma to mitigate and manage COVID-19. Retrieved from: https://www.thefuturefactory.com/blog/52

Lin, S.Y., Gavney, D., Ishman, S.L., \& Cady-Reh, J. (2013). Use of lean sigma principles in a tertiary care otolaryngology clinic to improve efficiency. The Laryngoscope, 123(11), 2643-2648. doi:10.1002/lary.24110

Maguire, M. (2013). Using Human Factors Standards to Support User Experience and Agile Design. Universal Access in Human-Computer Interaction. Design Methods, Tools, and Interaction Techniques for eInclusion, held as part of HCI International 2013, Las Vegas, July 21-26, 201: Proceedings. Berlin: Springer. doi:10.1007/978-3-642-39188-0_20 
Mazzocato, P., Savage, C., Brommels, M., Aronsson, H., \& Thor, J. (2010). Lean thinking in healthcare: A realist review of the literature. BMJ Quality \& Safety, 19(5), 376-382. doi:10.1136/qshc.2009.037986

McIntyre, D., \& Chow, C.K. (2020). Waiting Time as an Indicator for Health Services Under Strain: A Narrative Review. INQUIRY: The Journal of Health Care Organization, Provision, and Financing, 57, 004695802091030. doi:10.1177/0046958020910305

McPherson, E., Zaleski, C., Benishek, K., Mccarty, C., Giampietro, P.F., Reynolds, K., \& Rasmussen, K. (2008). Clinical genetics provider real-time workflow study. Genetics in Medicine, 10(12), 699-706. doi:10.1097/GIM.0b013e318182206f

National Research Council. (2011). Chapter 3: What is Human Factors. In Health Care Comes Home: The Human Factors (pp. 61-74). Washington, D.C.: The National Academies Press.

National Society of Genetics Counselors. Retrieved in July 2020 from https://www.nsgc.org/history

Norman, M.L., Malcolmson, J., Armel, S.R., Gillies, B., Ou, B. Thain, E., McCauaig, J.M., \& Kim, R.H. (2020). Stay at home: implementation and impact of virtualising cancer genetic services during COVID-19. Journal of Medical Genetics, 1-5. doi: 10.1136/jmedgenet-2020-107418

Parkash, P., Eble, T. N., \& Dhar, S. U. (2018). Quality Improvement of Clinic Flow for Complex Genetic Conditions: Using Ehlers-Danlos Syndrome as a Model. Molecular Genetics \& Genomic Medicine, 6(6), 993-1000. Doi:10.1002/mgg3.472

Pereira, E. M., \& Chung, W.K. (2020). COVID-19's Impact on Genetics at One Medical Center in New York. Genetics in Medicine, 22(9), 1467-1469. Doi:10.1038/s41436-020-0857-7

Pletcher, B. A., Jewett, E. A., Cull, W. L., Brotherton, S. E., Hoyme, H. E., Pan, R. J., \& Mulvey, H. J. (2002). The Practice of Clinical Genetics: A Survey of Practitioners. Genetics Medicine, 4(3), 142149. doi:10.1097/00125817-200205000-00008

Reason, J. (1990). Human Error. New York, N.Y: Cambridge University Press.

Riahi, S., Fischler, I., Stuckey, M. I., Klassen P. E., \& Chen, J. (2017). The Value of Electronic Medical Record Implementation in Mental Health Care: A Case Study. JMIR Medical Informatics, 5(1). doi:10.2196/medinform.6512

Robson, C., \& McCartan, K. (2016). Real World Research 4th Ed. John Wiley \& Sons Ltd.: West Essex, $\mathrm{UK}$.

Sampalli, T., Desy, M., Dhir, M., Edwards, L., \& Dickson, R. (2015). Improving wait times to care for individuals with multimorbidities and complex conditions using value stream mapping. International Journal of Health Policy and Management, 4(7), 459-466. doi:10.15171/ijhpm.2015.76

Surh, L. C., Wright, P. G., Cappelli, M., Kasaboski, A., Hastings, V. A., \& Hunter, A. G. (1995). Delivery of molecular genetic services within a health care system: time analysis of the clinical workload. The Molecular Genetic Study Group. American Journal of Human Genetics, 53(3), 760-768.

TCPS2. (2018). Tri-Council Policy Statement: Ethical Conduct for Research Involving Humans TCPS2. Retrieved in June 2020 from https://ethics.gc.ca/eng/documents/tcps2-2018-eninteractive-final.pdf

Waddington, K. (2005). Using diaries to explore the characteristics of work-related gossip: Methodological considerations from exploratory multimethod research: Diary studies in work psychology. Journal of Occupational and Organizational Psychology, 78(2), 221-236. doi:10.1348/096317905x40817

Waldhausen, J.H., Avansino, J.R., Libby, A., \& Sawin, R.S. (2010). Application of lean methods improves surgical clinic experience. Journal of Pediatric Surgery, 45(7), 1420-1425. doi:10.1016/j.jpedsurg.2009.10.049

Wickens, C., Lee, J., Liu, Y. and Becker, S. (2004). An Introduction to Human Factors Engineering. New Jersey: Pearson Education Inc. 


\section{Appendices}

Appendix A Supportive Documents to Chapter 4

Appendix A.1 Ethics Approval 


\section{Appendix A.1.1 Departmant of Genetics - CHEO Approval}
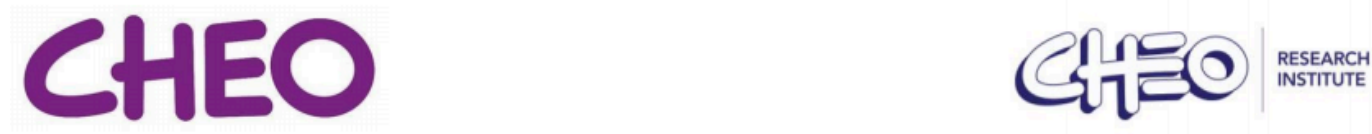

uOttawa

September 8, 2020

Research Ethics Board

Carleton University

\section{Re: Improving Genetics Clinic Capacity and Efficiency Using Human Factors Methods}

Dear Members of the REB,

I am writing to provide context for the project proposed by Maryam Attef as part of her Masters of Design program at Carleton University, which will be completed at CHEO. The project summary is attached to this letter. From our perspective at CHEO, the proposed project is a Quality Improvement initiative. The student will be performing data-guided activities in collaboration with our clinical team to develop an informed strategy to bring about immediate improvement in service delivery in the Department of Genetics.

Please don't hesitate to reach out if further clarification is needed.

Sincerely,

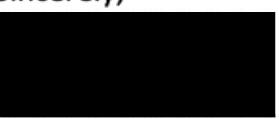

Kym M Boycott, MD, PhD, FRCPC, FCCMG

Chair, Department of Genetics, CHEO

Clinical Geneticist, CHEO

Senior Scientist, CHEO Research Institute

Professor, Department of Pediatrics, University of Ottawa

Tier 1 Canada Research Chair in Rare Disease Precision Health

Children's Hospital of Eastern Ontario

401 Smyth Road, Ottawa, ON K1H $8 \mathrm{~L} 1$

Tel: (613) 737-7600' www.cheo.on.ca

Making a difference in the lives of children, youth and families
Centre hospitalier pour enfants de l'est de l'Ontario

401, chemin Smyth, Ottawa (ON) K1H 8L1

Tél. : (613) 737-7600' www.cheo.on.ca

Faire une différence dans la vie des enfants et des adolescents 


\section{Appendix A.1.2 Carleton's Research Ethics Board Approval}

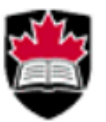

Carleton

Canada's Capital University
Carleton University Research Ethics Board A/B

4500 Arise Building

1125 Colonel By Drive

Ottawa, ON K1S $5 B 6$

Tel: (613) 520-2600, ext. 4085

September 14, 2020

Re: exemption for proposed study examining Genetics Clinic Capacity and Efficiency

Dear Maryam Attef,

Upon review of submission materials, the REB has determined that this project constitutes a program evaluation, quality improvement, or quality assessment activity. It is therefore exempt from REB review according to Article 2.5 of the Tri-Council Policy Statement, and so does not require prior review or approval by the Board.

Please note that in order to undertake your project at Carleton you may need to seek permissions from other parties such as departmental or faculty managers or directors, your supervisor, or the Privacy office and must otherwise meet Carleton requirements to carry out the project. In particular, Carleton University recently issued the following requirements for on-campus research: "Principles and Procedures for On-campus Research at Carleton University." Please contact your Dean's Office to learn in their approval is required for any in-person interactions that will take place at CHEO.

If, during the course of this study, there are changes to the project or new information comes to light, which would affect the determination stipulated above, these should be brought to the immediate attention of the REB for re-assessment.

Sinroraly

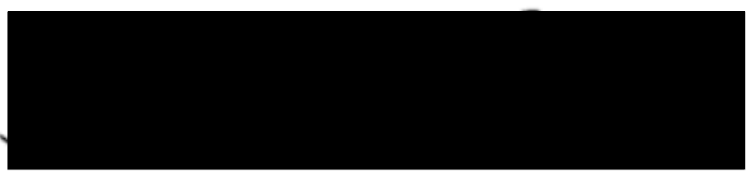

Bernadette Campbell, Ph.D.

Associate Professor, Department of Psychology

Chair, Carleton University Research Ethics Boards A \& B (CUREB-A \& B)

6135202600 ext. 4085 
Appendix A.2 Diary Study Method

Appendix A.2.1 $1^{\text {st }}$ Coloured Diary Study - Pilot Study

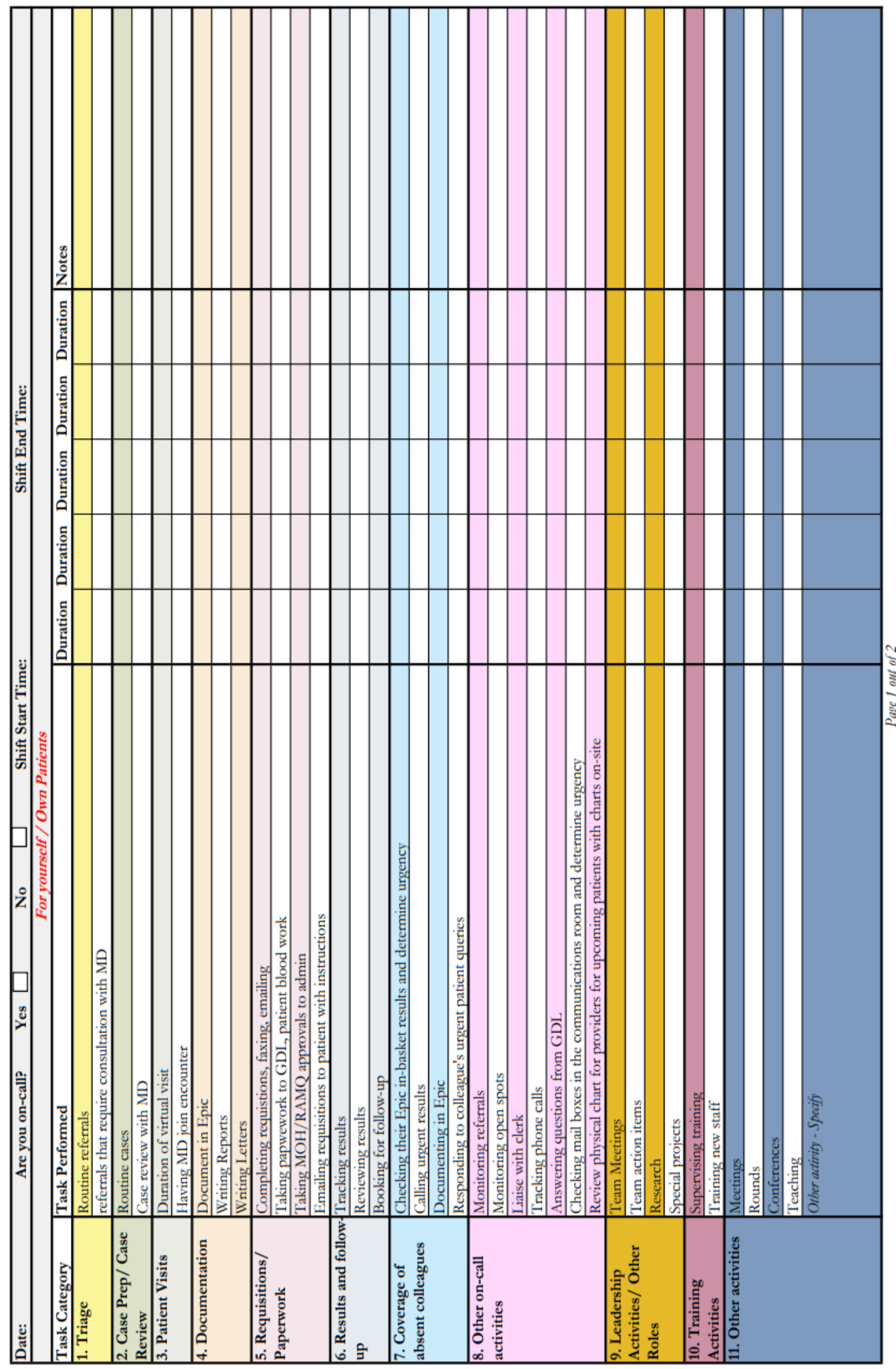




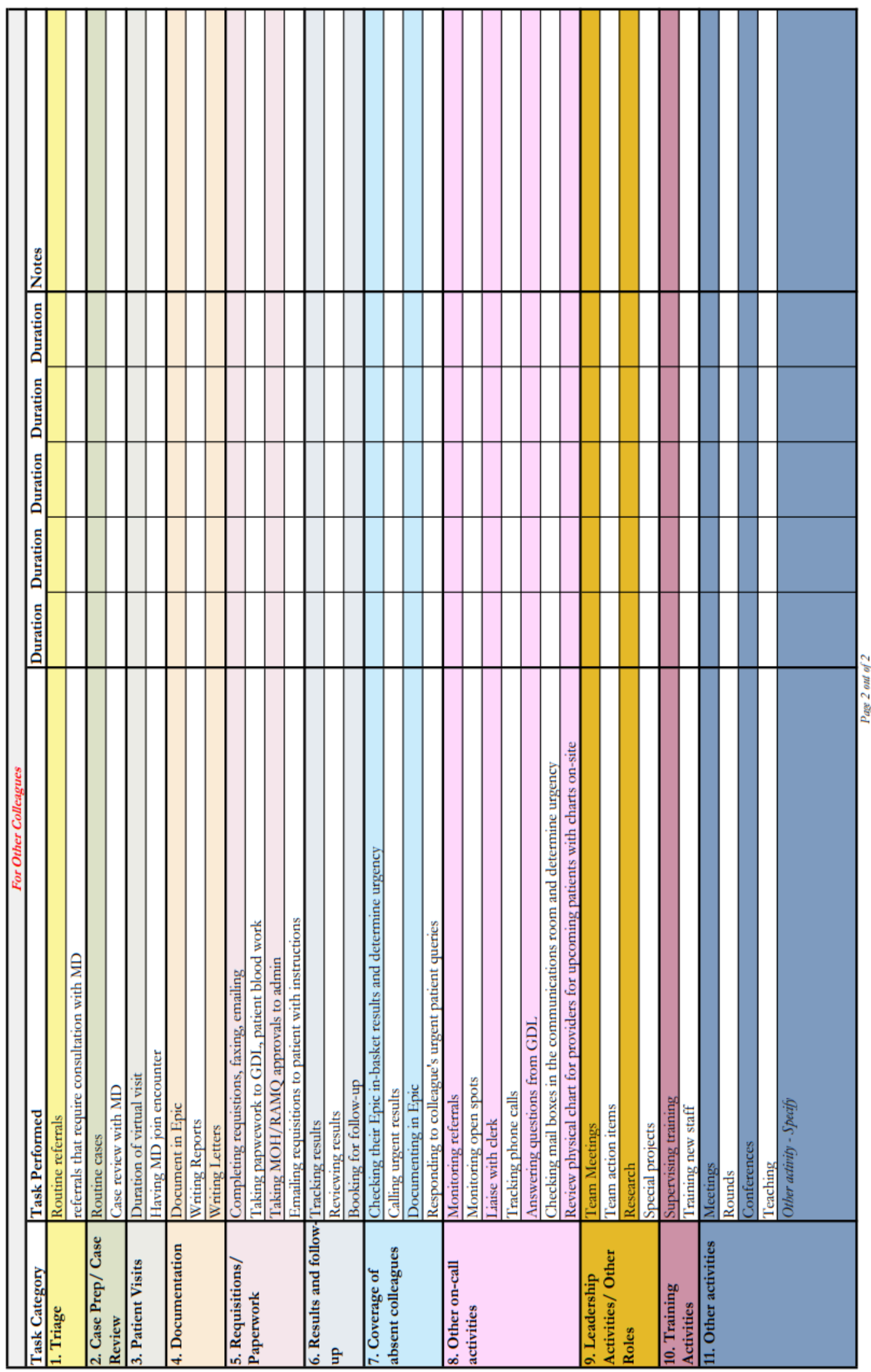


Appendix A.2.2 $1^{\text {st }}$ Grey-Scale Diary Study - Pilot Study

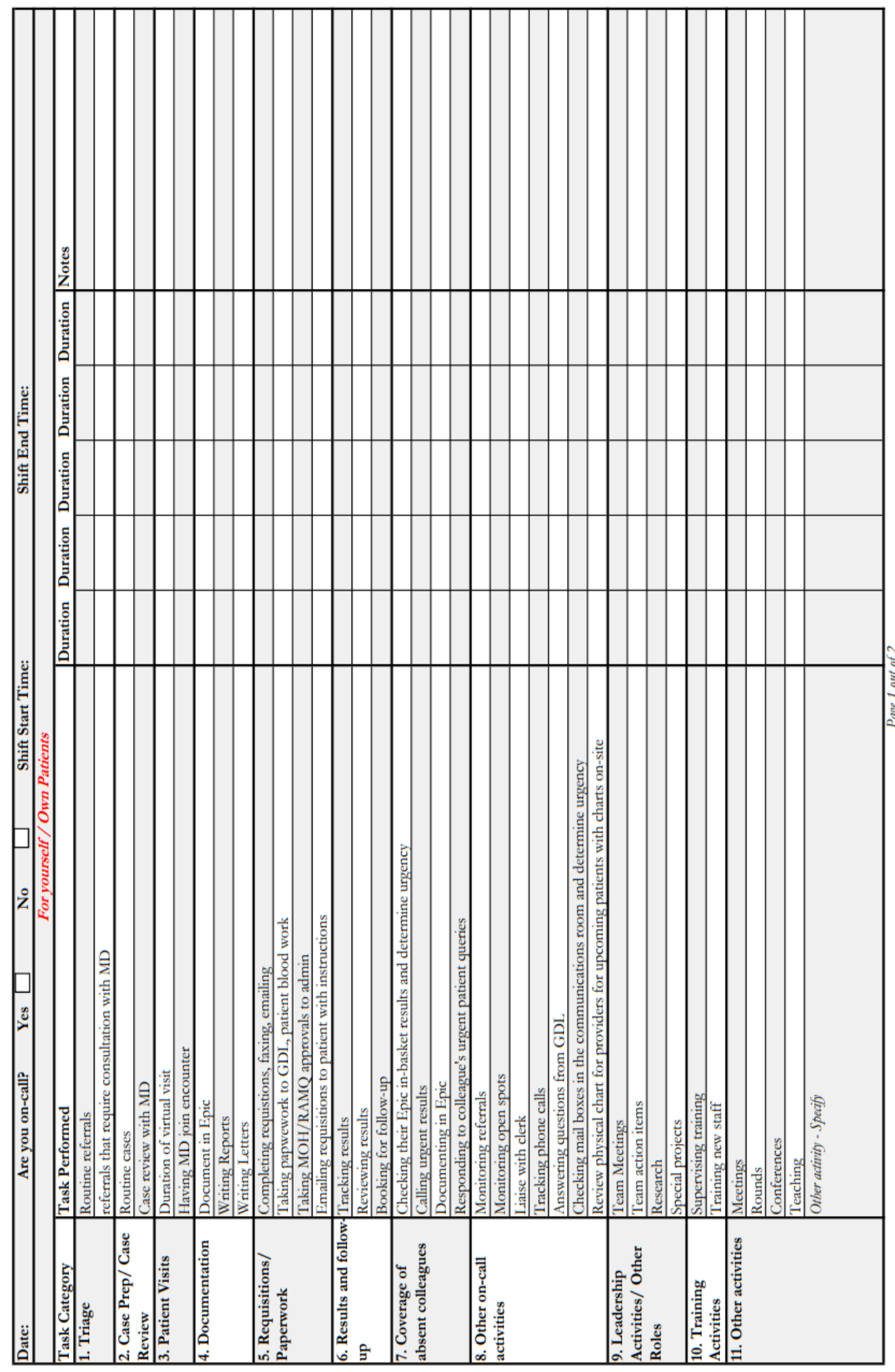




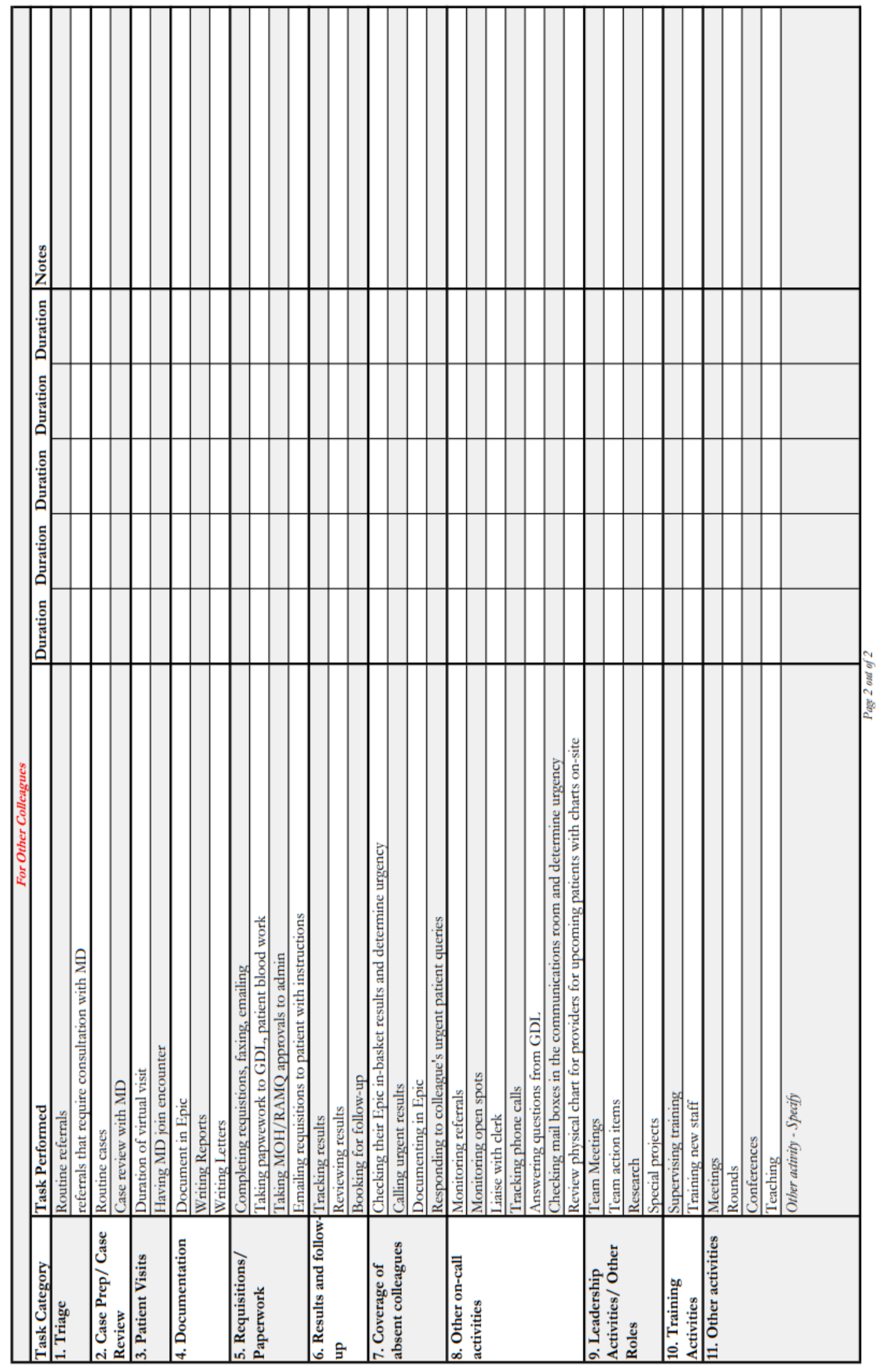


Appendix A.2.3 $2^{\text {nd }}$ Grey-Scale Diary Study - Pilot Study

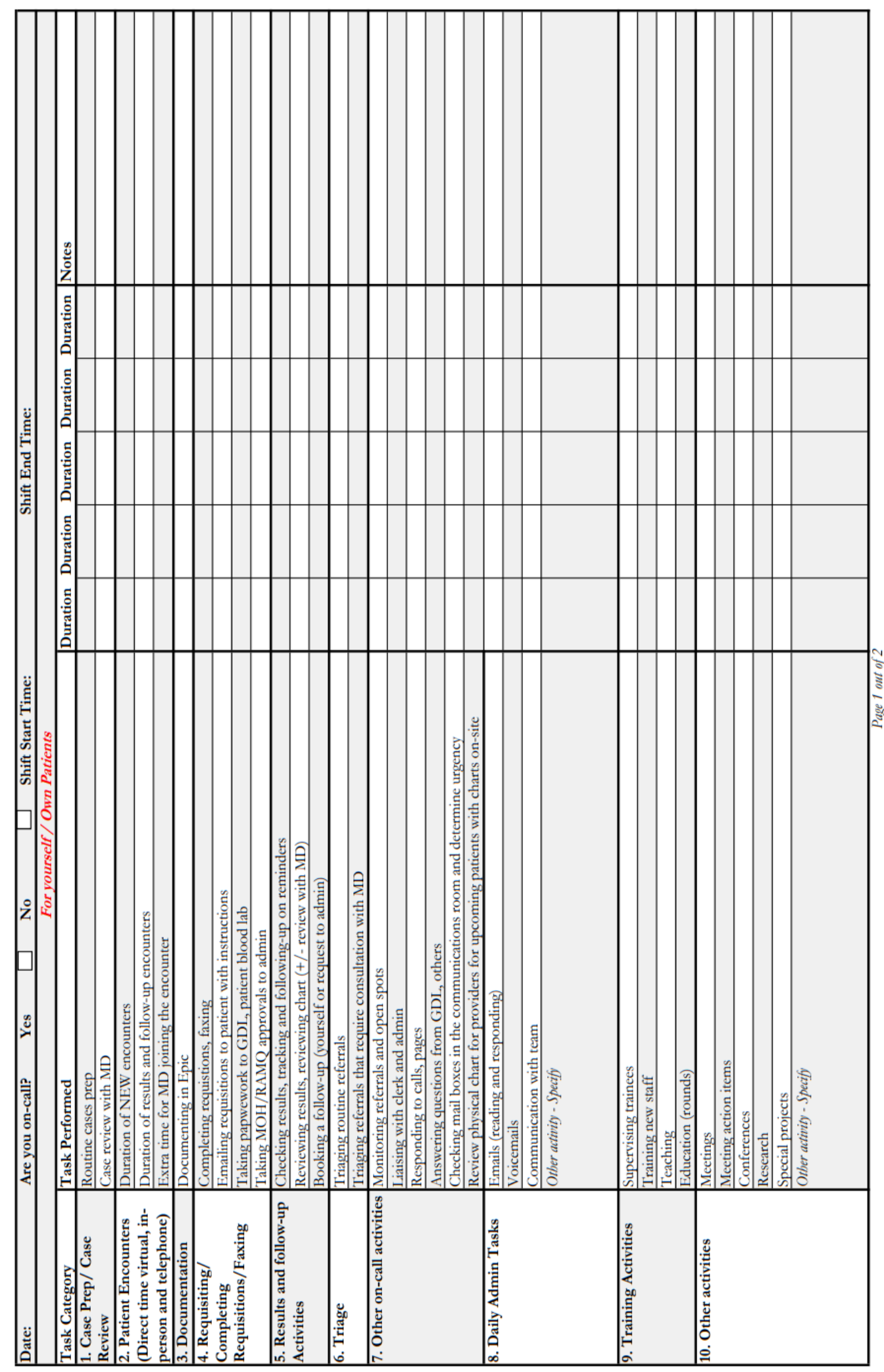




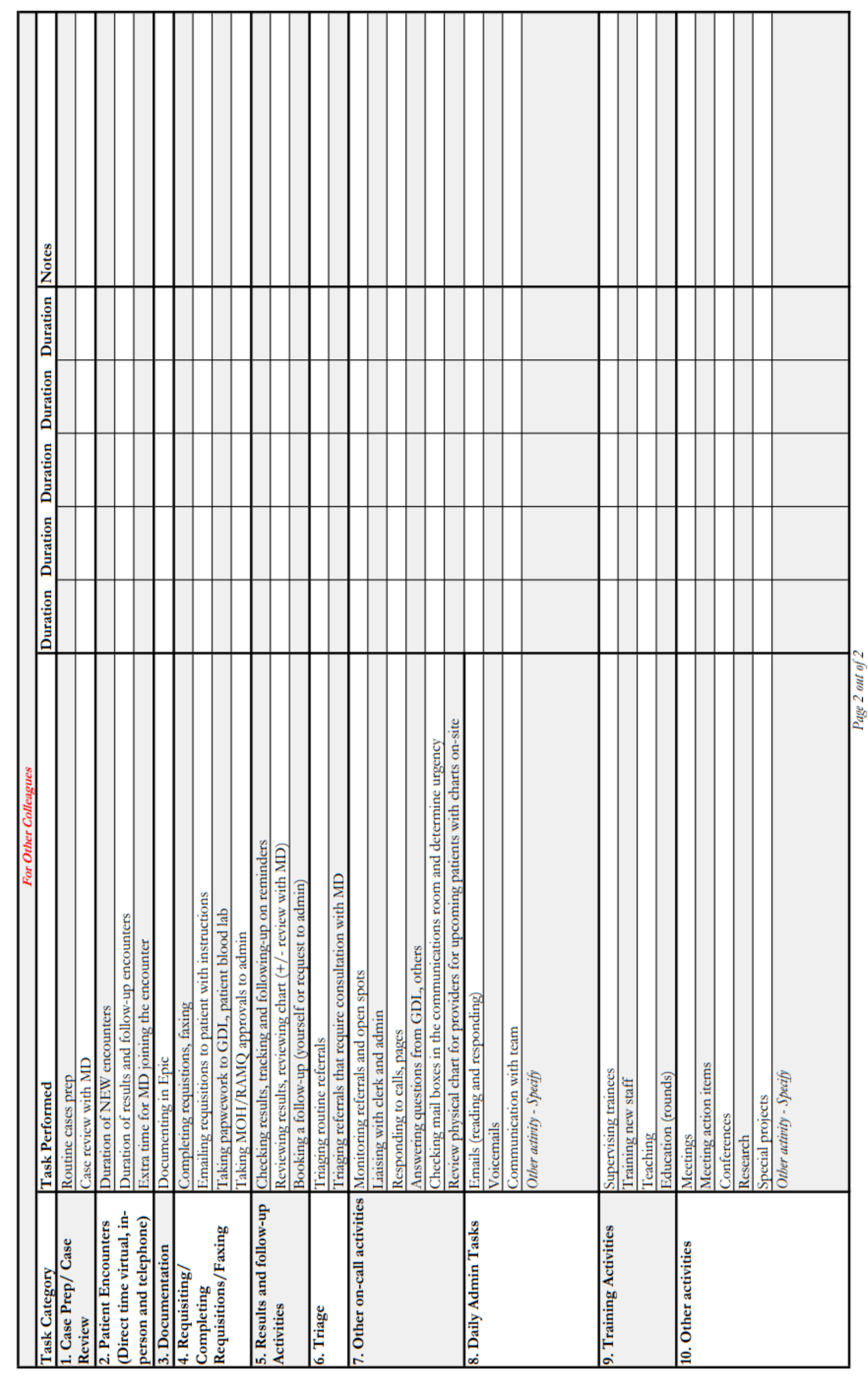


Appendix A.2.4 Final Grey-Scale Diary Study

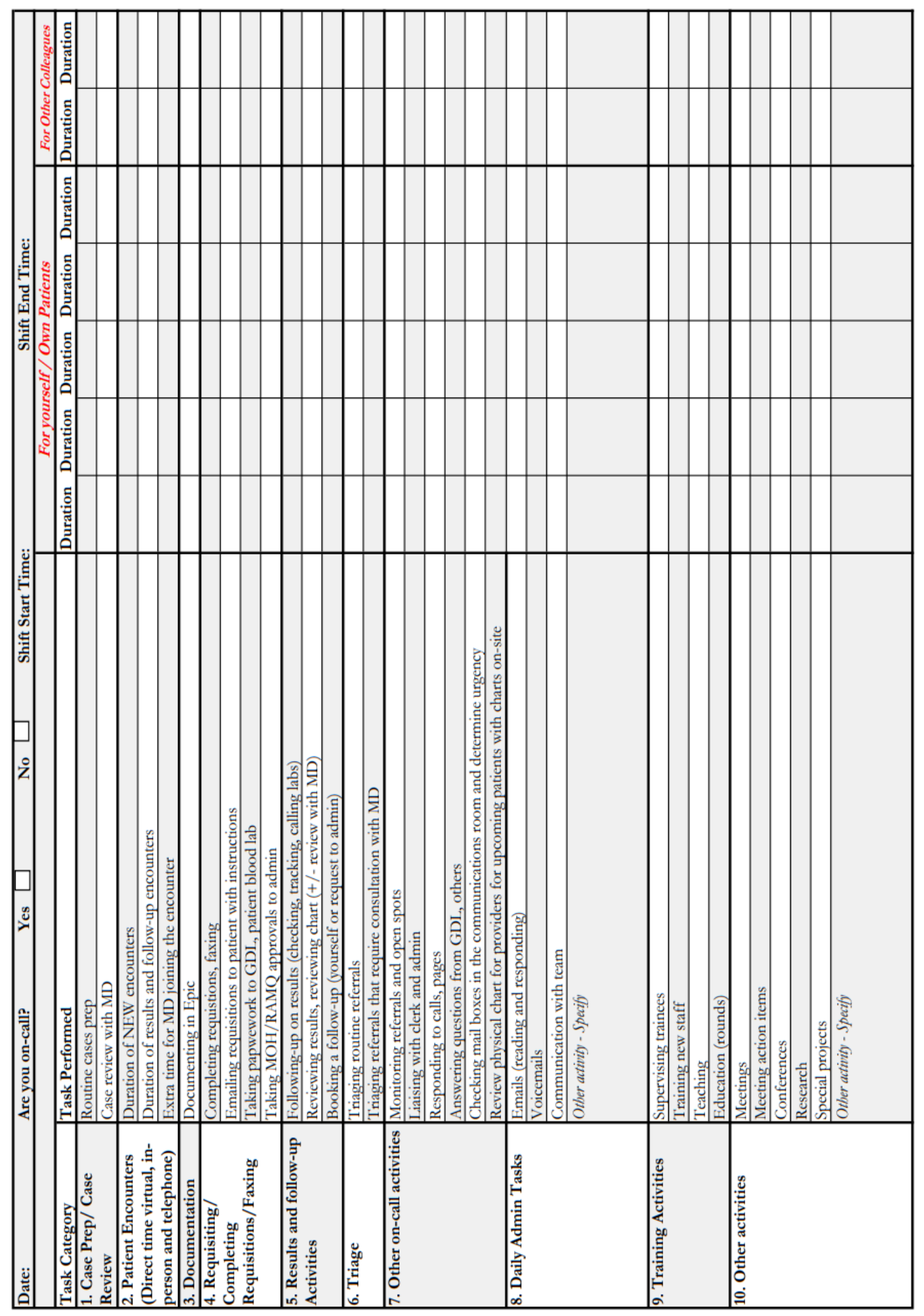


Appendix B Supportive Documents to Chapter 5

Appendix B.1 Findings from Diary Study 
Appendix B.1.1 Diary Study completed Excel sheets for each GC

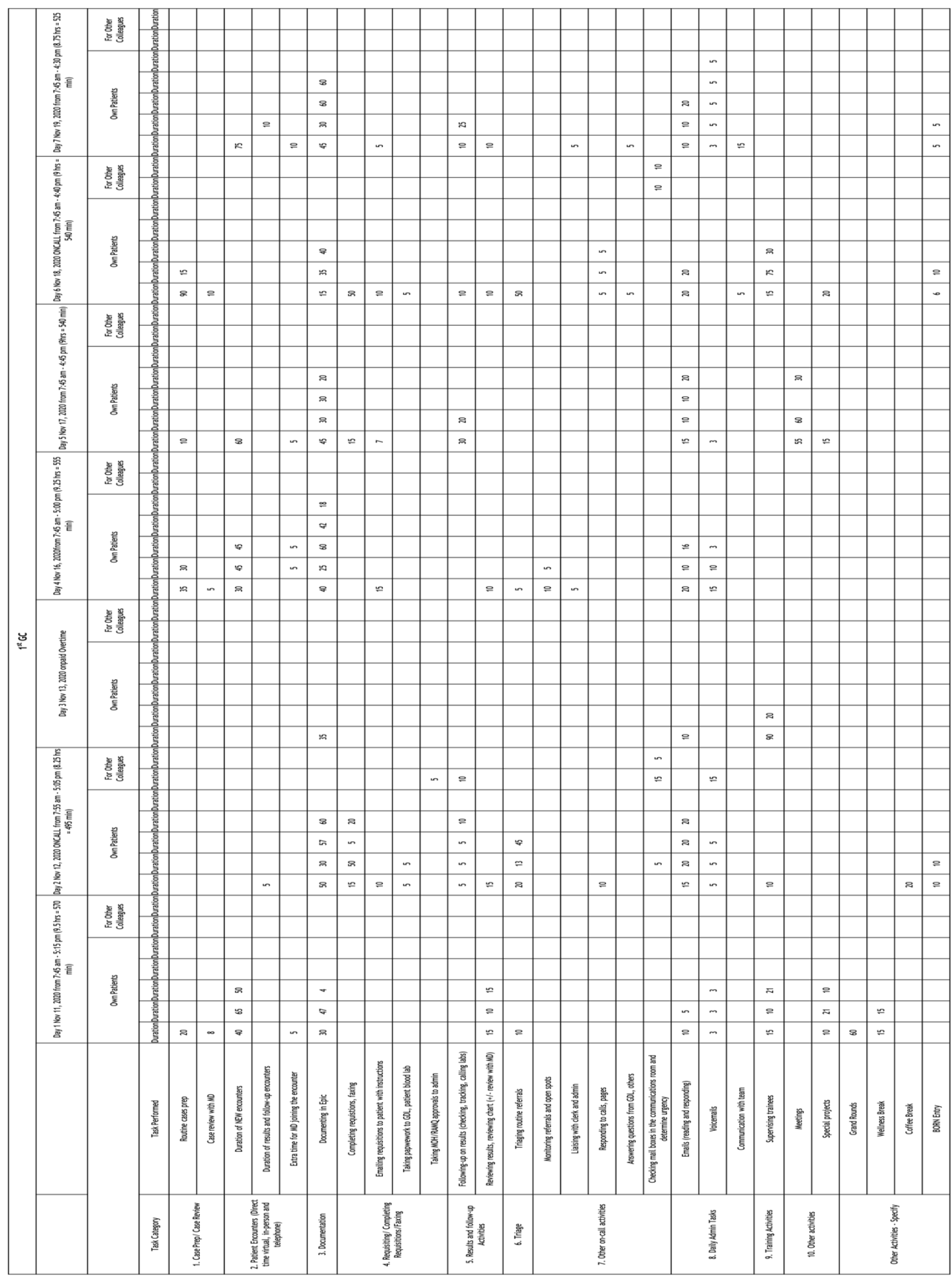




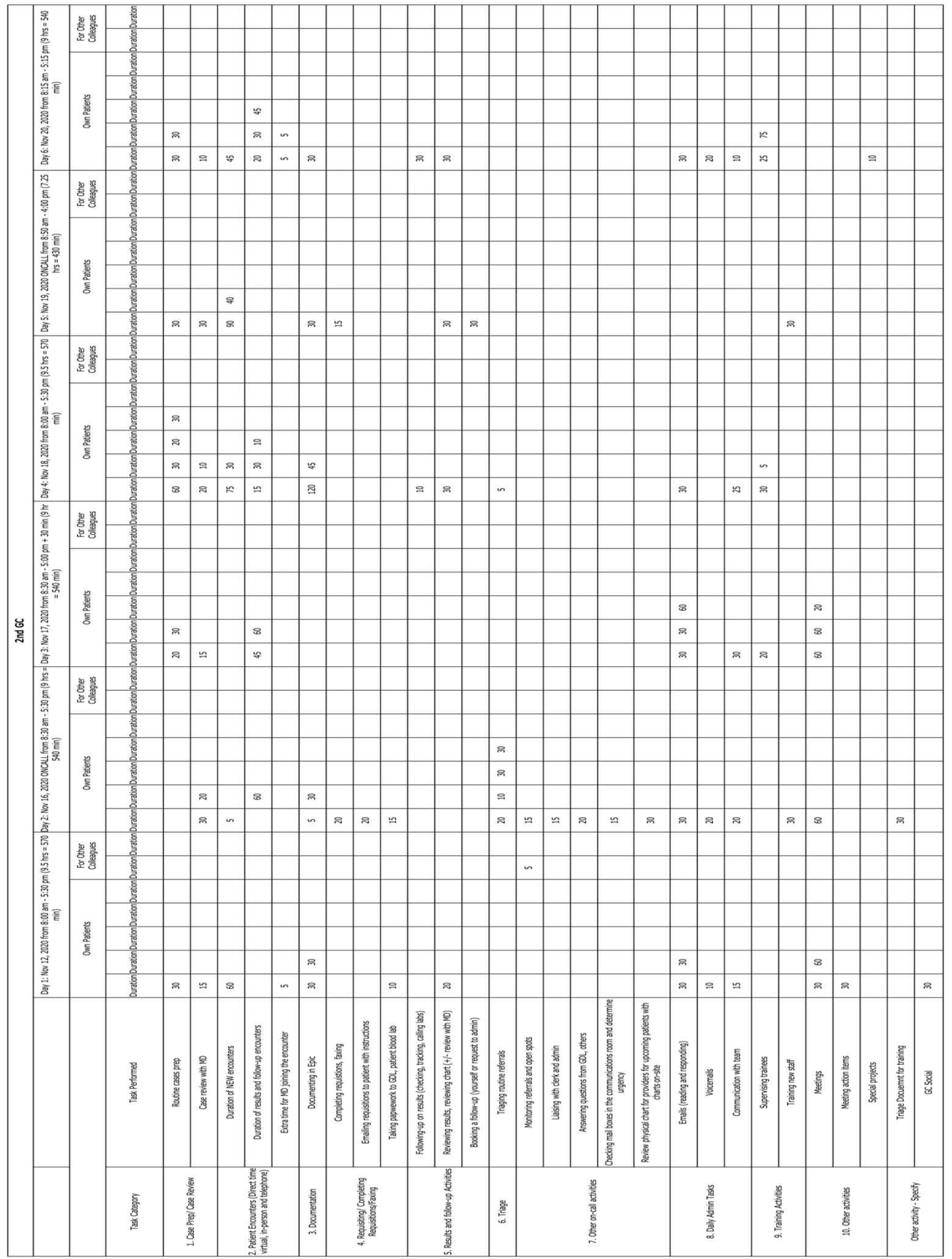




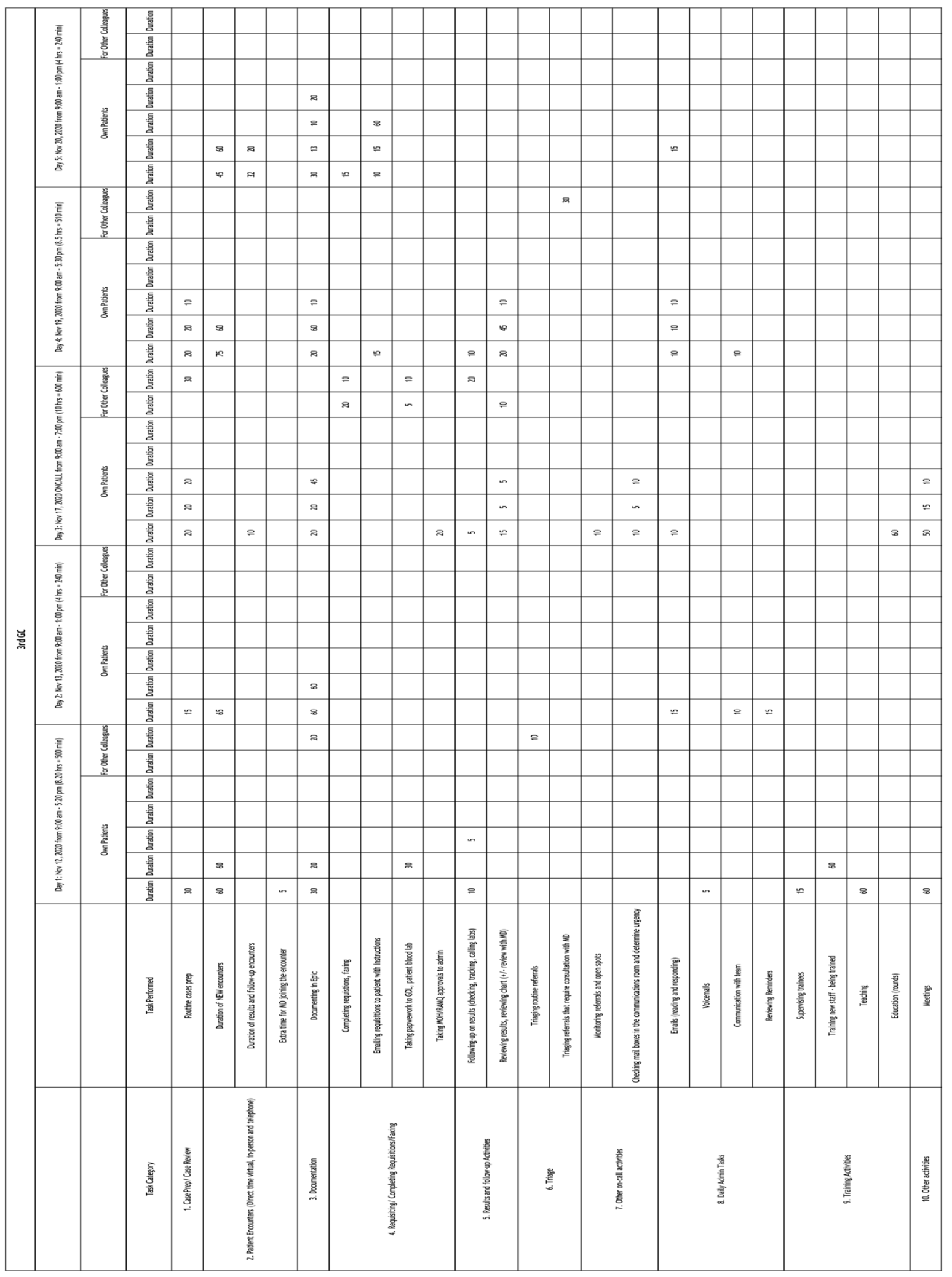




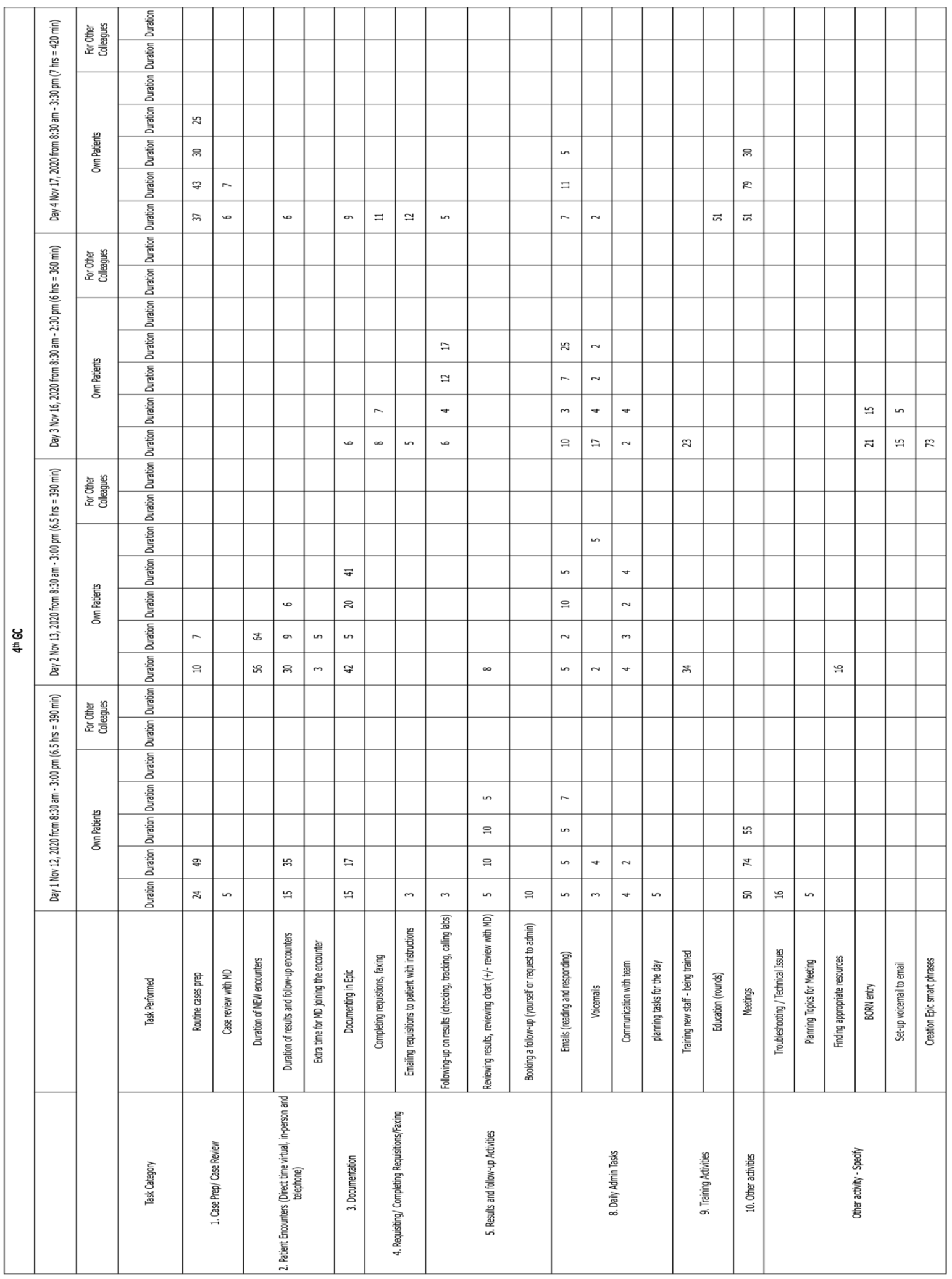




\title{
Appendix B.1.2 Calculated Frequency and Average time per task per category
}

\author{
Appendix B.1.2 A - Combined Data 'Own Patient' Category
}

\begin{tabular}{|c|c|c|c|c|c|}
\hline \multicolumn{6}{|c|}{ Combined Data - Own Patient } \\
\hline Task Category & Task Performed & TOTAL & AVERAGE & FREQUENCY & Total per Task Category \\
\hline \multirow{2}{*}{$\begin{array}{l}\text { 1. Case Prep/ Case } \\
\text { Review }\end{array}$} & Routine cases prep & 890 & 27.8125 & 32 & 41.45535714 \\
\hline & Case review with $M D$ & 191 & 13.64285714 & 14 & \\
\hline \multirow{3}{*}{$\begin{array}{l}\text { 2. Patient Encounters } \\
\text { (Direct time virtual, in- } \\
\text { person and telephone) }\end{array}$} & Duration of NEW encounters & 1300 & 54.166666667 & 24 & 84.08939394 \\
\hline & Duration of results and follow-up encounters & 493 & 24.65 & 20 & \\
\hline & Extra time for $M D$ joining the encounter & 58 & 5.272727273 & 11 & \\
\hline 3. Documentation & Documenting in Epic & 1801 & 33.35185185 & 54 & 66.82133059 \\
\hline \multirow{4}{*}{$\begin{array}{l}\text { 4. Requisiting/ } \\
\text { Completing } \\
\text { Requisitions/Faxing }\end{array}$} & Completing requistions, faxing & 231 & 19.25 & 12 & 65.30128205 \\
\hline & Emailing requisitions to patient with instructions & 187 & 14.38461538 & 13 & \\
\hline & Taking papwework to GDL, patient blood lab & 70 & 11.666666667 & 6 & \\
\hline & Taking $M O H / R A M Q$ approvals to admin & 20 & 20 & 1 & \\
\hline \multirow{3}{*}{$\begin{array}{l}\text { 5. Results and follow-up } \\
\text { Activities }\end{array}$} & Following-up on results (checking, tracking, calling labs) & 237 & 11.28571429 & 21 & 46.42207792 \\
\hline & Reviewing results, reviewing chart $(+/-$ review with $M D)$ & 333 & 15.13636364 & 22 & \\
\hline & Booking a follow-up (yourself or request to admin) & 40 & 20 & 2 & \\
\hline \multirow[t]{2}{*}{ 6. Triage } & Triaging routine referrals & 238 & 21.63636364 & 11 & 21.63636364 \\
\hline & Triaging referrals that require consultation with $M D$ & 0 & 0 & 0 & \\
\hline \multirow{6}{*}{$\begin{array}{l}\text { 7. Other on-call } \\
\text { activities }\end{array}$} & Monitoring referrals and open spots & 40 & 10 & 4 & 73.58333333 \\
\hline & Liaising with clerk and admin & 25 & 8.333333333 & 3 & \\
\hline & Responding to calls, pages & 25 & 6.25 & 4 & \\
\hline & Answering questions from GDL, others & 30 & 10 & 3 & \\
\hline & Checking mail boxes in the communications room and determine urgency & 45 & 9 & 5 & \\
\hline & Review physical chart for providers for upcoming patients with charts on-site & 30 & 30 & 1 & \\
\hline \multirow[t]{4}{*}{ 8. Daily Admin Tasks } & Emails (reading and responding) & 733 & 15.27083333 & 48 & 41.1910014 \\
\hline & Voicemails & 174 & 6.214285714 & 28 & \\
\hline & Communication with team & 165 & 9.705882353 & 17 & \\
\hline & Other activity - Specify & 20 & 10 & 2 & \\
\hline \multirow[t]{4}{*}{ 9. Training Activities } & Supervising trainees & 456 & 30.4 & 15 & 181.3 \\
\hline & Training new staff & 177 & 35.4 & 5 & \\
\hline & Teaching & 60 & 60 & 1 & \\
\hline & Education (rounds) & 111 & 55.5 & 2 & \\
\hline 10. Meetings & Meetings & 909 & 47.84210526 & 19 & 47.84210526 \\
\hline \multirow[t]{4}{*}{ 11. Other activities } & Meeting action items & 30 & 30 & 1 & 44.33333333 \\
\hline & Conferences & 0 & 0 & 0 & \\
\hline & Research & 0 & 0 & 0 & \\
\hline & Special projects & 86 & 14.33333333 & 6 & \\
\hline
\end{tabular}




\section{Appendix B.1.2 B - Combined Data 'Other Colleagues' Category}

\begin{tabular}{|c|c|c|c|c|c|}
\hline \multicolumn{6}{|c|}{ Combined Data - Other Colleagues Updated } \\
\hline Task Category & Task Performed & TOTAL & AVERAGE & FREQUENCY & Total per Task Category \\
\hline \multirow{2}{*}{$\begin{array}{c}\text { 1. Case Prep/ Case } \\
\text { Review }\end{array}$} & Routine cases prep & 30 & 30 & 1 & 30 \\
\hline & Case review with $M D$ & 0 & 0 & 0 & \\
\hline 3. Documentation & Documenting in Epic & 20 & 20 & 1 & 20 \\
\hline \multirow{4}{*}{$\begin{array}{l}\text { 4. Requisiting/ } \\
\text { Completing } \\
\text { Requisitions/Faxing }\end{array}$} & Completing requistions, faxing & 30 & 15 & 2 & 27.7 \\
\hline & Emailing requisitions to patient with instructions & 0 & 0 & 0 & \\
\hline & Taking papwework to GDL, patient blood lab & 15 & 7.5 & 2 & \\
\hline & Taking MOH/RAMQ approvals to admin & 5 & 5 & 1 & \\
\hline \multirow{3}{*}{$\begin{array}{l}\text { 5. Results and follow-up } \\
\text { Activities }\end{array}$} & Following-up on results (checking, tracking, calling labs) & 30 & 15 & 2 & 25 \\
\hline & Reviewing results, reviewing chart $(+/-$ review with MD) & 10 & 10 & 1 & \\
\hline & Booking a follow-up (yourself or request to admin) & 0 & 0 & 0 & \\
\hline \multirow[t]{2}{*}{ 6. Triage } & Triaging routine referrals & 10 & 10 & 1 & 40 \\
\hline & Triaging referrals that require consultation with $M D$ & 30 & 30 & 1 & \\
\hline \multirow{6}{*}{$\begin{array}{l}\text { 7. Other on-call } \\
\text { activities }\end{array}$} & Monitoring referrals and open spots & 5 & 5 & 1 & 5 \\
\hline & Liaising with clerk and admin & 0 & 0 & 0 & \\
\hline & Responding to calls, pages & 0 & 0 & 0 & \\
\hline & Answering questions from GDL, others & 0 & 0 & 0 & \\
\hline & Checking mail boxes in the communications room and determine urgency & 40 & 10 & 4 & \\
\hline & Review physical chart for providers for upcoming patients with charts on-site & 0 & 0 & 0 & \\
\hline \multirow[t]{4}{*}{ 8. Daily Admin Tasks } & Emails (reading and responding) & 0 & 0 & 0 & 15 \\
\hline & Voicemails & 15 & 15 & 1 & \\
\hline & Communication with team & 0 & 0 & 0 & \\
\hline & Other activity - Specify & 0 & 0 & 0 & \\
\hline \multirow[t]{4}{*}{ 9. Training Activities } & Supervising trainees & 0 & 0 & 0 & 0 \\
\hline & Training new staff & 0 & 0 & 0 & \\
\hline & Teaching & 0 & 0 & 0 & \\
\hline & Education (rounds) & 0 & 0 & 0 & \\
\hline 10. Meeting & Meetings & 0 & 0 & 0 & 0 \\
\hline \multirow[t]{12}{*}{ 11. Other activities } & Meeting action items & 0 & 0 & 0 & 0 \\
\hline & Conferences & 0 & 0 & 0 & \\
\hline & Research & 0 & 0 & 0 & \\
\hline & Special projects & 0 & 0 & 0 & \\
\hline & Grand Rounds & 0 & 0 & 0 & \\
\hline & Wellness Break & 0 & 0 & 0 & \\
\hline & Coffee Break & 0 & 0 & 0 & \\
\hline & BORN Entry & 0 & 0 & 0 & \\
\hline & Triage Docuemnt for training & 0 & 0 & 0 & \\
\hline & GC Social & 0 & 0 & 0 & \\
\hline & Set-up voicemail to email & 0 & 0 & 0 & \\
\hline & Creation Epic smart phrases & 0 & 0 & 0 & \\
\hline
\end{tabular}




\section{Appendix B.2 Results from Lean Improvement process}

\section{B.3.1 Triage Workflows}

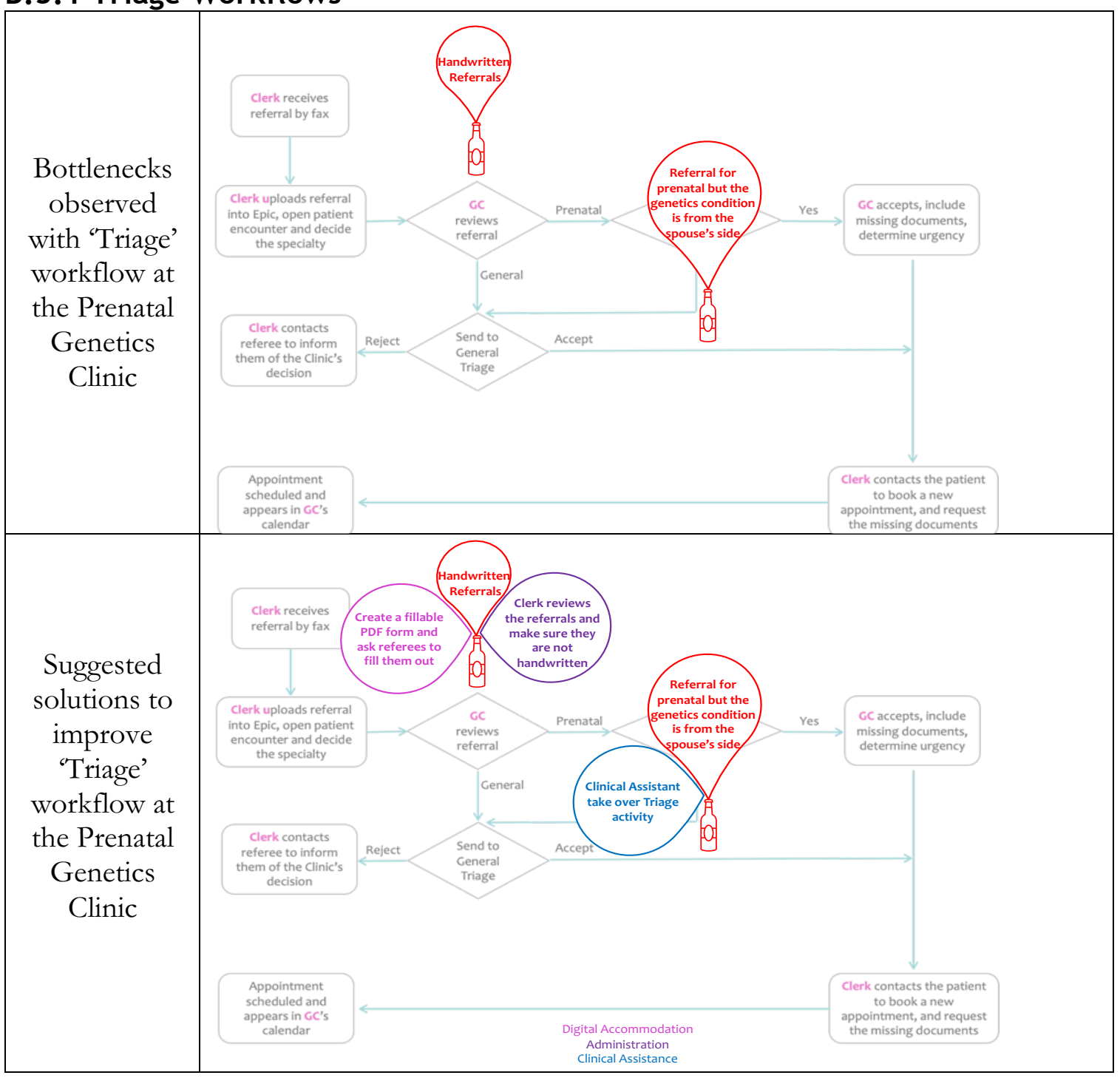




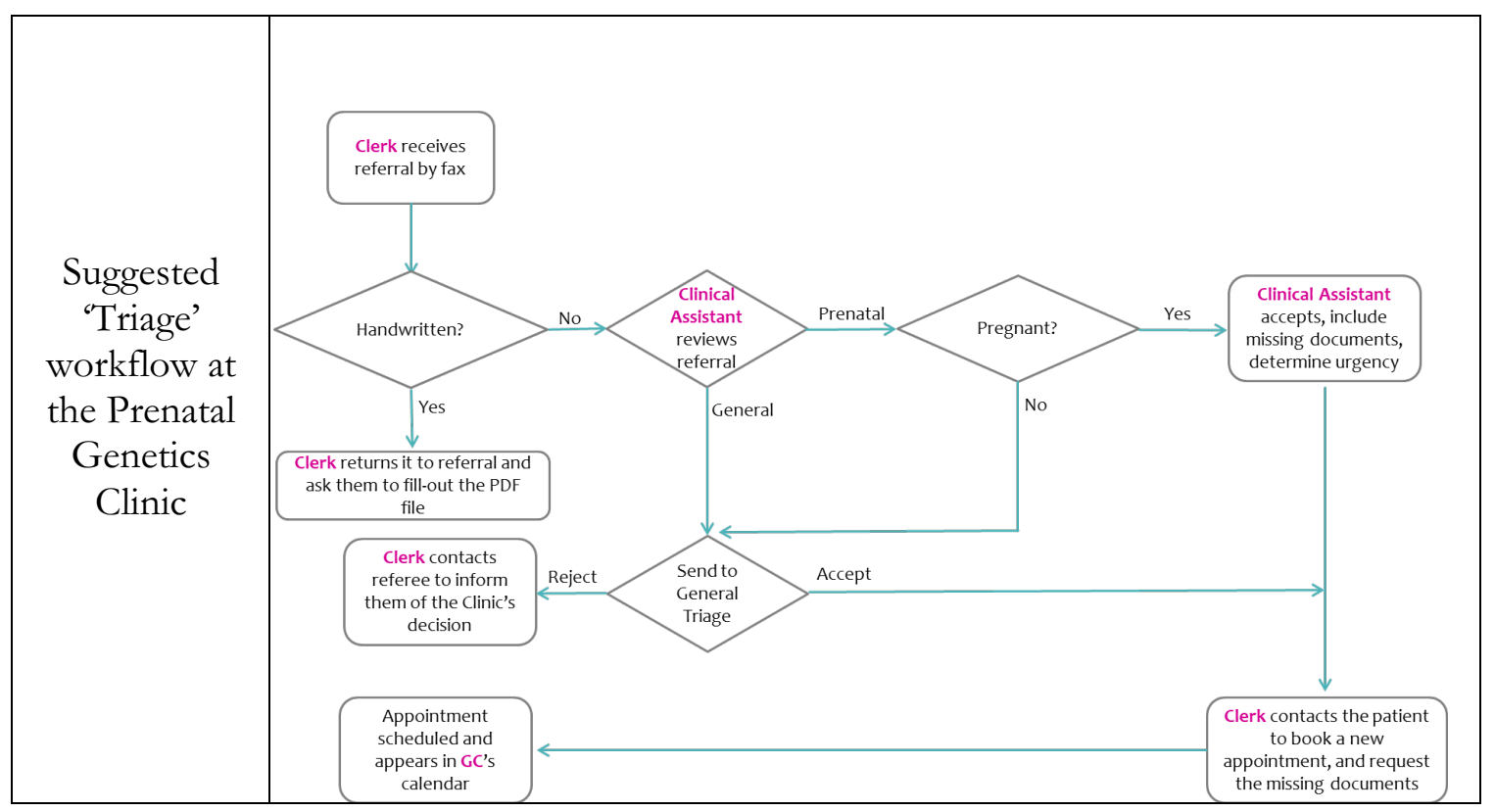

\section{B.3.2 Case Preparation/ Case Review Workflows}

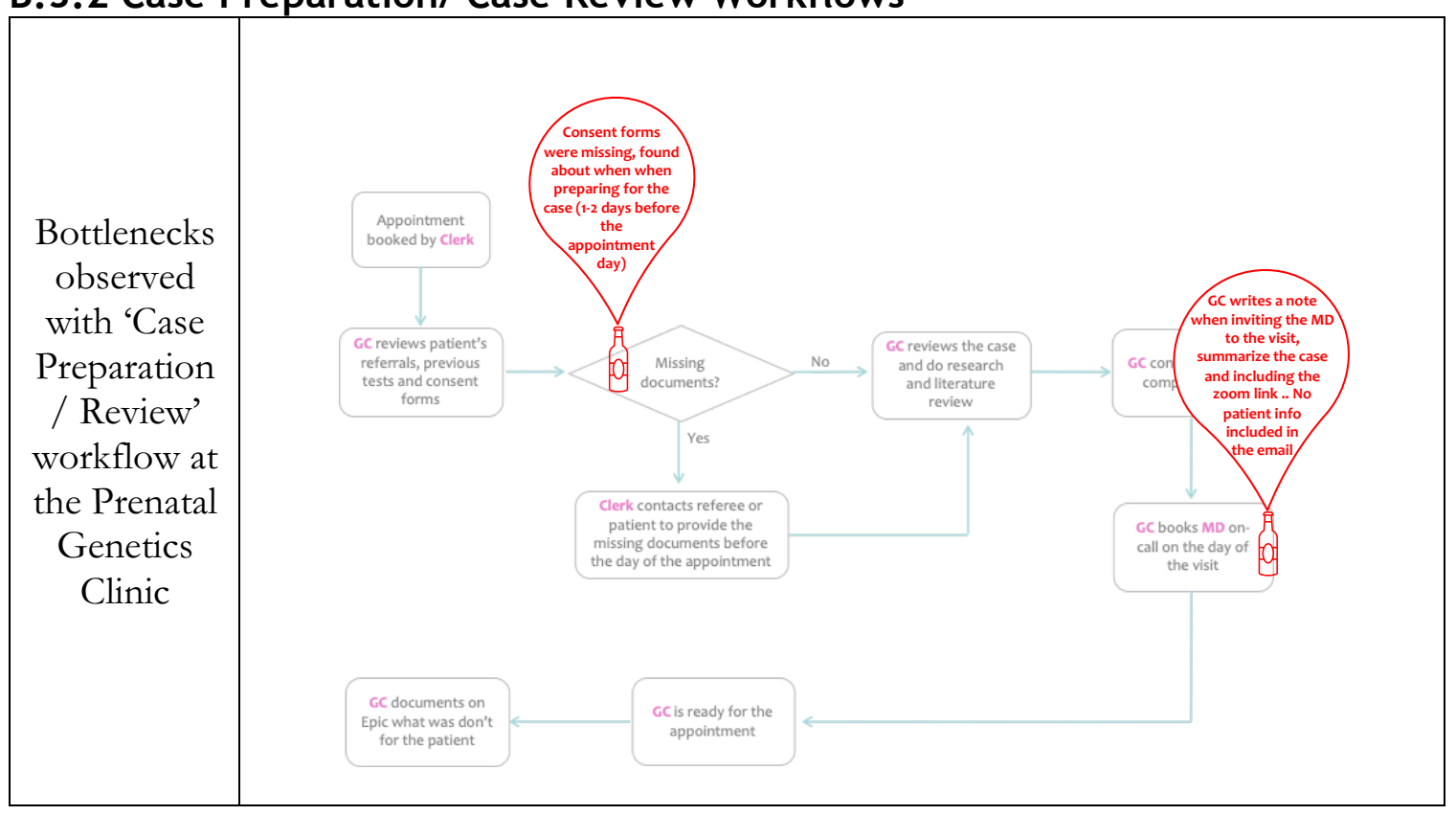




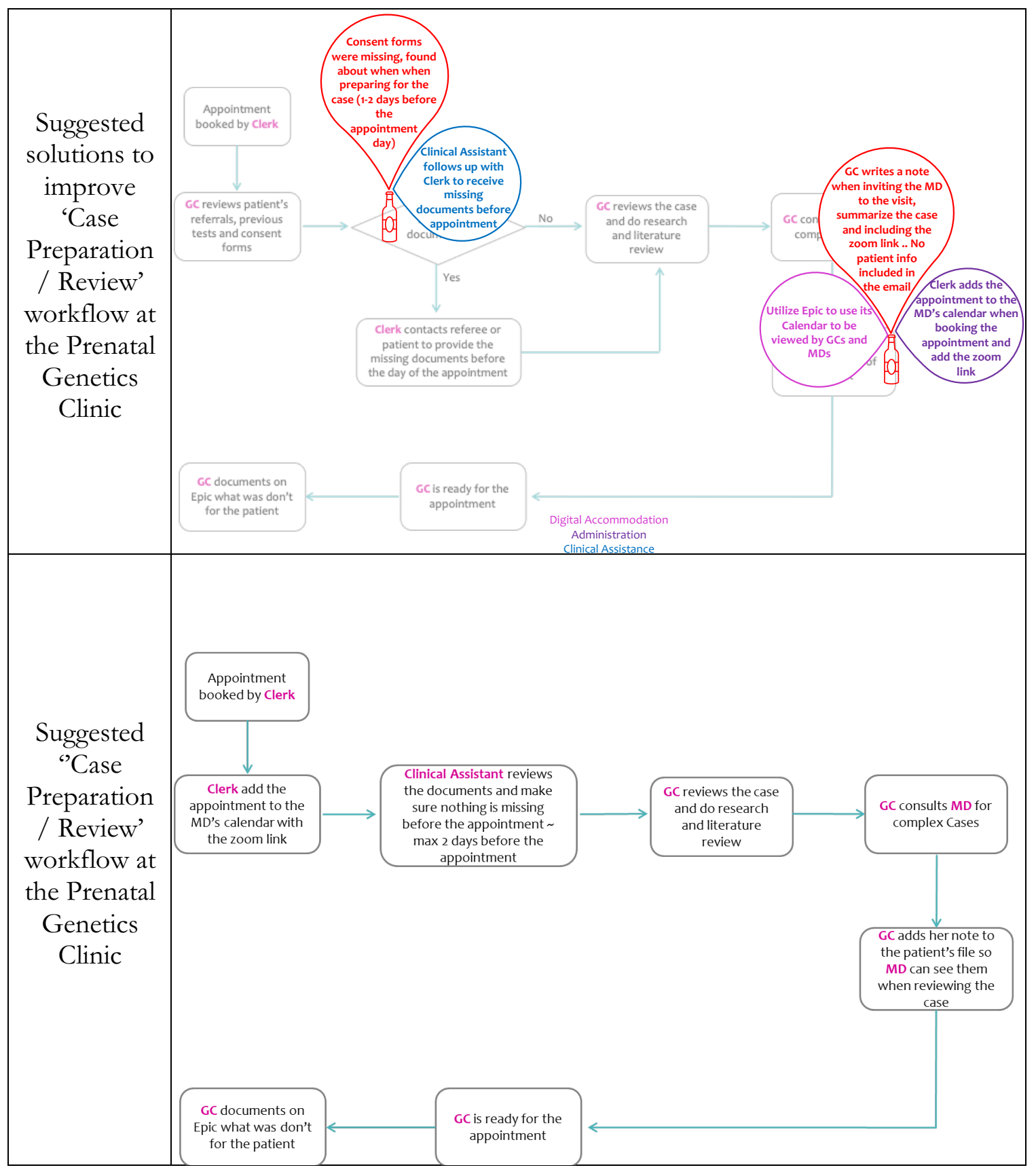




\section{B.3.3 Referring Doctor Following-Up on Results Workflows}

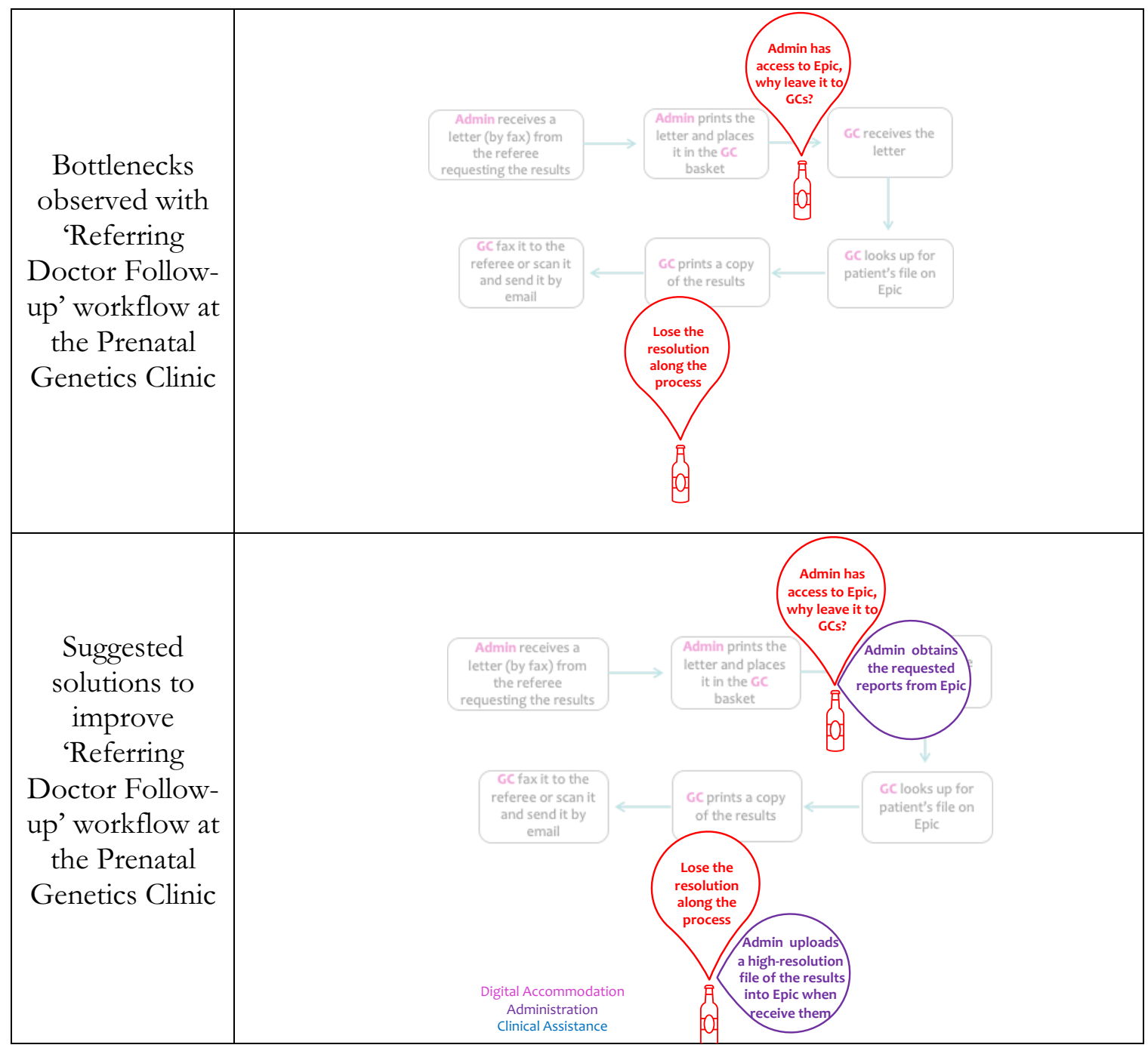




\section{B.3.4 Patient Follow-Up Consultation Workflows}

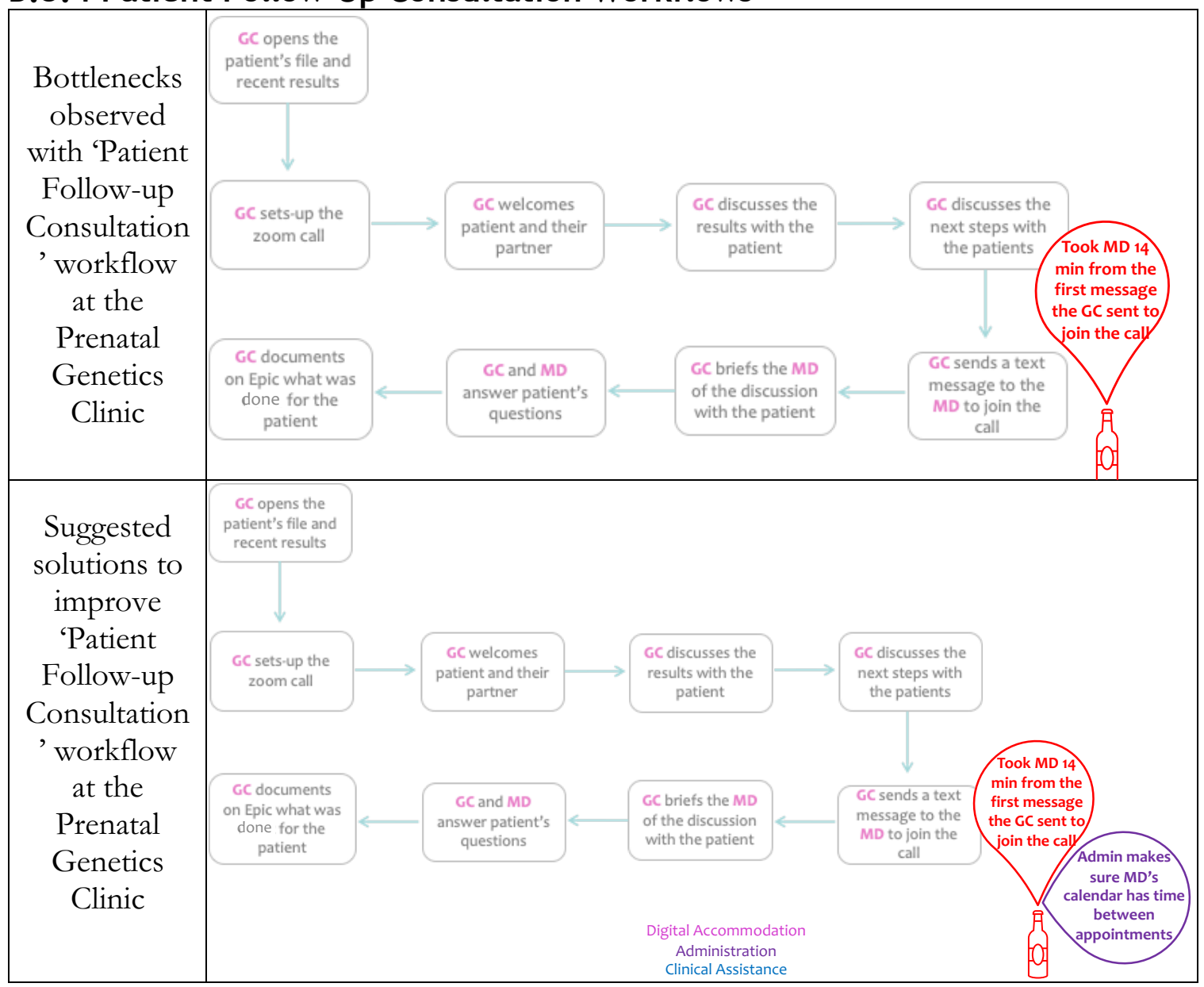

